\title{
Tesis Doctoral \\ CARTERA DE MARCAS DE DISTRIBUIDOR EN EL ESTABLECIMIENTO MINORISTA: VALOR DE MARCA Y CARACTERIZACIÓN DE COMPRA
}

Mariana de S. Fustinoni Venturini

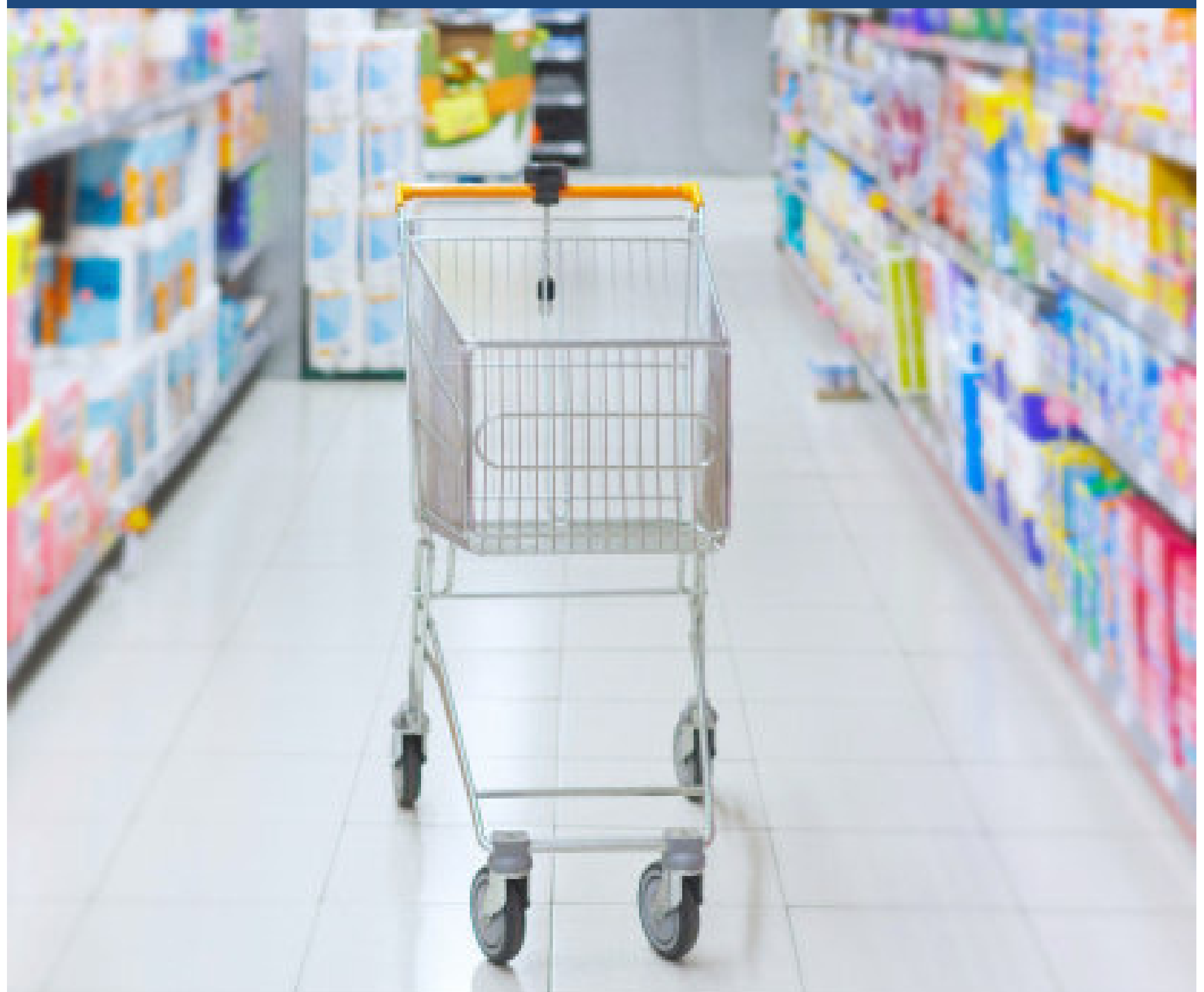

Directores:

Dra. Mercedes Martos Partal Dr. Óscar González Benito

VNNTIRSIDAD

D RALAMANCA 


\section{Tesis Doctoral}

Cartera de marcas de distribuidor en el establecimiento minorista:

Valor de marca y caracterización de compra

Mariana de S. Fustinoni Venturini

Departamento de Administración y Economía de la Empresa UNIVERSIDAD DE SALAMANCA

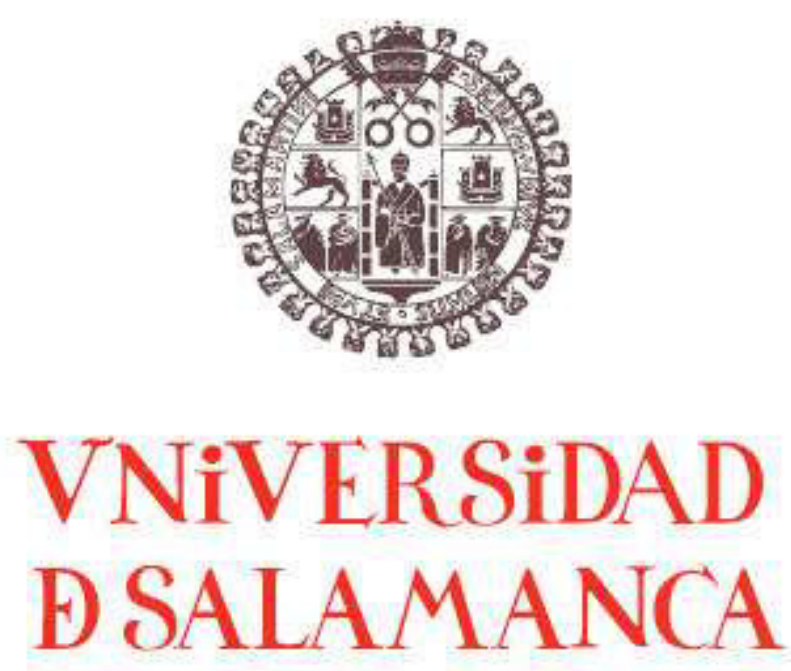

DIRECTORES:

MERCEDES MARTOS PARTAL

ÓSCAR GONZÁLEZ BENITO 


\section{VNiVERSiDAD \\ DSALAMANCA}

\section{AUTORIZACIÓN \\ DE LOS DIRECTORES DE LA TESIS DOCTORAL \\ PARA SU PRESENTACIÓN}

Dra. Mercedes Martos Partal y Dr. Óscar González Benito, como Directores de la Tesis Doctoral "CARTERA DE MARCAS DE DISTRIBUIDOR EN EL ESTABLECIMIENTO MINORISTA: VALOR DE MARCA Y CARACTERIZACIÓN DE COMPRA", realizada por Dna. Mariana de S. Fustinoni Venturini en el Departamento de Administración y Economía de la Empresa de la Universidad de Salamanca, autorizan su presentación a trámite dado que reúne las condiciones necesarias para su defensa.

Y para que conste a los efectos oportunos, se firma la presenta en Salamanca a 02 de julio de 2012.

Fdo. Óscar González Benito

Fdo. Mercedes Martos Partal 
1. INTRODUCCIÓN _ 13

1.1.CONTEXTO DE LA INVESTIGACIÓN____ 13

1.2.OBJETIVOS DE LA INVESTIGACIÓN____ 15

1.3.ESTRUCTURA DE LA TESIS __ 18

1.4.REFERENCIAS__ 21

2. MARCO CONCEPTUAL _ 25

2.1.MARCA DE DISTRIBUIDOR _ 25

2.1.1.CONCEPTO DE MARCA DE DISTRIBUIDOR __ 25

2.1.2. SITUACIÓN Y TENDENCIAS DE LA MARCA DE DISTRIBUIDOR_25

2.1.3. MARCA DE DISTRIBUIDOR Y POSICIONAMIENTO DEL

DISTRIBUIDOR 32

2.1.4. CARTERA DE MARCAS DE DISTRIBUIDOR 33

2.2.SEGMENTACIÓN POR BENEFICIOS BUSCADOS 38

2.2.1. CONCEPTO DE SEGMENTACIÓN POR BENEFICIOS BUSCADOS 38

2.2.2. BENEFICIOS BUSCADOS Y MARCA DE DISTRIBUIDOR 39

2.2.3.PAPEL DEL POSICIONAMIENTO DEL DISTRIBUIDOR Y DE SUS MARCAS 41

2.3.VALOR DE MARCA 42

2.3.1. CONCEPTO DEL VALOR DE MARCA 42

2.3.2. MEDIDA DEL VALOR DE MARCA 44

2.3.3. VALOR DE MARCA Y MARCA DE DISTRIBUIDOR 45 
3. CARACTERIZACIÓN MOTIVACIONAL DEL COMPRADOR DE MARCA DE DISTRIBUIDOR: PAPEL MODERADOR DEL POSICIONAMIENTO EN PRECIOS DEL MINORISTA

3.1.INTRODUCCIÓN 57

3.2.MARCO TEÓRICO E HIPÓTESIS 59

3.2.1.BENEFICIOS BUSCADOS POR EL COMPRADOR DE MARCAS DE DISTRIBUIDOR 59

3.2.2.PAPEL MODERADOR DEL POSICIONAMIENTO EN PRECIOS DEL DISTRIBUIDOR 64

3.3.METODOLOGÍA 69

3.4.ANÁLISIS Y RESULTADOS 74

3.5.CONCLUSIONES E IMPLICACIONES 78

3.6.REFERENCIAS 82

4. VALOR DE MARCA Y CARTERAS DE MARCAS DE DISTRIBUIDOR 91

4.1.INTRODUCCIÓN 91

4.2.MARCO TEÓRICO E HIPÓTESIS 94

4.2.1.VALOR DE LAS MARCAS DE DISTRIBUIDOR Y MARCAS DE FABRICANTE 94

4.2.2.POSICIONAMIENTO DE LAS MARCAS DE DISTRIBUIDOR 98

4.3.METODOLOGÍA 102

4.3.1.CONTEXTO Y DISEÑO DE LA INVESTIGACIÓN 102

4.3.2.MEDIDAS Y ESCALAS 104

4.4.ANÁLISIS Y RESULTADOS 105

4.4.1.MARCA DE DISTRIBUIDOR VERSUS MARCA DE FABRICANTE 105 4.4.2.CARTERA DE MARCAS DE DISTRIBUIDOR VERSUS MARCAS NACIONALES 108

4.5.CONCLUSIONES E IMPLICACIONES 113 
5. CARACTERIZACIÓN MOTIVACIONAL DEL COMPRADOR DE MARCA DE DISTRIBUIDOR: DIFERENCIAS ENTRE POSICIONAMIENTOS

5.1.INTRODUCIÓN 127

5.2.MARCO TEÓRICO E HIPÓTESIS 129

5.2.1.CARTERA DE MARCAS DE DISTRIBUIDOR 129

5.2.2.PERFIL MOTIVACIONAL DE LOS COMPRADORES DE MARCAS DE DISTRIBUIDOR 132

5.3.METODOLOGÍA 138

5.4.ANÁLISIS Y RESULTADOS 143

5.5.CONCLUSIONES 148

5.6.REFERENCIAS 152

6. REFLEXIONES FINALES 161

6.1.REFERENCIAS 170

APENDICE 1 - CUSTIONARIO DEL TEST CIEGO 175

APENDICE 2 - CUESTINARIO DEL TEST CON MARCA 177 


\section{AGRADECIMENTOS}

En primer lugar, le agradezco a Dios por su bondad y fidelidad con mi vida. Seguramente en este tiempo, en especial durante los años lejos de mi país y de mi familia, he podido experimentar más del amor y del cuidado del Señor.

Le agradezco a mi marido y mejor amigo Wander, que es el hombre más espectacular que he conocido nunca. Le agradezco por su incentivo, su comprensión y su amor en todo ese tiempo. Seguramente, no habría llegado hasta aquí sin su apoyo e incentivo. Le amo de todo mi corazón y para siempre.

Mi familia ha tenido un papel fundamental, todos ellos. Pero en especial, les agradezco a mis padres Osvaldo y Amélia, quienes han participado de todos los desafíos y alegrías en este tiempo. Su apoyo incondicional que ha sido fundamental para la elaboración de esta tesis doctoral. Además, agradezco a mi hermanda Fernanda, a mi abuela Balbina y a mi padrino Claudio por su cariño y soporte, aunque desde lejos.

A mis tutores Mercedes y Óscar: muchísimas gracias por su excelente direccionamiento y contribuciones en este trabajo, pero sobre todo por sus consejos, encorajamiento, paciencia y amistad. Me siento afortunada por haber trabajado sob su tutela.

También le debo un agradecimiento especial a Pablo, el coordinador de este programa de doctorado. Gracias por estar siempre disponible, gracias por sus sugerencias y su especial motivación para que yo hiciera este doctorado.

A Amarilis y Adriana, gracias por su amistad y su ayuda en inúmeros momentos.

Gracias también a KANTAR WORLDPANEL (antes TNS) por dos datos sumnistrados que hicieron posible los análisis de los capítulos 2 y 4 . 
INTRODUCCIÓN 


\section{INTRODUCCIÓN}

\subsection{Contexto de la investigación}

Las marcas están en todos los lugares y no hay dudas de que son uno de los activos intangibles más importantes de una empresa. La creación y gestión de marcas de alto valor es una prioridad para empresas alrededor del mundo (Keller, 2000). Como no podría dejar de ser, la marca también es importante en el mercado minorista y puede afectar a la percepción de los consumidores y afectar a laelección de la cadena y por ende, a la lealtad (Ailawadi y Keller, 2004).

Los minoristas poseen marcas propias. Fue en la década de 70 cuando los distribuidores empezaron a desarrollar y comercializar marcas propias (Kumar y Steenkamp 2007), normalmente como productos genéricos de baja calidad, sin cualquier nombre o como imitadores que copiaban a las marcas nacionales. Desde entonces, las marcas de distribuidor han evolucionado, mejorado en calidad y ganado la confianza de los consumidores a un nivel que en España ya tienen una cuota de mercado de un $49 \%$. La cuota de mercado también supera los $40 \%$ en países como Reino Unido, Suiza y Portugal, segundo datos de la PLMA en 2012 (Private Label Manufacturer Association). En los Estados Unidos, uno en cada cuatro productos vendidos son de marcas de distribuidores. La figura 1.1 muestra la cuota de mercado actual de las marcas de distribuidore en Europa. Notese que las marcas de distribuidor también son un fenómeno fuerte en economías emergentes como Polonia, Republica Checa, Eslovaquia y Turquía.

Para Ailawadi y Keller (2004), este nuevo contexto de ventas crecientes y mayor aceptación de las marcas de distribuidor, es consecuencia también de una estrategia de marcas muy bien diseñada por los minoristas. La oferta de una cartera de marcas propias es parte de esta estrategia: los minoristas ofrecen una marca genérica 0 económica, una marca estándar y una marca premium que ocupan, cada una, un posicionamiento distinto en la mente del consumidor (Geyskens, Gielens y Gijsbrechts, 2010; Kumar y Steenkamp 2007). Dicha estrategia está en línea con estudios más recientes que destacan que otros factores en lugar del precio están llevando los consumidores a una actitud más favorable a las marcas de distribuidor 
y, como consecuencia, a la compra de dichas marcas (Garretson, Fisher y Burton, 2002; Sethuraman, 2006; Baltas, 1997).

Figura 1.1. Cuota de marcas de distribuidores por país (en volumen)

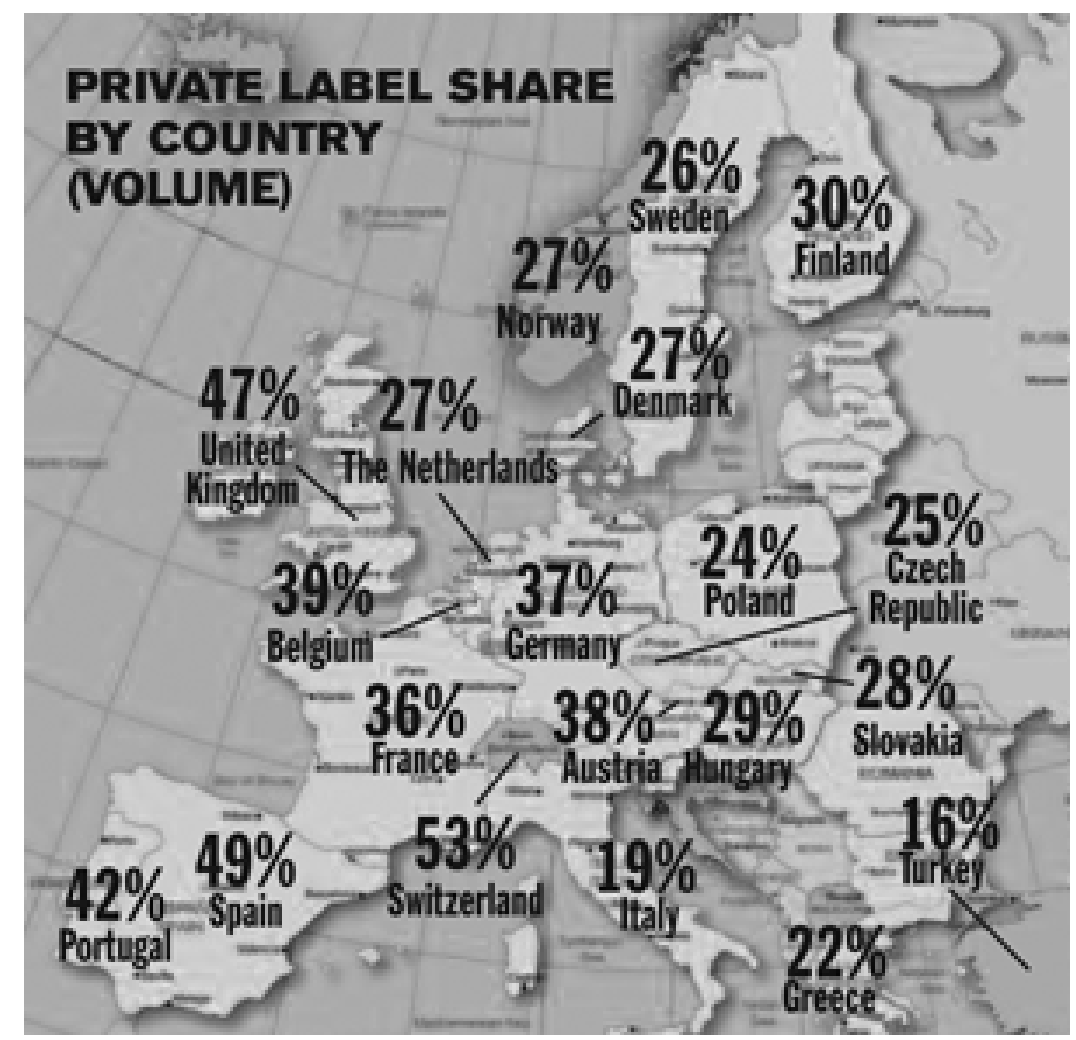

Fuente: PLMA, 2012

Vale resaltar que, adicionalmente, el momento económico en Europa es bastante favorable a las marcas de distribuidor. Lamey et al (2012) señalan que los consumidores son más receptivos a las marcas de distribuidor en tiempos de dificultad y que, por lo tanto, los períodos de contracción económica son una oportunidad "de oro" para los minoristas. Y también lo puede ser para los fabricantes de marcas nacionales que decidan fornecer los distribuidores con productos para sus marcas propias.

Una investigación reciente de la consultoría Price Waterhouse Coopers en España (PWC, 2011) mostró que con la crisis, hubo un incremento en la selección de marcas de distribuidor y de ofertas en la categoría de alimentación y bebidas y que ese efecto debe mantenerse después da crisis, conforme muestra la figura 1.2. Así mismo, la presencia de las marcas de distribuidor se está ampliando cada vez 
más allá de las categorías alimentarias, con un crecimiento significativo en las categorías de droguería y perfumería, por ejemplo.

Figura 1.2. Frecuencia de compra de alimentación y bebida

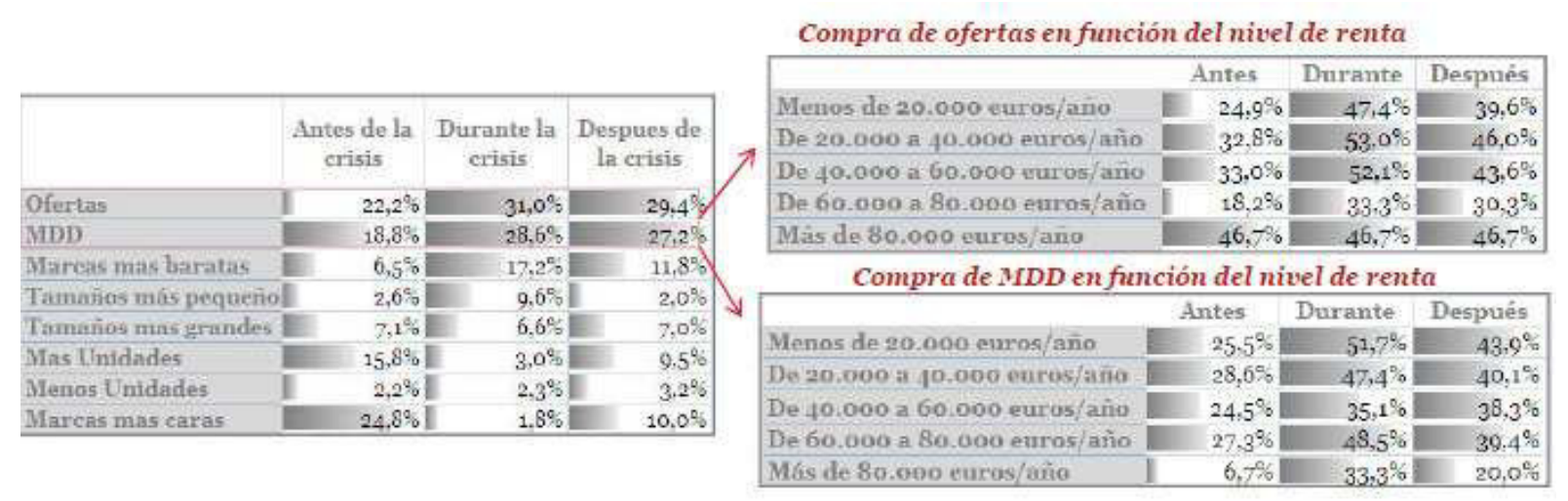

Fuente: PWC, 2011

Además, las propuestas de valor de las marcas de distribuidor cubren un amplio espectro - los distintos posicionamientos de las marcas de distribuidor tienen una propuesta de valor distintapara atender a distintos perfiles de consumidores. Por lo tanto, conocer a los consumidores más propensos a su compra es importante para tener ventajas en categorías en las que las marcas de distribuidor tienen mayor poder (Ailawadi et al, 2010).

Así, en un escenario en que las marcas de distribuidor tienen cada vez más relevancia, comprender las razones de compra de dichas marcas parece fundamental. Una mayor comprensión de los consumidores puede aumentar la satisfacción del consumidor bien como el desempeño del establecimiento (Puccinelli et al., 2009).

\subsection{Objetivos de la investigación}

La explicación de los factores que conducen a la compra de marcas de distribuidor es probablemente uno de los temas más investigados en la literatura 
acerca de marcas propias hasta ese momento. Para caracterizar al comprador de marcas de distribuidor, se ha explorado variables sociodemográficas, de personalidad y medidas de percepción de los consumidores, comparando marcas nacionales y marcas de distribuidor (Richardson, Jain y Dick, 1996). Sin embargo, poco se ha explorado factores motivacionales o beneficios buscados en la compra de marcas de distribuidor, tampoco se ha analizado las percepciones de los consumidores, concretamente cuanto al valor de marca, de marcas de distribuidor considerando las actuales propuestas de valor de dichas marcas. Esta propuesta de investigación pretende avanzar en la comprensión y solución de esta realidad.

Así, el primer como reto de este trabajo es aportara la literatura previa sobre la caracterización de compradores de marcas de distribuidor centrándonos en la caracterización por motivaciones y beneficios buscado. Son escasos los trabajos que han profundizado en este tema (Ailawadi, Neslin y Gedenk, 2001; Burton et al., 1998; Martos-Partal y Gónzalez-Benito, 2009). Con relación a las características del comprador de marcas de distribuidor, vale resaltar que este es un tema pionero de investigación, iniciado con Meyer (1967). La mayoría de los estudios se han centrado en criterios socio-económicos y demográficos. A su vez, la segmentación por beneficios buscados se basa en medir el sistema de valores de los consumidores en detalles. Este enfoque profundiza en las motivaciones y factores causales del consumo en lugar de analizar factores descriptivos, por lo que resulta más relevante en el contexto actual al determinar de forma más precisa el comportamiento de compra (Haley, 1968) en lugar de los clásicos criterios descriptivos de segmentación, como el socio demográfico.

El segundo objetivo de este trabajo es analizar como el posicionamiento en precio del distribuidor influye en el perfil del comprador de marca de distribuidor. Semeijn, van Riel y Ambrosini (2004) proponen que la imagen del distribuidor se ve afectada por sus marcas propias y, además, las marcas propias permiten la diferenciación entre minoristas. Por ender, LIs minoristas, tienden a comercializar marcas propias que son coherentes con su posicionamiento estratégico. De tal forma que el perfil del comprador de marca de distribuidor se veria moderado porel posicionamiento del minorista. 
La tercera cuestión de investigación de este trabajo es analizar si las marcas de distribuidor han logrado crear valor de marca. Se pretende analizar conocer si el esfuerzo realizado por los minoristas en su estrategia de marcas de distribuidor está dando sus frutos y está generando valor a sus marcas propias. La marca es importante también en el contexto minorista, dado que influyeen la percepción de los consumidores y en su elección (Ailawadi y Keller, 2004). Tantominoristas como fabricantes buscan conseguir valor de marca y trabajan para aumentar la reputación y credibilidad de sus marcas. Sin embargo, a pesar de la creciente investigación académica sobre las marcas de distribuidor, es escaso el análisis de dicho fenómeno desde una perspectiva de valor de marca (Cuneo, Lopez y Yagüe, 2012) . $Y$ no se han considerado la múltiple oferta de marca de distribuidor, carteras de marcas de distribuidor con distintos posicionamientos. Por tanto, tambiénse pretende analizar el efecto del posicionamiento de las marcas de distribuidor en el valor de dichas marcas. Es decir, entender si el valor de las marcas de distribuidor depende del tipo de marca que se considere, en particular, marca genérica, estándar o premium.

Finalmente, los resultados empíricos de este trabajo con relación al valor de marca nos llevan a revisitar nuestro primer objetivo al evidenciar diferencias en las percepciones del consumidor sobre las marcas genéricas, estándar y premium. Parece evidente, entonces, que marcas de distribuidor no pueden más ser analizadas de manera agregada. Los minoristas gestionan una cartera de marcas propias para atender a distintos segmentos de mercado, usando distintos posicionamientos (Geyskens, Gielens y Gijsbrechts, 2010; Kumar y Steenkamp, 2007) en el continuo calidad-precio. Por lo tanto, así como el posicionamiento de marcas de distribuidores modera el valor de marca, cabe esperar que las motivaciones y beneficios buscados por los consumidores de cada tipo de marca también sean afectados por dicho posicionamiento. Por más sencillo que este racionamiento pueda parecer, hasta el momento no hay trabajos académicos que lo analicen. Por tanto, el último objetivo de esta tesis será analizar si el posicionamiento de las marcas de distribuidor afecta a la caracterización motivacional y por beneficios buscados por los compradores de marcas de distribuidor.

En resumen, los objetivos de esta tesis son: 
I. Añadir a literatura actual sobre la caracterización de compradores de marcas de distribuidor centrándose en la caracterización por motivaciones y beneficios buscados;

II. Analizar como el posicionamiento en precio del distribuidor influye en el perfil del comprador de marca de distribuidor;

III. Conocer si las marcas de distribuidor han logrado valor de marca;

IV. Verificar si el valor de marca de las marcas de distribuidor varia en función de su posicionamiento en genérica, estándar o premium;

V. Investigar si el posicionamiento de las marcas de distribuidor afecta a la caracterización motivacional y por beneficios buscados por los compradores de marcas de distribuidor.

\subsection{Estructura de la tesis}

La tesis se estructura de la siguiente forma.. En primer lugar se establece un marco conceptual para comprender la situación actual de las marcas de distribuidores, cómoson gestionadas por los minoristas y las últimas tendencias sobre dicho fenómeno. A continuación, se aborda el tema de los beneficios buscados en la compra de dichas marcas, tanto considerándolas de manera agregada como considerando sus posicionamientos: genérica, estándar o premium. A continuación, se presente la temática de las marcas de distribuidores desde una óptica del valor de marca.

Los capítulos 3, 4 y 5 profundizan en los objetivos y cuestiones de investigación de propuestos en esta tesis. Cada uno de estos artículos está estruturados como un artículo académico, y por lo tanto, contienene marco teórico, metodología, análisis y resultados e implicaciones. Aunque se trata de trabajos separados, los tres están relacionados entre sí y profundización en los objetivos de investigación listados en esta tesis doctoral. Centrado en los objetivos I y II, el capítulo 3, "Caracterización Motivacional del Comprador de Marca de Distribuidor: Papel Moderador del 
Posicionamiento en Precios del Minorista", caracteriza al comprador de marca de distribuidor considerando las motivaciones y beneficios buscados por el consumidor en la compra de estas marcas. A su vez, analiza el papel moderador del posicionamiento en precio del distribuidor en la caracterización del comprador. Se cuenta con datos del historial de compra en la categoría de productos de alimentación en una muestra de más de 2000 hogares representativos de la población española. Los resultados empíricos obtenidos muestran que el comprador de marcas de distribuidor puede caracterizarse motivacionalmente como un consumidor más sensible a precios, y menos sensible a la calidad del servicio y a las marcas reconocidas. También se muestra que en las cadenas menos orientadas al precio, la compra de marcas de distribuidor parece estar menos motivada por la búsqueda de precios ventajosos, y más por la calidad, reconocimiento y reputación de las mismas.

El capítulo 4, "Valor de Marca y Cartera de Marcas de Distribuidor", se centra en el tercer y el cuarto objetivo y busca profundizar en el conocimiento del valor de marca de marcas nacionales y marcas de distribuidor en un contexto reciente. Así mismo, analiza el efecto del posicionamiento de las marcas de distribuidor en el valor de marca, de manera a determinar si el valor depende del posicionamiento, más concretamente, de que sea una marca genérica, estándar o premium. El estudio usa un experimiento del tipo test de sabor para comparar las evaluaciones de consumidores entre productos de marcas nacionales y marcas de distribuidor en un test ciego y no ciego. Dos modelos de regresiones son estimados: el primer con enfoque exclusivo en comparar el valor de marca de marcas de fabricante vs. marcas de distribuidor y el segundo avaliando el valor de marca de todos los fabricantes y todos los tipos de marcas de distribuidor. Los resutados evidencian la falta de valor de marcas de marcas de distribuidor cuando comparadas a marcas de fabricantes, incluso cuando se mira específicamente a las marcas premium.

Enfocado en el objetivo V, el capítulo 5, "Caracterización Motivacional del Comprador de Marca de Distribuidor: Diferencias a través de los Posicionamientos en Calidad", profundiza en la caracterización del comprador de marcas de distribuidor evaluando como el posicionamiento de la marca afecta a los beneficios buscados por el comprador de marcas propias. Se considera consumidores españoles de dos principales cadenas en el mercado de distribución 
español en lo que se refiere a sus compras y características motivacionales. Los resultados indican que el posicionamiento de marcas de distribuidores modera los beneficios buscados por compradores de marcas de distribuidores de manera que cada marca atrae un segmento de consumidor distinto. Se discute implicaciones de tales resultados.

Por último, en el capitulo 6 se sintetizan los resultados de los tres estudios y se exponen las principales conclusiones y aportaciones en el ámbito académico y empresarial. Además, describe las limitaciones y sugiere líneas para investigación futura, algunas de ellas motivadas por dichas limitaciones. 


\subsection{Referencias}

Ailawadi, Kusum L., Eric T. Bradlow, Michaela Draganska, Vincent Nijs, Robert P. Rooderkerk, K. Sudhir, Kenneth C. Wilbur y Jie Zhang (2010), "Empirical models of manufacturer-retailer interaction: A review and agenda for future research", Marketing Letters, 21 (3): 273-285

Ailawadi, Kusum L. y Kevin L. Keller (2004), "Understanding retail branding: conceptual insights and research priorities," Journal of Retailing, 80 (4): 331-342.

Ailawadi, Kusum L., Scott A. Neslin y Karen Gedenk (2001), "Pursuing the valueconscious consumer: store brands versus national brand promotions," Journal of Marketing, 65 (1): 71-89

Baltas, George (1997), "Determinants of store brand choice: a behavioral analysis," The Journal of Product and Brand Management, 6 (5): 315-324

Burton, Scot, Donald R. Lichtenstein, Richard G. Netemeyer y Judith A. Garretson (1998): "A scale for measuring attitude toward private label products and an examination of its psychological and behavioral correlates", Journal of the Academy of Marketing Science, 26 (4): 293-306

Cuneo, Andres, Pilar Lopez y Maria Jesús Yagüe (2012). "Measuring private labels' brand equity: a consumer perspective". European Journal of Marketing. Vol. 46 (7)

Garretson, Judith A., Dan Fisher y Scot Burton (2002), "Antecedents of private label attitude and national brand promotion attitude: similarities and differences", Journal of Retailing, 78 (2): 91-99

Geyskens, Inge, Katrijn Gielens y Els Gijsbrechts (2010): "Proliferating private-label portfolios: how introducing economy and premium private labels influences brand choice", Journal of Marketing Research, 47 (5): 791-807.

Haley, Russel I. (1968), "Benefit segmentation: a decision-oriented research tool," Marketing Management, 32 (3): 30-35 
Keller, Kevin L. (2000), "The brand report card," Harvard Business Review, 78 (Jan/Feb): 147-157

Kumar, Nirmalya y Jan-Benedict E. M. Steenkamp (2007), "Private label strategy: how to meet the store brand challenge," Harvard Business School Press.

Lamey, Lien, Barbara Deleersnyder, Jan-Benedict E.M. Steenkamp y Marnik G. Dekimpe (2012). "The effect of business-cycle fluctuations on privatelabel share: What has marketing conduct got to do with it?", Journal of Marketing, 76 (1): 1-19

Martos-Partal, Mercedes y Oscar González-Benito (2009), “¿Qué busca el comprador de marcas de distribuidor? Caracterización del comprador de marca de distribuidor por beneficios buscados”, Universia Business Review, 24: 76-95

Meyer, John G. (1967), "Determinants of private brand attitude", Journal of Marketing Research, 4 (1): 73-81

PWC, Price WaterHouse Coopers (2011). "Evolución o revolución. ¿Un nuevo consumidor o una nueva forma de consumir?". Disponible en www.pwc.es (Acesso el 19 Abril 2012)

PLMA Private Label Manufacturers Association, (2012), Disponible en http://plma.com/storeBrands/sbt10.html (Acesso el 23 Abril 2012)

Richardson, Paul S., Arun K. Jain y Alan Dick (1996), "Household store brand proneness: a framework", Journal of Retailing, 72 (2): 159-185

Semeijn, Janjaap, Allard C. R. van Riel y Ana Beatriz Ambrosini (2004), "Consumer evaluations of store brands: effects of store image and product attributes," Journal of Retailing and Consumer Services, 11 (4): 247-58.

Sethuraman, Raj (2006), "Private-label marketing strategies in packaged goods: management beliefs and research insights," Marketing Science Institute Working Paper, 27-44. 


\section{MARCO CONCEPTUAL}




\section{MARCO CONCEPTUAL}

\subsection{Marca de distribuidor}

\subsubsection{Concepto de marca de distribuidor}

Las marcas de distribuidor son las únicas marcas en las que los distribuidores tienen responsabilidad completa, desde el desarrollo, la investigación y el almacenaje hasta la promoción y comercialización. De manera que el distribuidor tiene un papel determinante en el éxito o fracaso de sus marcas propias. Este hecho no ocurre con las marcas nacionales dado que la responsabilidad recae en las acciones de los fabricantes (Dhar y Hoch, 1997).

A su vez, Kumar y Steenkamp (2007a) definen la marca de distribuidor como cualquier marca que es propiedad del distribuidor y que se vende sólo en sus establecimientos. Las marcas de distribuidor también se conocen como marcas propias, marcas privadas o marcas del establecimiento.

\subsubsection{Situación y tendencias de la marca de distribuidor}

En la última década, se ha asistido a una revolución en las marcas de distribuidor. Si hace diez años eran conocidas como marcas de poca calidad o simples imitadoras, las inversiones en desarrollo de productos, el lanzamiento de distintas marcas de distribuidor y una gestión más estratégica de dichas marcas por parte de los minoristas han contribuido al importante crecimiento de las marcas de distribuidor en un contexto global. Los datos de mercado revelan más claramente dicha realidad - las marcas de distribuidor tienen una cuota de mercado de más del $40 \%$ en algunos países europeos y un 25\% en los Estados Unidos (PLMA, fecha??).

Las marcas de distribuidor han ido ganando cuota a costa de las marcas nacionales. Pero son las marcas secundarias (no líderes) las que más sufren con el avanze de las marcas de distribuidor. En el mercado español, las marcas secundarias han perdido un $4,2 \%$ de cuota de mercado, mientras que las principales 
marcas de fabricante han perdido un 2,2\% para las marcas de distribuidor entre los años 2004 y 2010 (Figura 2.1, Kantar WorldPanel, 2010). La figura 2.2 presenta la misma realidad para el mercado alemán, en el cual las marcas de distribuidor hoy son "ganadoras", mientras que las marcas seguidoras, en especial las que ocupaban el segundo puesto en cuota de mercado, están perdiendo espacio a favor de dichas marcas.

Figura 2.1 Evolución de las marcas de distribuidor en España.

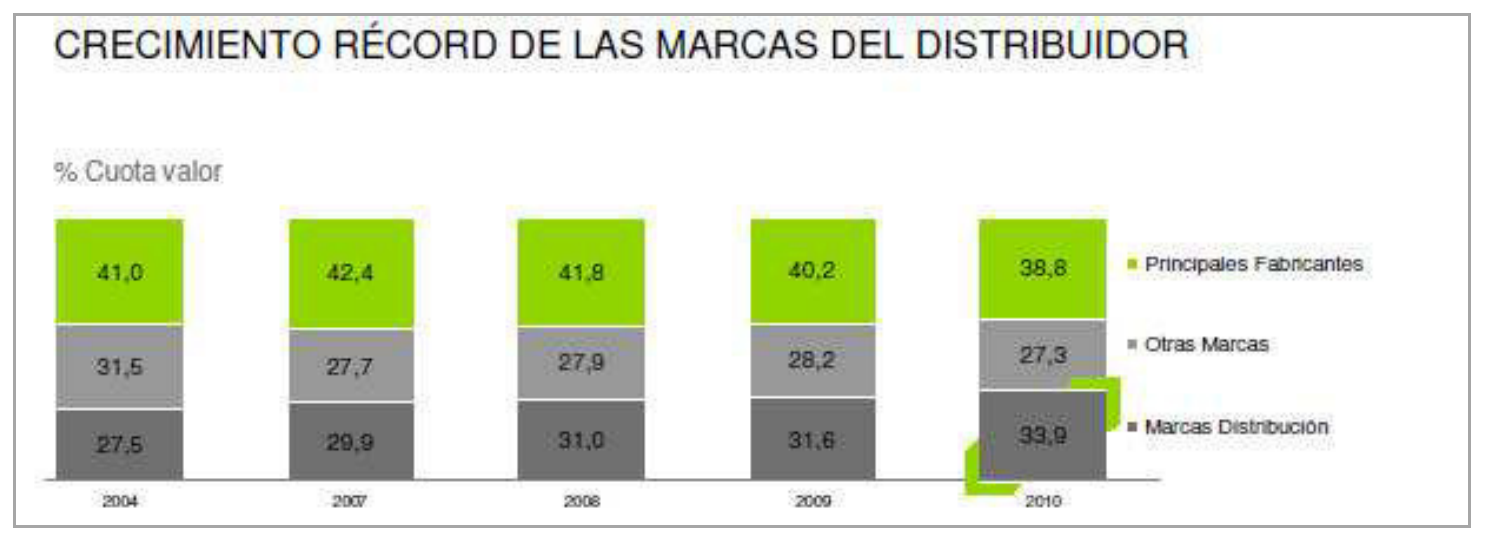

Fuente: Kantar WorldPanel, 2010

Figura 2.2. Marcas nacionales versus marcas de distribuidor en Alemania

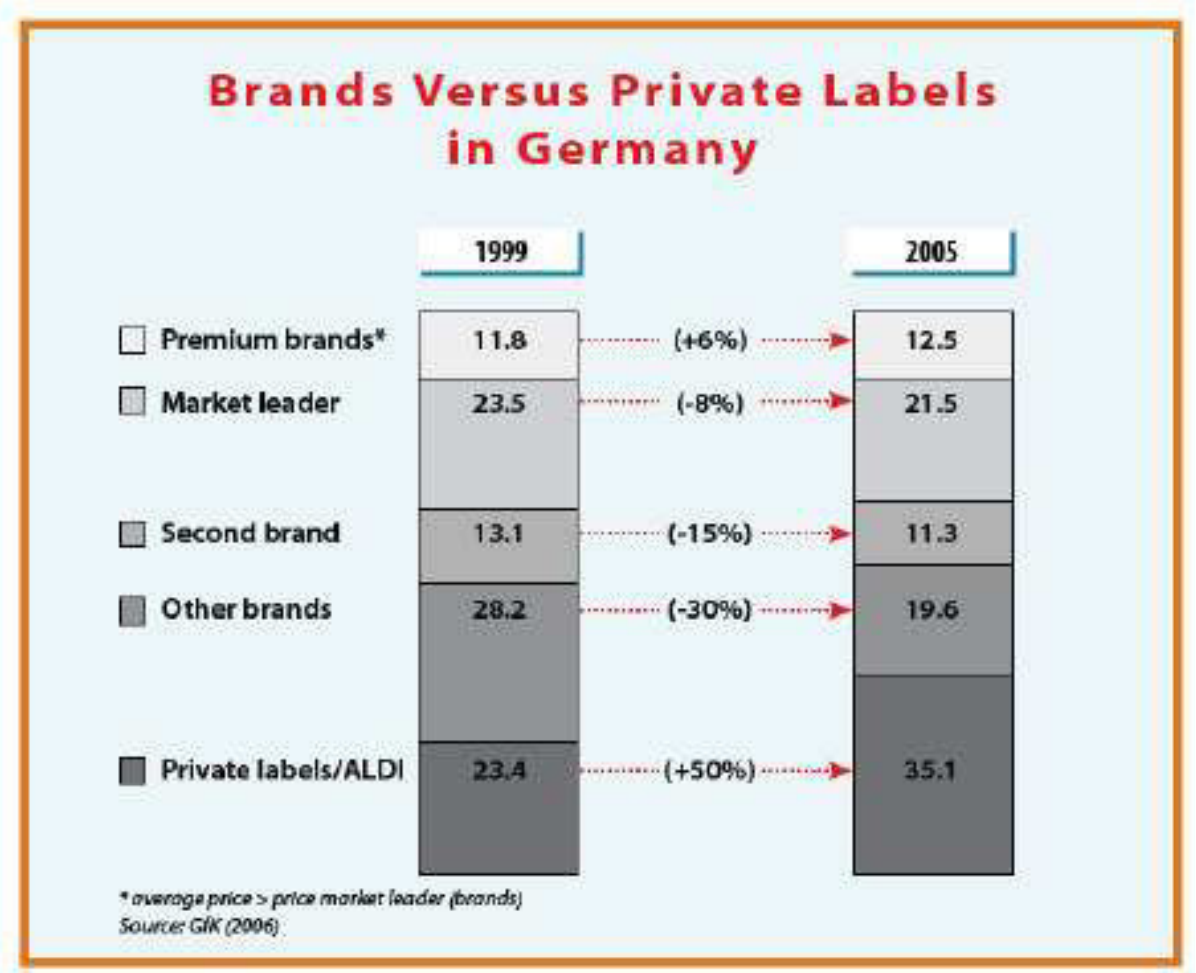

Fuente: Kumar y Steenkamp (2007b) 
El crecimiento de la cuota de mercado de las marcas de distribuidor en España, ha sido impulsionado, en los últimos años, por la situación económica, mayor sensibilidad al precio y por el desarrollo de mercado (Kantar WorldPanel, 2012). Un importante porcentaje $(27,2 \%)$ de los encuestados que durante la crisis han probado las opcionesmás baratas, en especial las marcas de distribuidores, dicen que van a seguir consumiéndolas una vez que la crisis haya terminado (PWC, 2011). En un contexto mundial, AC Nielsen (2011) y Ernest Young (2011) confirman dicha tendencia: dada la reciente desaceleración de la economía en los mercados desarollados, los consumidores "conscientes de valor" son en mayor número cada día. Y no restan dudas de que dicha tendencia continuará aunque la economía retome su crecimiento. La figura 2.3 muestra los resultados del estudio llevado a cabo por AC Nielsen (2011), y destaca que $91 \%$ de los internautas dicen que continuarán a comprar marcas de distribuidores después de la crisis.

Figura 2.3. 91\% de los internautas continuarán a comprar marcas de distribuidor después de la crisis

\section{When the economy improves, virtually all consumers will continue to purchase private label brands}

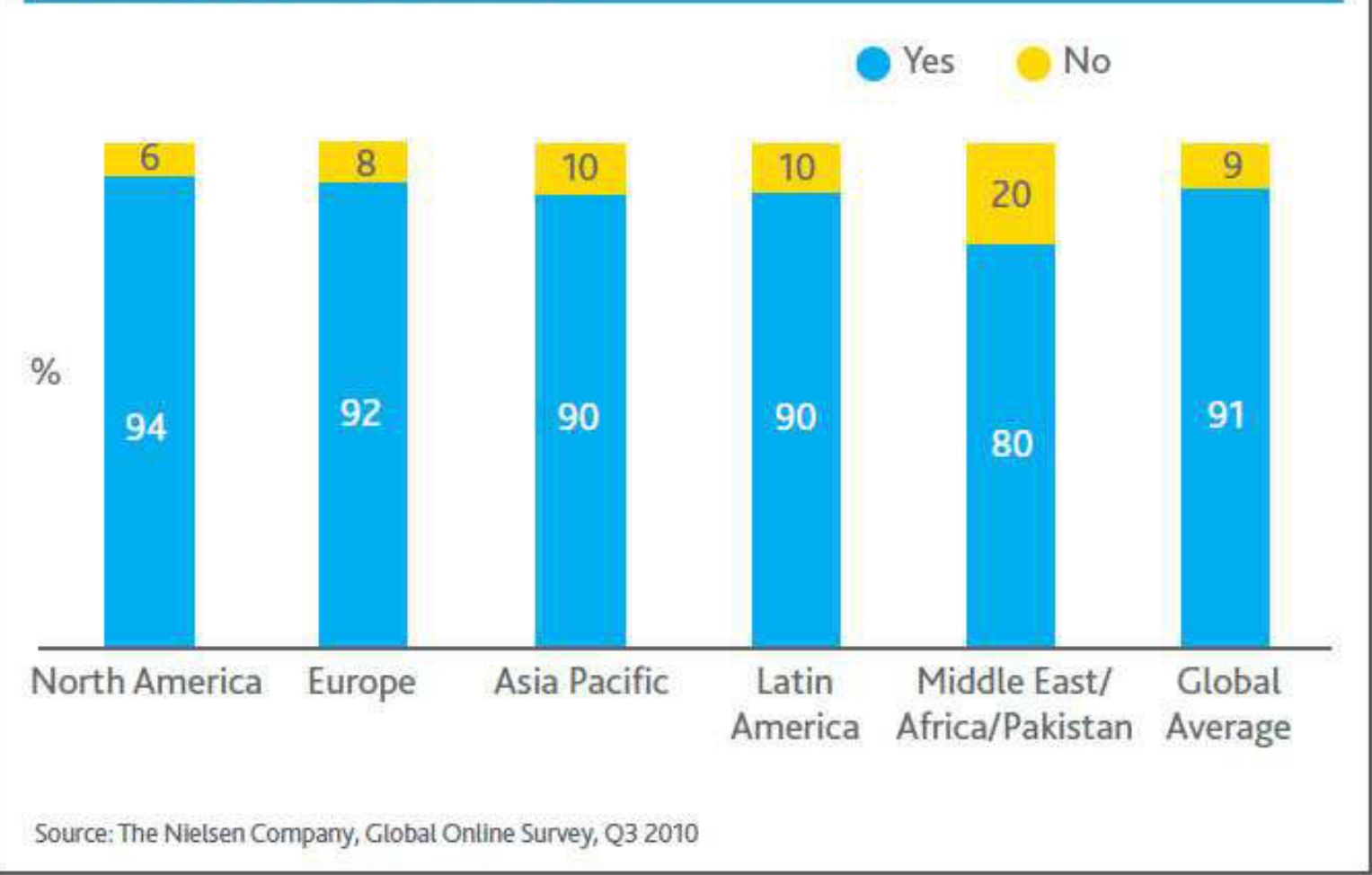

Fuente: AC Nielsen, 2011 
Si en Europa el contexto ecónomico ha favorecido a las marcas de distribuidor, en una escala global, el impacto del ambiente económico sobre las marcas de distribuidores ha tenido un papel marginal. Al hacer una comparación entre los mercados, hay un lento pero continuo progreso de las marcas de distribuidores. Tal progreso es consecuencia principalmente de la utilización de marcas propias por los minoristas en un número cada vez mayor de categorías, fenómeno que ha sido constante en las últimas dos décadas. $Y$ en la medida en que los distribuidores continúen promocionando sus marcas propias, el crecimiento seguramente continuará (AC Nielsen, 2011). La figura 2.4 muestra la cuota de mercado de las marcas de distribuidor en el contrexto internacional.

Figura 2.4. Cuota de mercado de las marcas de distribuidor en el mundo

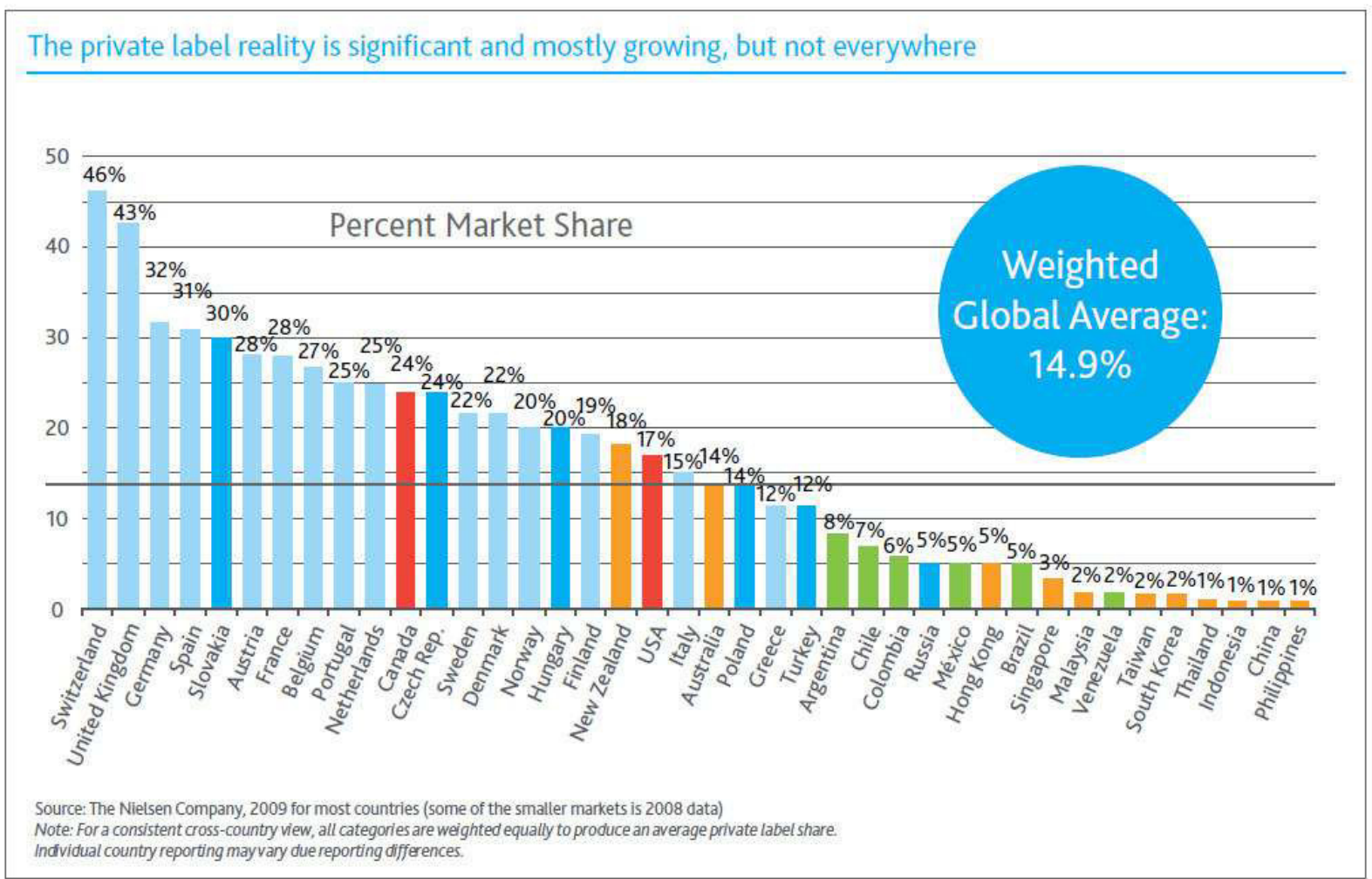

Fuente: AC Nielsen, 2011

Es relevante también el papel de las marcas de distribuidor en la elección de la cadena. El estudio más reciente de Kantar WorldPanel (2012) muestra que la calidad de las marcas propias es el cuarto motivo considerado para elegir una cadena, mientras que en 2010 dicho motivo ocupaba el setimo lugar (Figura 2.5). 

cadena

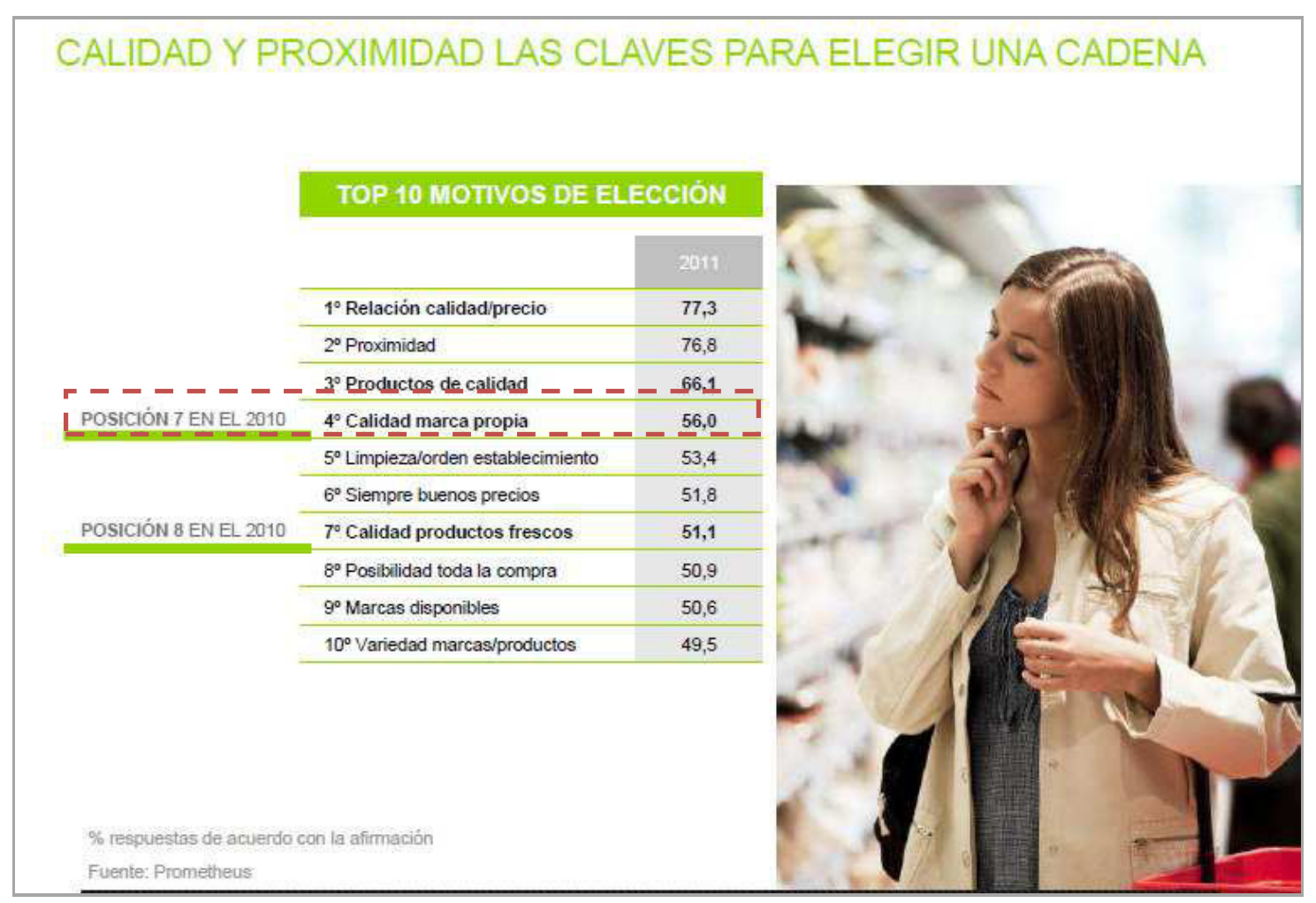

Fuente: Kantar WorldPanel, 2012

En línea con la importancia dada a la calidad de las marcas propias está también el cambio en las percepciones del consumidor con relación a dichas marcas. Desde 2003, hubo una significativa mejora en la percepción de calidad de las marcas de distribuidor por los consumidores españoles. En 2003, 53\% de los escuestados creían que las marcas de distribuidor tenian la misma calidad que las marcas de fabricante, mientras que en $2011,57 \%$ de ellos concordaron con dicha afirmación (Kantar WorldPanel, 2012), conforme muestra la figura 2.6.

El desempeño de las marcas de distribuidor difiere a través de las distintas categorías: los itens más vendidos tienden a ser productos con margen limitada y que se ven más afectados por el aumento en el coste de la materia prima. En la categoría de alimentación, los productos más vendidos son huevos, leche y productos lácteos, mientras que en la categoría de no-alimentación, los productos más vendidos son el papel de aluminio, toallitas higiénicas, platos de papel y el papel higiénico (AC Nielsen, 2008). 
Figura 2.6. Las marcas de distribuidor se fortalecen en la mente del consumidor

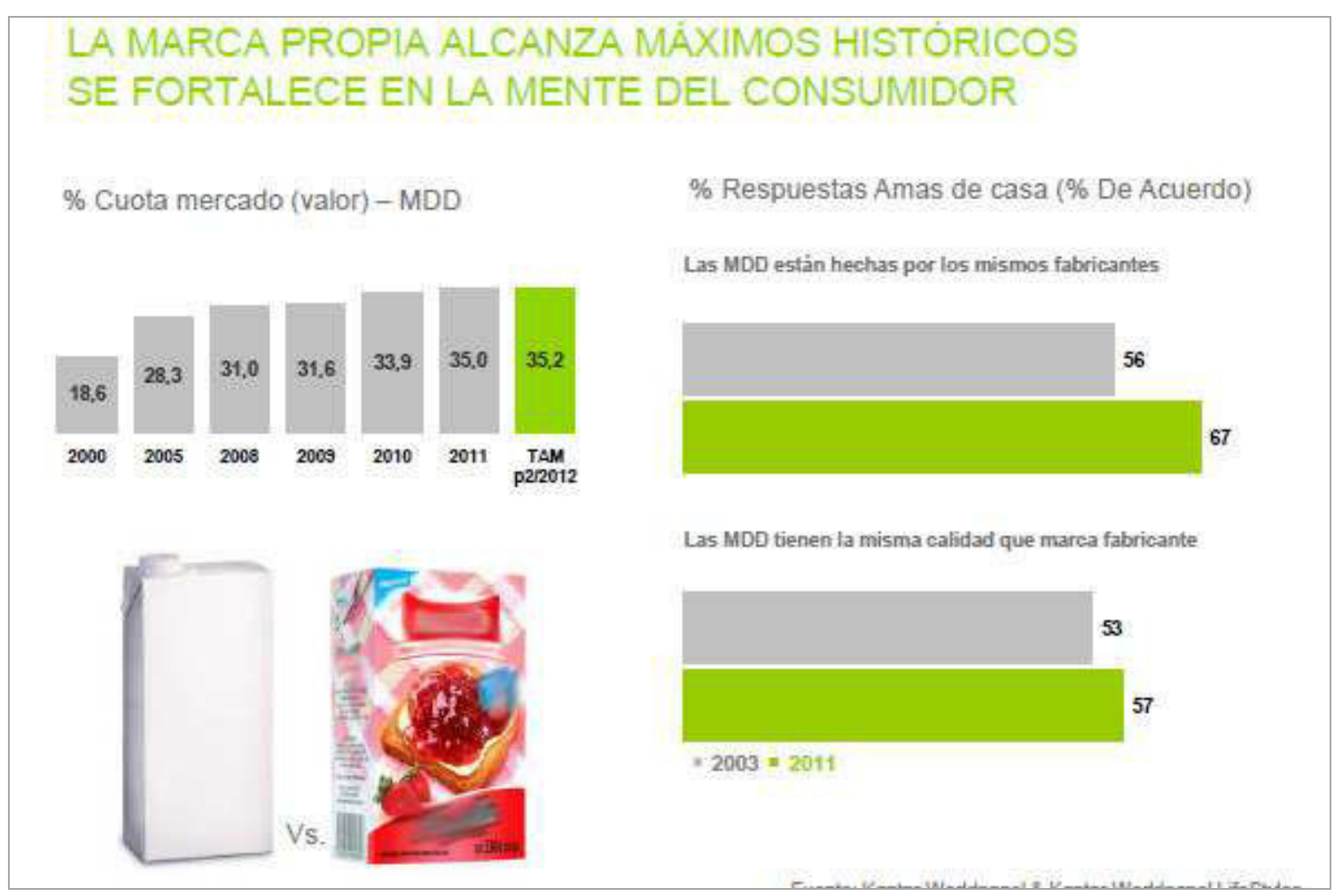

Fuente: Kantar WorldPanel, 2012

En España, las marcas de distribuidor también crecen en todos los sectores, aún que a un ritmo desigual. Datos de Kantar WorldPanel (2010) muestran que el sector que más ha crecido en los últimos años ha sido el sector de droguería. Además, el estudio de Kantar WorldPanel destaca el papel de las marcas propias de Mercadona, que ha sido el principal responsable por el crecimiento de las marcas de distribuidor en España en los últimos años (Figura 2.7).

Aún hay mucho espacio para crecimiento en la categoría de perfumaría y cosmética, sin embargo las marcas de distribuidor ya han llegado a este segmento también. Mercadona ha sido pionera en desarrollos de la marca propia en gamas reservadas a las enseñas de los fabricantes, con productos como la crema de caviar para el cuidado facial, pero praticamente todos los distribuidores han entrado en el juego - Eroski con la marca Belle, Carrefour con Les Cosmétiques y El Corte Inglés con la marca Veckia. La tendencia en este segmento es que las marcas premium se desarrollen cada día, pero eso tampoco disminuye la importancia de las marcas más baratas (Resa, 2012). 
Figura 2.7. Crecimiento de las marcas de distribuidor en España

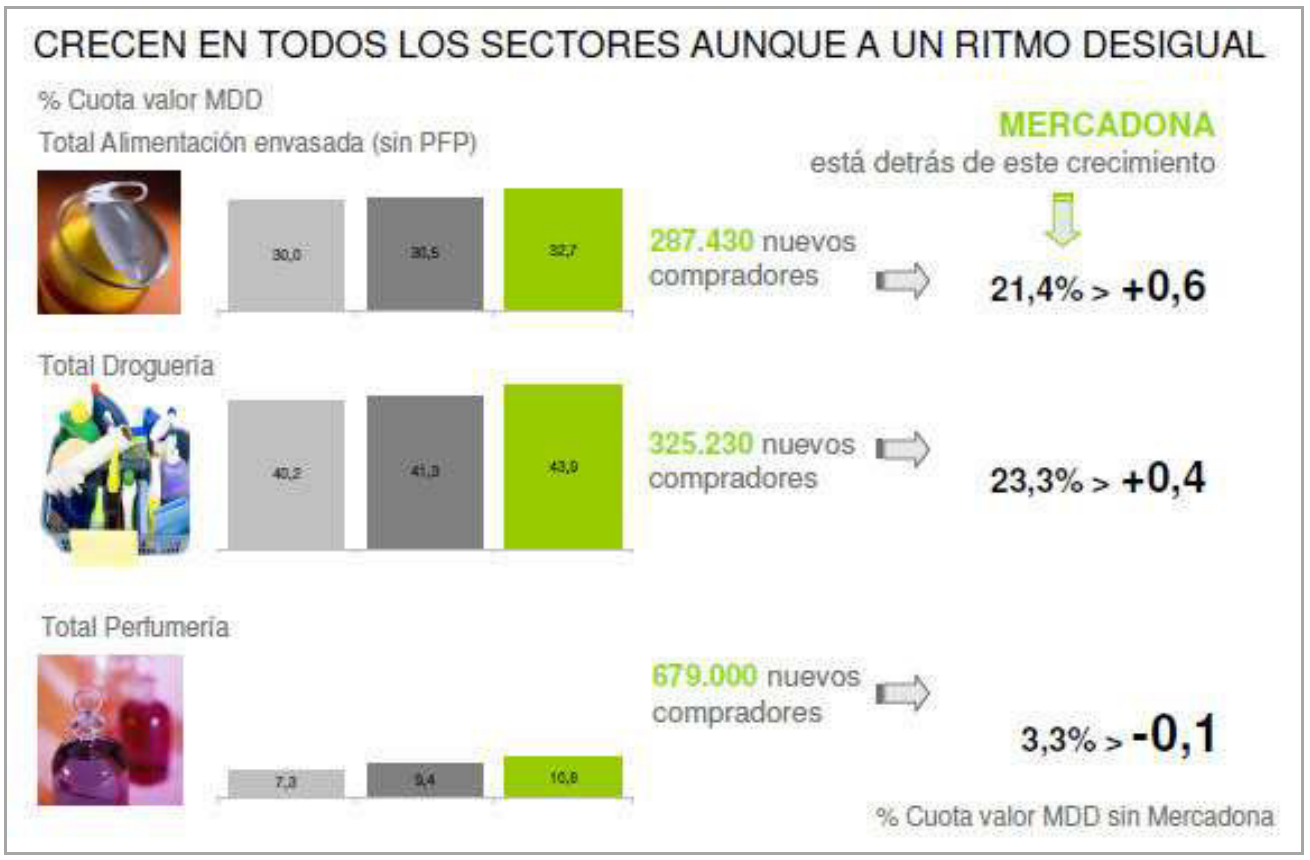

Fuente: Kantar WorldPanel, 2010

Todavía existe oportunidad de crecimento para las marcas de distribuidor en los productos de alimentación orgánica y natural, las ventas de estos productos se mantienen fuertes a pesar del escenario económico. Los consumidores consideran la salud y el bienestar como una prioridad y las ventas muestran que los productos "bajos en calorias", "sin glúten", "pro-biótico" y "natural" resuenan en los consumidores conscientes de la salud, lo que seguramente es un camino para las marcas de distribuidor (Ernest \& Young, 2011).

Por fin, cabe destacar que en mercados fuera del contexto tradicionalmente estudiados - Estados Unidos y Eruopa - hay un enorme potencial de crecimiento de las marcas de distribuidor en Asia y America Latina. Las marcas de distribuidor tienen un grado diferente de madurez en los distintos mercados (Steenkamp, Van Heerde y Geyskens, 2010). 
Figura 2.8. Cuota de mercado de marcas de distribuidor en Asia

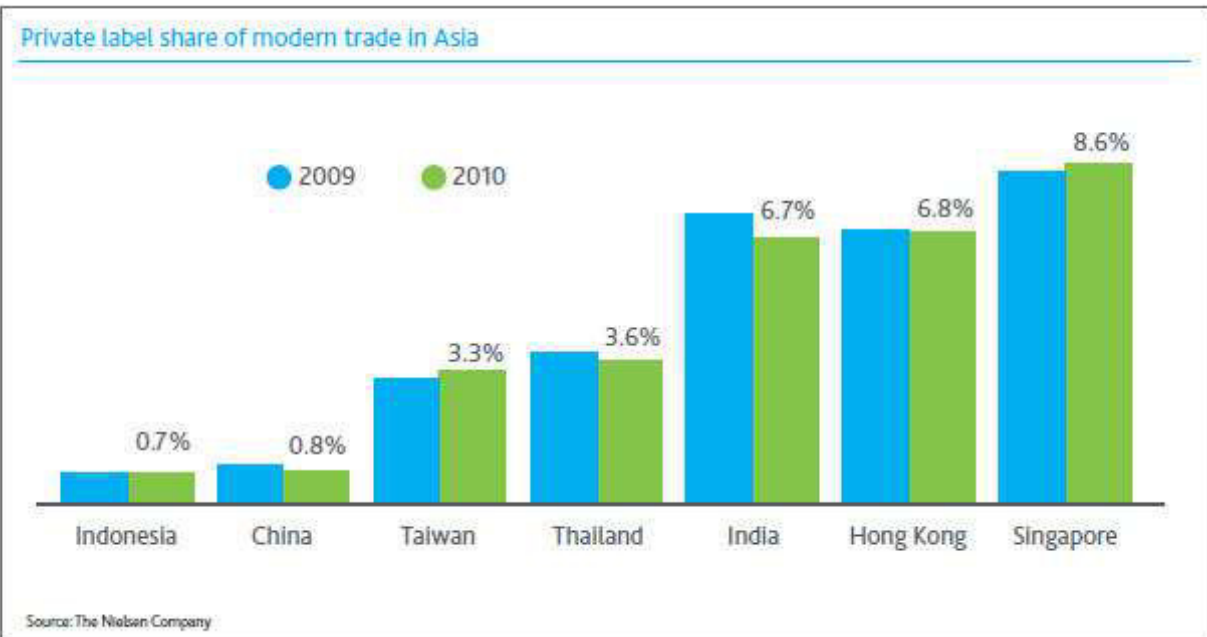

Fuente: AC Nielsen, 2011

Figura 2.9. Cuota de mercado de marcas de distribuidor en América Latina

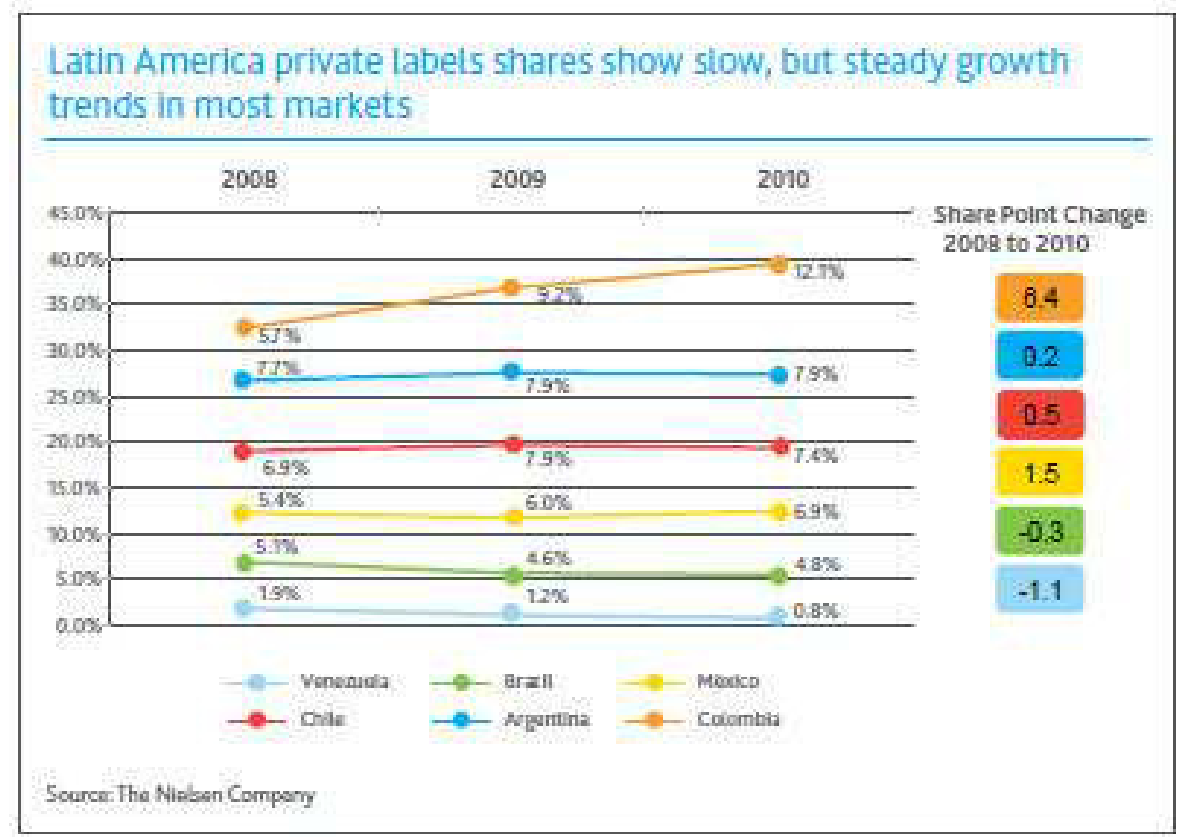

Fuente: AC Nielsen, 2011

\subsubsection{Marca de distribuidor y posicionamiento del distribuidor.}

El formato de precio del distribuidor, EDLP (Every Day Low Price) y el Hi-Lo (and High-Low Promotional Pricing), tiene influencia en el comportamiento de 
compra del consumidor e inflfuye en su elección del establecimiento (Ailawadi y Keller, 2004).

En este contexto, las marcas de distribuidor están tendiendo a utilizarse como una herramienta para el posicionamiento del distribuidor (Ailawadi y Keller, 2004; Dekimpe et al., 2011) y las estrategias de marcas propias tienden a ser coherentes con el posicionamiento del distribuidor, en particular, en su posición de calidadprecio (Luijten y Reijnders, 2009).

La teoría de la congruencia (Jacoby y Mazursky, 1984) aclara la relación entre la imagen del distribuidor, su posicionamiento en precio y sus marcas propias y propone que se produce inconsistencia o incongruencia cuando la fuente (el distribuidor) y el objeto (la marca propia del distribuidor) no son percibidas como igualmente asociadas. Dicha incongruencia podría dañar la imagen del distribuidor.

Nenycz-Thiel y Romaniuk (2011) detectan congruencia entre la imagen de "buena relación calidad-precio" del distribuidor y de sus marcas propias y destacan que esta relación es aun más fuerte entre los consumidores que no utilzan marcas propias con frecuencia. LLos consumidores infieren la calidad del producto a través de la imagen y reputación del establecimiento (Yoo, Donthu y Lee, 2000).

\subsection{4. . Cartera de marcas de distribuidor}

Las marcas de distribuidor pueden posicionarse de distintas maneras, en función de distintos criterios de segmentación, buscando un posicionamiento en la mente de los consumidores. Kumar y Steenkamp (2007a), distinguen tres estrategias principales de segmentación: la basada en la categoría de producto, la basada en beneficios buscados y la basada en precios, más común ente los minoritas europeos.

La segmentación basada en la categoría consiste en desarrollar distintas marcas propias para las distintas categorías de productos demandadas por los consumidores En general, es una estrategia de "casa de marcas", es decir, marcas independientes -no están vinculadas entre ellas, ni al establecimiento-. Es el ejemplo 
del alemán Aldi, que tradicionalmente evita usar su nombre de enseña en cualquier de sus productos. Además, González-Benito y Martos-Partal (2007) comentan que el desarrollo de marcas propias para categorías específicas permite que el distribuidor se adapte a distintas asociaciones establecidas por los consumidores para cada categoría.

A su vez, la segmentación basada en los beneficios buscados por el consumidor construye las marcas de distribuidor según las necesidades específicas de los consumidores. Los minoristas están pendientes de los cambios en las necesidades y estilos de vida de los consumidores y el hecho de tener marcas propias que cubran dichas necesidades permite al distribuidor dirigirse a distintos estilos de vida. Es la estrategia adoptada, por ejemplo, por Carrefour con sus marcas "Carrefour Bio" para consumidores conscientes del medio ambiente- y la "Gourmet" -de alimentación específica para gastrónomos.

La estrategia más común de los distribuidores es ofrecer una carterade tres escalones con una marca económica o genérica, una marca estándar o copia y una marca premium (Geyskens, Gielens y Gijsbrechts, 2010; Kumar y Steenkamp 2007a), estratégia basada en precio, conforme muestra el gráfico 2.1.

\section{Gráfico 2.1. Posicionamiento tradicional de las marcas de distribuidor}

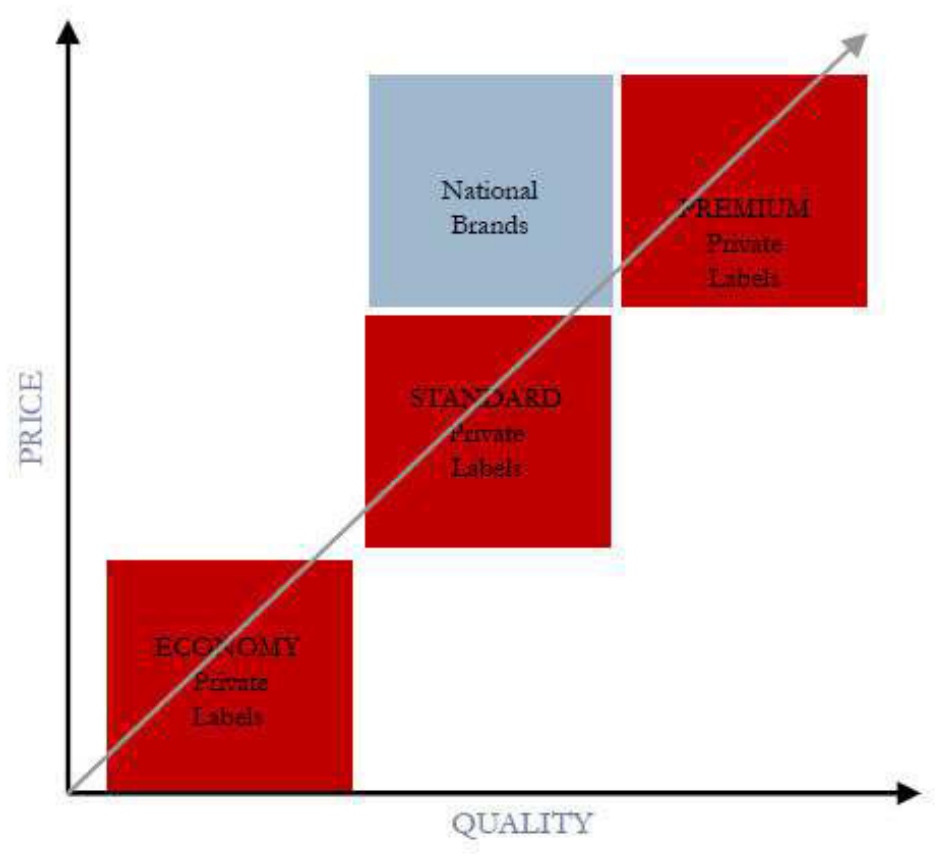

Fuente: Gielens, 2011 
A las marcas genéricas también se las ha denominado marcas blancas o marcas de primer precio. Las marcas genéricas enfatizan el uso básico del producto. Un envase de diseño sencillo, actividades promocionales limitadas y cortes en los ingredientes más caros garantizan un posicionamiento en el precio más bajo (Yelkur, 2000; Harris y Strang, 1985).

Otro tipo de marca de distribuidor es la marca copia. Su envase suele ser semejante al de las marcas nacionales. Se ubican en los lineales cerca de las marcas líderes para generar comparación, y a veces confusión en los consumidores dada su estrategia de calidad similar pero a un precio más ventajoso.

Por otro lado, en los últimos años, los distribuidores también ofrecen marcas premium como herramienta de diferenciación. Son marcas de calidad igual o superior al líder del mercado, con un precio también similar o superior. Dunne y Narasimham (1999) consideran las marcas premium como substitutas cercanas de las marcas líderes. Los minoristas pretenden con estas marcas, además de diferenciarse, mejorar su imagen, generar consumidores leales y aumentar la rentabilidad.

La Tabla 2.1 resume los tipos de marca de distribuidor, sus estrategias, objetivos, propuesta al consumidor y otros rasgos que las caracterizan.

Por lo tanto, las marcas de distribuidor no son todas iguales. La distinción entre las marcas de distribuidor de alta/aceptable calidad y de baja calidad es fundamental para entender su contribución a la estrategia del minorista. Son las marcas de alta calidad que posibilitan la diferenciación, la lealtad y rentabilidad. Por otro lado, las marcas de baja calidad actúan en la guerra de precios a medida en que enfatizan e intensifican la sensibilidad al precio Corstjens y Lal (2000).

Hoy en día, los distribuidores trabajan con una mezcla de estrategias. Las carteras de producto que siguen una mezcla de estrategia combinan tres tipos de marca de distribuidor -genérica, copia y premium- con los tres tipos de segmentación -basada en precios, en categorías o en necesidades. Ejemplos de distribuidores líderes que siguen este tipo de estrategia son Wal-Mart y Tesco. 
Tabla 2.1. Tipología de marca de distribuidor según estrategia de mercado

\begin{tabular}{|c|c|c|c|}
\hline & Genérica & Copia & Premium \\
\hline Estrategia & $\begin{array}{l}\text { La más barata - sin } \\
\text { diferenciación }\end{array}$ & Yo también, más barato & Valor añadido \\
\hline Objetivos & $\begin{array}{l}\text { Proporcionar al } \\
\text { consumidor una opción } \\
\text { de precio bajo. } \\
\text { Aumentar la base de } \\
\text { clientes }\end{array}$ & $\begin{array}{l}\text { Incrementar el poder de } \\
\text { negociación frente al } \\
\text { fabricante. Aumentar la } \\
\text { cuota del minorista en } \\
\text { los beneficios de la } \\
\text { categoría }\end{array}$ & $\begin{array}{l}\text { Suministrar productos } \\
\text { de valor añadido. } \\
\text { Diferenciar las enseñas } \\
\text { comerciales. } \\
\text { Incrementar las ventas } \\
\text { en la categoría. Mejorar } \\
\text { los márgenes. }\end{array}$ \\
\hline $\begin{array}{l}\text { Estrategia de } \\
\text { marca }\end{array}$ & $\begin{array}{l}\text { No tiene nombre o se } \\
\text { identifica como marca } \\
\text { de primer precio }\end{array}$ & $\begin{array}{l}\text { Marca paraguas o } \\
\text { marca propia específica } \\
\text { para la categoría }\end{array}$ & $\begin{array}{l}\text { Nombre del distribuidor } \\
\text { con submarca o marca } \\
\text { propia }\end{array}$ \\
\hline Precio & $\begin{array}{l}\text { Gran descuento, entre } \\
20 \% \text { y } 50 \% \text { más bajo } \\
\text { que la marca líder }\end{array}$ & $\begin{array}{l}\text { Descuento moderado, } \\
\text { entre } 5 \% \text { y } 25 \% \text { más } \\
\text { bajo que la marca líder }\end{array}$ & $\begin{array}{l}\text { Similar o mayor que la } \\
\text { marca líder }\end{array}$ \\
\hline Categorías & $\begin{array}{l}\text { Categorías de productos } \\
\text { básicas y funcionales }\end{array}$ & $\begin{array}{l}\text { Categorías grandes con } \\
\text { líderes fuertes }\end{array}$ & $\begin{array}{l}\text { Categorías clave en la } \\
\text { imagen del minorista }\end{array}$ \\
\hline $\begin{array}{l}\text { Calidad frente al } \\
\text { líder }\end{array}$ & Calidad limitada & $\begin{array}{l}\text { Calidad cercana a las } \\
\text { marcas de fabricante }\end{array}$ & $\begin{array}{l}\text { Calidad similar o } \\
\text { superior, publicitada } \\
\text { como la mejor }\end{array}$ \\
\hline $\begin{array}{l}\text { Desarrollo de } \\
\text { producto }\end{array}$ & $\begin{array}{l}\text { Ninguno, requisitos } \\
\text { tecnológicos básicos } \\
\text { para los fabricantes }\end{array}$ & $\begin{array}{l}\text { Ingeniería inversa } \\
\text { contratando fabricantes } \\
\text { con tecnología similar a } \\
\text { los líderes }\end{array}$ & $\begin{array}{l}\text { Esfuerzo considerable } \\
\text { para desarrollar } \\
\text { productos con } \\
\text { tecnología similar o } \\
\text { mejor que las marcas } \\
\text { líderes }\end{array}$ \\
\hline Envase & Barato y básico & $\begin{array}{l}\text { Tan cercana al líder } \\
\text { como sea posible }\end{array}$ & $\begin{array}{l}\text { Único y fuente de } \\
\text { diferenciación }\end{array}$ \\
\hline $\begin{array}{l}\text { Ubicación en el } \\
\text { lineal }\end{array}$ & $\begin{array}{l}\text { Marginal, en los } \\
\text { espacios menos visibles }\end{array}$ & Cercano a la marca líder & $\begin{array}{l}\text { Lugares prominentes } \\
\text { visualmente más } \\
\text { accesibles }\end{array}$ \\
\hline $\begin{array}{l}\text { Promoción y } \\
\text { publicidad }\end{array}$ & Ninguna & $\begin{array}{l}\text { Promociones frecuentes } \\
\text { en precio }\end{array}$ & $\begin{array}{l}\text { Promoción publicitaria } \\
\text { pero escasas } \\
\text { promociones en precio }\end{array}$ \\
\hline $\begin{array}{l}\text { Propuesta al } \\
\text { consumidor }\end{array}$ & $\begin{array}{l}\text { Vendidas como del } \\
\text { producto más barato }\end{array}$ & $\begin{array}{l}\text { Vendidas como de la } \\
\text { misma calidad pero con } \\
\text { precios más bajos }\end{array}$ & $\begin{array}{l}\text { Vendidas como los } \\
\text { mejores productos en el } \\
\text { mercado }\end{array}$ \\
\hline
\end{tabular}

Fuente Kumar y Steenkamp (2007a) 
El minorista británico Tesco, con cerca de $50 \%$ de sus ventas provenientes de marcas propias, continuamente promociona sus valores organizacinales que involucra promover los más excelentes productos para sus marcas propias. Este minorista tiene un portfolio de marca coherente y efectivo con las marcas Tesco Finest (250 productos cuya calidad excede a la de las marcas de fabricante), Tesco (comparable a las marcas de fabricante) y Tesco Value, además de marcas especiales como Tesco Organic y Tesco Healthy Living (Aaker, 2011).

En el contexto español, vale comentar sobre la cartera de marcas propias de Carrefour, la primera empresa de distribución en España que lanzó su propia marca, en 1982. Su propuesta en lanzar cada año más de 3.000 nuevos productos de marca Carrefour en alimentación, cosmética, deporte, hogar y textil (Carrefour). Dentro de la cartera de marcas propias de Carrefour, Carrefour Selección es la propuesta del minorista como "el mejor de Carrefour", su marca premium; Carrefour, como la marca estándar y Carrefour Discount es su line de productos básicos al mejor precio, su opción como marcas genéricas. El minorista ofrece también marcas especiales como la Carrefour Bio y la Carrefour Eco Planet.

Cabe destacar, sin embargo, algunos riesgos de esas estrategias, como el canibalismo de productos, los prejuicios en la imagen si al consumidor no le gusta uno de sus productos y la pérdida de espacio en los lineales (Kumar y Steenkamp, 2007a).

La cartera de marcas de distribuidor tiene tal importancia hoy que los minoristas gestionan su cartera de marcas como parte de una visión total para la categoría y para el establecimiento. Además, deben elegir el mix de marca ideal para cada categoría y decidir que tipo de marca ofrecer - marcas propias o marcas de fabricante - para obtener la mayor rentabilidad (Kapferer, 2008). 


\section{2.- Segmentación por beneficios buscados}

\subsection{1. . Concepto de segmentación por beneficios buscados}

La segmentación del mercado es un proceso encaminado a la identificación de aquellos consumidores con similares necesidades o necesidades homogéneas a fin de que resulte posible establecer para cada grupo una oferta comercial diferenciada, orientada de un modo específico hacia las necesidades, intereses y preferencias de los consumidores que componen ese grupo o segmento (Munuera y Escudero, 2002).

Hay diversas maneras de segmentar el mercado y los profesionales de marketing deben contrastar distintas variables de segmentación aisladamenteo de manera combinada para encontrar el mejor critério de segmentación. Los principales tipos de segmentación de mercado de consumo final son la segmentación geográfica, demográfica, psicográfica y comportamental. La segmentación geográfica requiere una división del mercado en diferentes unidades geográficas, con especial atención a las diferencias entre las regiones en términos de necesidades y preferencias. A su vez, la segmentación demográfica usa variables demográficas como sexo, edad, renta, tamaño de familia y otros para dividir el mercado. Son las variables más fácilmente avaliadas y se cree que las necesidades y deseos de uso varíen conforme los cambios demográficos. La segmentación psicográfica divide los consumidores en grupos distintos basados en la clase social, en el estilo de vida o en características de personalidad. Por último, la segmentación comportamental divide los consumidores en términos de su conocimiento, actitud, usos o respuestas a un producto en específico. Muchos profesionales de marketing creen que las variables de comportamiento son el mejor punto de partida para la construcción de la segmentación (Kotler y Armstrong, 1999).

La segmentación por beneficios buscados es un tipo de segmentación comportamental. Requiere la investigación de los principales beneficios deseados para una clase de productos, los tipos de personas que desean estos beneficios y las principales marcas que lo ofrecen (Kotler y Armstrong, 1999). Por ende, lo que distingue los segmentos es la importancia relativa otorgada a los atributos cuando los compradores son inducidos a hacer elecciones entre ellos (Munuera y Escudero, 2002). Lambin (2000) complementa la relevancia de dicha segmentación al señalar 
que este tipo de caracterización está basada en los valores de las personas y no en sus perfiles socio-demográficos. Dos personas idénticas en términos de perfiles sociodemográficos pueden tener sistemas de valores muy distintos. Por porfundizar en factores causales del consumo en lugar de analizar factores descriptivos, la segmentación por beneficios buscados resulta más relevante en el contexto de esta tesis al determinar de forma más precisa el comportamiento de compra, una vez que que la segmentación basada en los beneficios buscados se apoya directamente en aquellas razones por las cuales el consumidor es atraído hacia un producto. (Haley, 1968).

\subsection{2. . Beneficios buscados y marca de distribuidor}

A pesar de su importancia, existe poca generalización empírica sobre los beneficios que busca el comprador de marcas de distribuidor. Además, aos resultados o son pocos concluyentes o han sido escasamente investigados.

En esto trabajo, nos centramos en seis beneficios buscados e investigaremos su relación con la compra de marcas de distribuidores. A seguir, se aborda brevemente los beneficios buscados utilizados:

1) Sensibilidad al precio: El precio bajo es un factor diferenciador entre marcas de distribuidor y marcas de fabricantes en la mente del consumidor (Nanycz-Thiel y Romaniuk, 2009) y resulta ser un determinante muy importante para la elección de este tipo de marcas (Ailawadi, Neslin y Gedenk, 2001; Baltas, 1997, Burton et al., 1998; Manzur et al., 2011; Méndez, Oubiña y Rubio, 2008; Sethuraman, 2006). Los resultados empíricos de Rubio y Yague (2007a, 2007b) y también muestran que un aumento en el diferencial de precio entre marcas de fabricante y marcas de distribuidor son un incentivo a la compra de las marcas de distribuidor a lo largo del tiempo. Por lo tanto, de manera general, la sensibilidad al precio está relacionada positivamente con la compra de marcas de distribuidor.

2) Propensión a la promoción: La propensión a la promoción es una función tanto del comportamiento de compra del consumidor como de la frecuencia con que un determinado producto es promocionado, pero siempre involucra una reducción 
del precio normal o en aumento de valor para el consumidor (Webster, 1965). Por su precio inferior a las marcas nacionales, las marcas propias son menos promocionadas. Por otro lado, los fabricantes utilizan cada vez más la promoción para evitar la migración de los consumidores hacia dichas marcas (Garretson, Fisher y Burton, 2002). Sin embargo, la investigación sobre este tema aún es escasa.

3) Sensibilidad a la calidad del servicio: Pocos estudios han tratado de caracterizar al comprador de marca de distribuidor en función de su sensibilidad a la calidad (Ailawadi, Neslin y Gedenk, 2001). Sin embargo, Ailawadi y Keller (2004) definen al consumidor de marca de distribuidor como un consumidor no sensible a la calidad del servicio y otros estudios confirman dicha relación, como Ailawadi, Neslin y Gedenk (2001) y Ailawadi, Pauwels y Steenkamp (2008)

4) Diversión en la compra: Williams, Slama y Rogers (1985) destacan la existencia de un segmento de consumidores a quienes les gusta comprar y lo consideran como una actividad recreacional. Entretanto, con respecto a la relación entre diversión en la compra y la compra de marcas de distribuidor, la literatura previa muestra evidencias mixtas. Por ejemplo, para Williams, Slama y Rogers (1985), consumidores que buscan diversión parecen comprar marcas nacionales. Sin embargo, Cox, Cox y Anderson (2005) sugieren que la búsqueda de gangas puede ser una de las mayores fuentes de diversión en la compra lo que afectaría positivamente la compra de marcas de distribuidor.

5) Propensión a la innovación: Por ser un fenómeno más reciente, las marcas de distribuidor deberían atraer a los consumidores innovadores, mientras que algunos autores comentan que consumidores innovadores consideran las marcas propias más novedosas y, por lo tanto, dicho comportamiento alejaría estos consumidores de las marcas propias (Gómez y Rubio, 2010). Sin embargo, no hay evidencias conclusivas acerca de esta relación.

6) Sensibilidad a la marca: Algunos consumidores utilizan el nombre de marca para inferir la calidad de los productos de manera que se esperaría que marcas reconocidas ofrezcan mayor calidad (Shannon y Mandhachitara, 2008). Hay pocas evidencias acerca de la relación entre sensibilidad a la marca y compra de 
marcas de distribuidor, pero ellas sugieren una relación negativa: en los hogares que muestran mayor presencia de marcas de distribuidores en sus cestas de la compra, los consumidores son menos orientados a los productos de marca (Baltas y Argouslidis 2007).

\subsubsection{Papel del posicionamiento del distribuidor y de sus marcas}

Como se ha destacado anteriormente, el posicionamiento en precio del distribuidor tiene influencia sobre las elecciones del consumidor. Martos-Partal y González-Benito (2011) observan que el posicionamiento en precio del distribuidor afecta la oferta de marcas de distribuidor y la motivación de sus consumidores: por ejemplo, distribuidores orientados a precio tienden a desarrollar estrategias de marca propia basadas en precio y sus consumidores tienden a ser más sensibles a precio. Estos autores ofrecen evidencias empíricas de que el posicionamiento en precio del distribuidor actúa como un moderador en la caracterización motivacional de los consumidores, como la sensibilidad a precio y la percepción de calidad de marcas del distribuidor

De la misma manera, el posicionamiento de las marcas de distribuidor puede afectar a los beneficios buscados en la compra de marcas de distribuidor. En otras palabras, se considera que las motivaciones subyacentes a la compra de marcas de distribuidor pueden depender del tipo de marca que se considere, en particular, marca genérica, estándar o premium.

Palmeira y Tomas (2011) destacan que, en la mente del consumidor, si hay dos marcas de la misma compañía en la misma categoría, debe haber alguna diferencia entre ellas. Los resultados de su trabajo muestran que la expectativa de calidad para marcas premium son más elevadas cuando el distribuidor comercializa también una marca más orientada a valor. Estudios anteriores también indican que la percepción de calidad es mayor para marcas tipo estándar que para marcas genéricas (Bellizi et al. 1981; Cunningham, Hardy e Imperia, 1982). 


\subsection{Valor de marca}

\subsection{1. . Concepto del valor de marca}

Existen muchas definiciones de valor de marca que adoptan distintas perspectivas. Bajo la perspectiva del consumidor, Farquhar (1990), define el valor de marca desde como el aumento en la fuerza de la actitud del consumidor en relación a un producto que lleva un nombre de marca específico. A su vez, Keller (1993) define el valor de marca como el efecto diferencial del conocimiento de marca en las respuestas del consumidor al marketing de una marca. Es decir, el valor de marca basado en el consumidor involucra las reacciones del consumidor a un elemento del mix de marketing para la marca en comparación con sus reacciones al mismo elemento del mix de marketing de una versión del producto o servicio con una marca ficticia o sin marca. Siguiendo ese mismo enfoque Keller y Lehmann (2006) definen el valor de marca como la parte de la atracción hacia un producto particular generada por la parte no objetiva de la oferta del producto (no por los atributos del producto per se).

Una definición más amplia del valor de marca que abarca no sólo la perspectiva del consumidor sino también la perspectiva de la empresa es la propuesta por Aaker (1994). Aaker considera el valor de marca como un conjunto de activos y pasivos vinculados a la marca, su nombre y símbolo, que incorporan o disminuyen el valor suministrado por un producto o servicio a los clientes de la compañía. Si el nombre o símbolo de la marca debieran cambiarse, algunos de estos activos o pasivos se verían afectados e, incluso, podrían perderse. Los activos y pasivos en los cuales el valor de marca esta basado difieren de contexto para contexto, pero pueden ser agrupados en 5 categorias: lealtad a la marca, conocimiento de marca, calidad percibida, asociaciones de marca, otros activos. El concepto de valor de marca propuesto por Aaker se resume en la figura 2.8

Cualquiera que sea la definición del valor de marca, existe un enorme interés en comprenderlo, por sus consecuencias para consumidores y para empresas. Actitudes, lealtad, recononocimiento de marca e imagen son algunos beneficios relacionados al consumidor que pueden ser afectados por el valor de marca, mientras que el precio, cuota de mercado, influencia en el canal de distribución, oportunidades de licenciarla marca, ingresos y flujo de caja marginal son algunos de 
Figura 2.8. Concepto de valor de marca, sus activos y pasivos

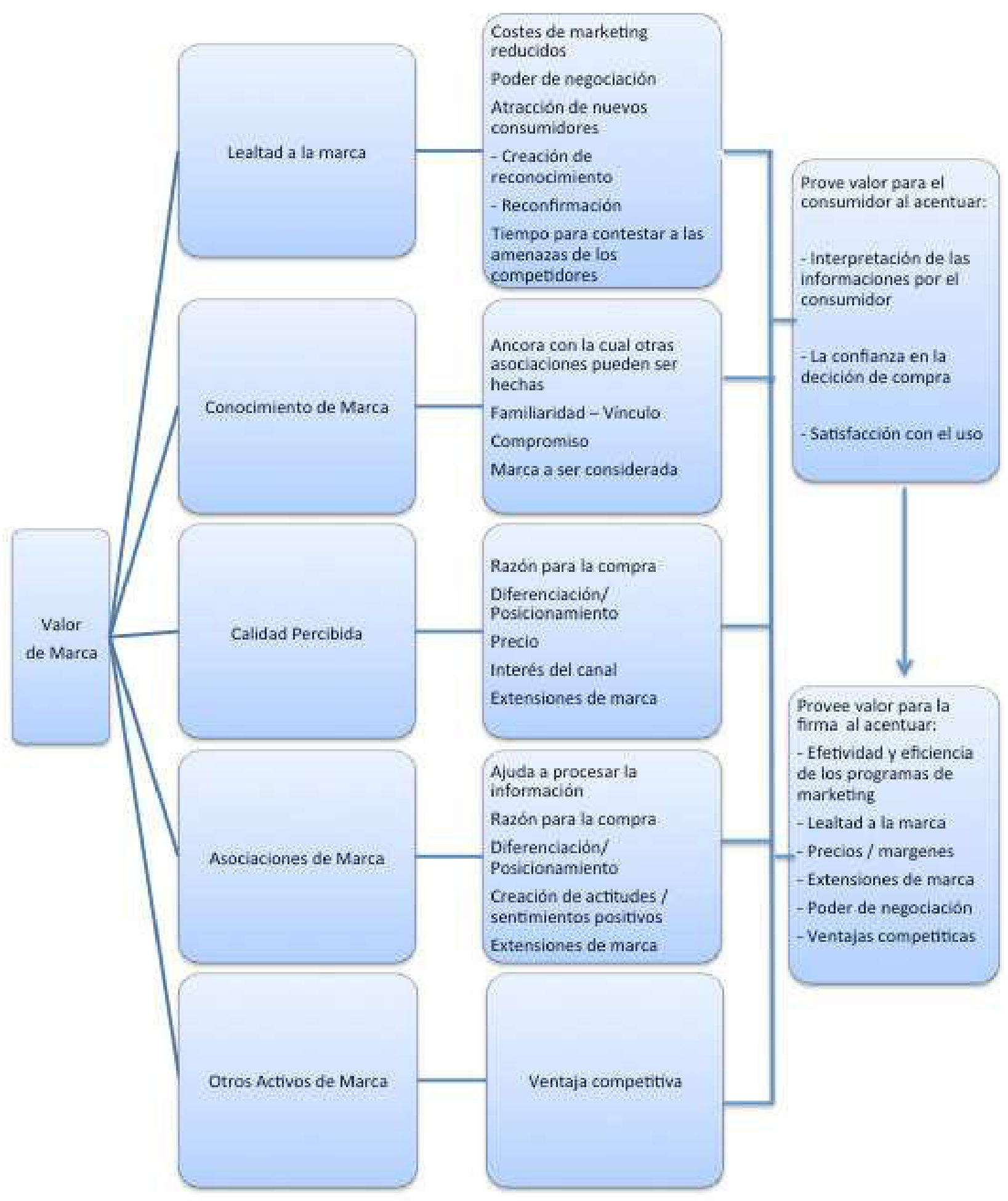

Fuente: Aaker, 1994 
los beneficios relacionados a la empresa (Ailawadi, Lehmann y Neslin, 2003; Aaker, 1994; Aaker, 1996; Simon y Sullivan 1993)

Dado que el interés de ese trabajo está en esta respuesta diferencial al marketing de la marca, se adoptará la definición de Keller, que compara los efectos de la mezcla de marketing de un producto de una marca específica con un producto sin marca.

\subsection{2. . Medida del valor de marca.}

Una buena gestión de una cartera de marcas y del mercado empieza con la elección y desarrollo de algunas medidas de desempeño. Medidas del valor de marca pueden y deben ser usadas para evaluar las actividades de construcción de la marca (Aaker, 1996). Distintos autores proponen diferentes maneras de se medir el valor de marca.

Keller (1993) afirma que hay valor de marca cuando el consumidor reconoce y está familiarizado con la marca, además de tener algunas asociaciones de marca favorables, fuertes y únicas. El autor destaca dos aproximaciones para medir el valor de marca: 1) de forma indirecta a través de la medida de conocimiento de marca (reconocimiento de la marca y de algunos elementos de su imagen) y 2) de forma directa, que mide los efectos del conocimiento de marca en las respuestas a las actividades de marketing.

Aaker (1996), por otro lado, sugiere otras 10 medidas que pueden ser usadas para evaluar las actividades de construcción de marca y las agrupa en 5 categorias:

1. Medidas de lealtad: sobreprecio y satisfacción del consumidor

2. Medidas de calidad / liderazgo: calidad percibida, popularidad de marca

3. Medidas de asociación: valor percibido, personalidad de marca, asocioaciones corporativas 
4. Medidas de conocimiento: reconocimiento de marca

5. Medidas de comportamiento del mercado: cuota de mercado y medidas de precio y distribución

Otros autores sugieren medidas financieras para estimar el valor de marca. Por ejemplo, Simon y Sullivan (1993) presentan una técnica para estimar el valor de marca basado en el valor financiero de mercado. El valor de marca es definido como el flujo de caja adicional que proviene de los productos con marca en comparación con los productos sin marca. Las propuestas de Ailawadi, Lehmann y Neslin (2003) y Sethuraman (2003) siguen en la misma línea al comparar los ingresos que una marca genera con los ingresos de su versión en marca marca de distribuidor.. Kapferer (2008) destaca la medida financiera "goodwill', que trata del valor monetario de la "buena voluntad" psicológica que la marca ha creado a lo largo del tiempo a través de las inversiones en comunicación y enfoque consistente en la satisfacción, ambos colaborando a la construcción de la reputación de la marca

A falta de una única medida del valor de marca y la escasa investigacion sobre el tema se debe en partes a la falta de un acuerdo sobre si la medida del valor de marca debe ser basada en la perspectiva del consumidor o en la de la empresa. Aunque ambas perspectivas estén relacionadas, una vez que los resultados de la empresa como volumen, ingresos, nivel de precios, flujo de caja y rentabilidad son, en realidad, consecuencias de los efectos a nivel del consumidor como una imagen positiva, actitud, reconocimiento y leltad (Ailawadi, Lehmann y Neslin, 2003).

\subsection{3. . Valor de marca y marca de distribuidor}

La investigación académica sobre el valor de marca se ha centrado sobretodo en el ámbito de las marcas de fabricante (Aaker, 1994; Keller, 2001). Sin embargo, desde una perscpectiva de la gestión de marca, las marcas de distribuidor son iguales a qualquier otra marca en el mercado: se enfocan a un público específico, seleccionan un competidor principal cuyos clientes se intentarán "robar", definen un precio y ofertas (Kapferer, 2008). Y los minoristas invierten cada vez más en sus marcas, persiguiendo la creación de una identidad para sus marcas propias que los 
permita rentabilizar su establecimiento, diferenciarse y crear lealtad en los consumidores (Obiña, Rubio y Yague, 2006)

La escasa literatura sobre el valor de marca de marcas de distribuidor, indica que los consumidores perciben diferencias entre marcas de distribuidor y marcas de fabricantes en cuanto a su precio, calidad y riesgo (Nenycz-Thiel y Romaniuk, 2009). Lo que se debe investigar es si esa diferencia se debe a la valoración objetiva de las características y atributos de los productos o a la reputación y reconocimiento que conllevan las marcas de fabricante.

Estudios previos sobre ese tema no llegan a una misma conclusión. Parece que cuando los estudios analizan las percepciones de marca como base del valor de marca, sobretodo sobre el valor objetivo, la conclusión es que las marcas de distribuidor tienen valor de marca (Apelbaum, Gerstner y Naik (2003), en el contexto americano, y Mendéz, Oubiña y Rubio (2008), en el contexto español). En cambio, cuando los estudios analizan el valor de marca considerando reconocimiento de marca y poder de diferenciación, la conclusión es la opuesta (Juhl et al, 2006; De Wulf et al, 2005; Fornerino y d'Hauteville, 2010).

Además, vale resaltar que la mayoría de estos estudios han analisado las marcas de distribuidor de manera agregada, es decir, no han considerado el contexto actual de dicho fenómeno en que diferentes tipos de marca de distribuidor son ofrecidas, con propuestas de valor también distintas.

Por lo que este trabajo intentará dar una respuesta a tales cuestiones de investigación. 


\subsection{Referencias}

Aaker, David A. (1994), "Gestión del valor de la marca: capitalizar el valor de la marca”. Madrid: Díaz de Santos.

Aaker, David A. (1996),"Measuring brand equity across products and markets", California Management Review, 38 (3): 102-120

Aaker, David A. (2011, "Private Label War", Disponible en http://www.prophet.com/blog/aakeronbrands/33-the-private-label-war (Acesso el 17 Junio 2012).

ACNielsen (2008) "Higher unit prices, not volume, behind rapid growth of U.S. private label sales". Disponible en http://nielsen.com/us/en/insights/pressroom/2008/nielsen_higher_unit.html (Acesso el 07 Junio 2012).

ACNielsen (2011) "The rise of the value-conscious shopper". Disponible en http://au.nielsen.com/site/documents/PrivateLabelGlobalReportMar2011.pdf (Acesso el 30 Maio 2011).

Ailawadi, Kusum L. y Bari. Harlam (2004). An empirical analysis of the determinants of retail margins: The role of store brand share“, Journal of Marketing, 68 (1): 147166.

Ailawadi, Kusum L. y Kevin L. Keller (2004), "Understanding retail branding: conceptual insights and research priorities," Journal of Retailing, 80 (4): 331-342.

Ailawadi, Kusum L., Koen Pauwels, y Jan-Benedict E.M. Steenkamp (2008), "Private-label use and store loyalty," Journal of Marketing, 72 (6): 19-30.

Ailawadi, Kusum L., Donald R. Lehmann y Scott A. Neslin (2003), "Revenue Premium as an Outcome Measure of Brand Equity, 
Ailawadi, Kusum L., Scott A. Neslin, y Karen Gedenk (2001), "Pursuing the valueconscious consumer: store brands versus national brand promotions," Journal of Marketing, 65 (1): 71-89

Apelbaum, Eidan, Eitan Gerstner y Prasad A. Naik (2003), "The effects of expert quality evaluations versus brand name on price premiums," The Journal of Product and Brand Management, 12 (3): 154-165

Baltas, George (1997), "Determinants of store brand choice: a behavioral analysis," The Journal of Product and Brand Management, 6 (5): 315-324

Baltas, George y Paraskevas C. Argouslidis (2007) "Consumer characteristics and demand for store brands", International Journal of Retail \& Distribution Management, 35 (5): 328-341

Bellizi, J., Krueckeberg, H., Hamilton, J. y Martin, W. (1981). "Consumer perceptions of national, private, and generic brands", Journal of Retailing, 57 (4): 56-70.

Burton, Scot, Donald R. Lichtenstein, Richard G. Netemeyer y Judith A. Garretson (1998): "A scale for measuring attitude toward private label products and an examination of its psychological and behavioral correlates", Journal of the Academy of Marketing Science, 26 (4): 293-306

Carrefour (2012). Disponible en www.carrefour.es/grupo-carrefour/las-marcascarrefour/ (Acesso en Abril, 2012).

Corstjens, Marcel y Rajiv Lal (2000), "Building store loyalty through store brands", Journal of Marketing Research, 37 (3): 281-291

Cox, Anthony D., Dena Cox y Ronald D. Anderson (2005), "Reassessing the pleasures of store shopping", Journal of Business Research, 58 (3): 250-259

Cuneo, Andres, Pilar Lopez y Maria Jesus Yague (2012). "Measuring private labels' brand equity: a consumer perspective". European Journal of Marketing. Vol. 46 (7) 
Cunningham, Isabella C. M., Andrew P. Hardy y Giovanna Imperia (1982), "Generic brands versus national brands and store brands: a comparison of consumers' preferences and perceptions", Journal of Advertising Research, 22 (7-8): 25-32

De Wulf, Kristof, Gaby Odekerken-Schröder, Frank Goedertier y Gino Van Ossel (2005), "Consumer perceptions of store brands versus national brands," The Journal of Consumer Marketing, 22 (4): 223-232.

Dekimpe, Marnik G., Katrijn Gielens, Jagmohan Raju, y Jacquelyn S. Thomas (2011), "Strategic assortment decisions in information-intensive and turbulent environments," Journal of Retailing, 87 (1): 17-28.

Dhar, Sanjay K. y Stephen J. Hoch (1997), "Why store brand penetration varies by retailer?", Marketing Science, 16 (3): 208-227

Dillon, William Fl., Thomas J. Madden, Amna Kirmani y Soumen Mukherjee (2001), "Understanding what's in a brand rating: a model for assessing brand and attribute effects and their relationship to brand equity", Journal of Marketing Research, 38 (4): $415-430$

Dunne, David y Chakravarthi Narasimhan (1999), "The new appeal of private labels," Harvard Business Review, 77 (May/Jun), 41-52

Ernest \& Young (2011), "Understanding risk: Analysing the top 11 risk for consumer products companies in 2011", Disponible en http://www.ey.com/Publication/vwLUAssets/Understanding risk/\$FILE/Understanding Risk.pdf (Acesso el 07 Junio 2012)

Farquhar, P. H. (1990), "Managing brand equity", Journal of Advertising Research, 30 (4): 7-12.

Forbes, 2011. "10 secrets about store brands". Disponible en http://www.forbes.com/sites/lauraheller/2011/06/29/10-secrets-about-store-brands/ (Acesso el 20 Abril 2011) 
Fornerino, Marianela y François d'Hauteville (2010), "How good does it taste? Is it the product or the brand? A contribution to brand equity evaluation", The Journal of Product and Brand Management, 19 (1): 34-43

Garretson, Judith A., Dan Fisher y Scot Burton (2002), "Antecedents of private label attitude and national brand promotion attitude: similarities and differences", Journal of Retailing, 78 (2): 91-99

Geyskens, Inge, Katrijn Gielens y Els Gijsbrechts (2010): "Proliferating private-label portfolios: how introducing economy and premium private labels influences brand choice", Journal of Marketing Research, 47 (5): 791-807.

Gielens, Katrijn (2011). "New products, the antidote to private label growth?". Yale Customer Insights Conference, Maio 2011. Disponible en http://cci.som.yale.edu/sites/cci.som.yale.edu/files/6-2SteenkampGielens.pdf, (Acesso el 23 Abril 2012)

Gómez, Mónica y Natalia Rubio (2010), "Re-thinking the relationship between store brand attitude and store brand loyalty: a simultaneous approach", The International Review of Retail, Distribution and Consumer Research, 20 (5): 515- 534

González-Benito, Óscar y Mercedes Martos-Partal (2007), Información Comercial Española, 2941 (Del 21 al 30 de Junio de 2008), 149-162.

Grewal Dhruv y Michael Levy (2007), "Retailing research: past, present and future", Journal of Retailing, 83 (4): 447-464

Haley, Russel I. (1968), "Benefit segmentation: a decision-oriented research tool," Marketing Management, 32 (3): 30-35

Harris, Brian F. y Roger A. Strang (1985), "Marketing strategies in the age of generics," Journal of Marketing, 49 (Fall), 70-81.

Hoch, Stephen y Shumeet Banerji (1993), "Why do private label succed?", Sloan Management Review; 34 (4): 57-67 
Jacoby, Jacob y David Mazursky (1984), "Linking brand and retailer images - do the potential risks outweigh the potential benefits?", Journal of Retailing, 60 (2): 105-22

Juhl, Hans Jorn, Lars Esbjerg, Klaus G. Grunert y Tino Bech-Larsen (2006), "The Fight between store brands and national brands-what's the score?" Journal of Retailing \& Consumer Services, 13 (09): 331-338.

Kantar WorldPanel (2010), "Balance 2010 del sector gran consumo". Disponible en http://www.kantarworldpanel.com/kwp ftp/Spain/NdP/20110209 balance2010/20110 209 balance2010 presentacion.pdf (Acesso el 12 Junio 2012)

Kantar WorldPanel (2012), "Radiografia de la distribución española y su comprador". Disponible en http://www.kantarworldpanel.com/kwp ftp/Spain/NdP/20120417 WPD2012/2012041 7 WPD2012 RdP.pdf (Acceso el 12 Junio 2012)

Kapferer, Jean Noel (2008), "The new strategic brand management: creating and sustaining brand equity long term", Kogan Page

Keller, Kevin L. (1993), "Conceptualizing, measuring, and managing customer-based brand equity," Journal of Marketing, 57 (Jan): 1-22

Keller, Kevin L. (2001), "Building customer-based brand equity," Marketing Management, 10 (Jul/Aug): 14-19.

Keller, Kevin L. y Donald R. Lehmann (2006), "Brands and branding: research findings and future priorities," Marketing Science, 25 (6): 740-759.

Kotler, Philip y Gari Armstrong (1999), "Principios de Marketing", LTC

Kumar, Nirmalya y Jan-Benedict E. M. Steenkamp (2007a), "Private label strategy: how to meet the store brand challenge," Harvard Business School Press.

Kumar, Nirmalya and Jan-Benedict E. M. Steenkamp (2007b), "Brand Versus Brand," International Commerce Review : ECR Journal, 7 (Spring), 47. 
Lambin, Jean-Jacques (2000), "Market-Driven Management: Strategic and Operational Marketing", Basingstoke: Macmillan.

Luijten, Ton y Will Reijnders (2009), "The development of store brands an store as a brand in supermarkets in the Netherlands", International Review of Retail, Distribution \& Consumer Research, 19 (1): 45-58

Manzur Maciej, Sergio Olavarrieta, Pedro Hidalgo, Pablo Farías y Rodrigo Uribe (2011), "Store brand and national brand promotion attitudes antecedents", Journal of Business Research, 64 (3): 286-291

Martos-Partal, Mercedes y Óscar González-Benito (2011) "Store brand and store loyalty: The moderating role of store brand positioning". Marketing Letters, 22 (3): 297-313

Mendéz, José Luiz, Javier Oubiña y Natalia Rubio (2008), "Expert quality evaluation and price of store vs. manufacturer brands: an analysis of the spanish mass market," Journal of Retailing and Consumer Services, 15 (3):144-155

Munuera, José Luis Alemán y Ana Isabel Rodríguez Escudero (2002), "Estrategia de marketing: teoría y casos", Ediciones Piramide.

Nenycz-Thiel, Magda y Jenni Romaniuk (2009), "Perceptual categorization of private labels and national brands," The Journal of Product and Brand Management, 18 (4): 251-261.

Nenycz-Thiel, Magda y Jenni Romaniuk (2011), "Value-for-money perceptions of supermarket and privatelabels”. Australasian Marketing Journal, 20 (2):171-177

Obiña, Javier, Natalia Rubio y Maria Jesus Yague (2006), "Strategic anagement of store brands: an analysis from the manufacturer's perspective", International Journal of Retail \& Distribution Management, 34 (10): 742-760

Palmeira, Mauricio M. y Dominic Thomas, (2011) "Two-tier store brands: the benefic impact of a value brand on perceptions of premium brand", Journal of Retailing, 87 (4): $540-548$ 
PLMA (2012), Private Label Manufacturers Association, Disponible en http://plma.com/storeBrands/sbt10.html (Acesso el 23 Abril 2012)

Resa, Sylvia (2012), "Las marcas de distribuidor ganan cuota en perfumaría y cosmética), Distribución y Consumo, 122 (Mar-Abr):41-46

Rubio, Natalia y Maria Jesus Yague (2007a), "The determinants of store brand market share: A temporal and cross-sectional analysis", International Journal of Market Research, 51 (4): 501-519

Rubio, Natalia y Maria Jesus Yague (2007b), "Alternative panel models to evaluate the store brand marketshare: evidence from the Spanish market", European Journal of Marketing, 43 (1/2): 110-138

Sethuraman, Raj (2003). "Measuring national brands' equity over store brands and exploring its antecedents", Review of Marketing Science, 1 (2): 1-26

Sethuraman, Raj (2006), "Private-label marketing strategies in packaged goods: management beliefs and research insights," Marketing Science Institute Working Paper, 27-44.

Steenkamp, Jan-Benedict E., Harald J. Van Heerde y Inge Geyskens (2010). "What makes consumers willing to pay a price premium for national brands over private labels?", Journal of Marketing Research, 47 (6): 1011-1024.

Shannon, Randall y Rujirutana Mandhachitara (2008). "Causal path modeling of grocery shopping in hypermarkets". Journal of Product \& Brand Management. 17 (5): 327-34

Simon, Carol J y Mary W. Sullivan (1993), "The measurement and determinants of brand equity: a financial approach", Marketing Science Winter, 12 (1): 28-52

Yelkur, Rama (2000), "Consumer perceptions of generic products: a Mexican study," The Journal of Product and Brand Management, 9 (7): 446-456. 
Yoo, Boonghee, Naveen Donthu y Sungho Lee (2000), "An examination of selected marketing mix elements and brand equity," Academy of Marketing Science.Journal, 28 (2): 195-211.

Webster, Frederick Jr. (1965). "The deal prone' consumer". Journal of Marketing Research, 2 (2): 186-189.

Williams, Tarrel G., Mark Slama y John Rogers (1985), "Behavioral characteristics of the recreational shoppers and implications for retail management", Journal of the Academy of Marketing Science, 13 (3): 307-16 
CARACTERIZACIÓN MOTIVACIONAL DEL COMPRADOR DE MARCA DE DISTRIBUIDOR: PAPEL MODERADOR DEL POSICIONAMIENTO EN PRECIOS DEL MINORISTA 


\section{CARACTERIZACIÓN MOTIVACIONAL DEL COMPRADOR DE MARCA DE DISTRIBUIDOR: PAPEL MODERADOR DEL POSICIONAMIENTO EN PRECIOS DEL MINORISTA}

\subsection{Introducción}

Según la PMLA (Private Label Manufacturers Association), hay marcas de distribuidor en la mayoría de las casas de los consumidores. Su estudio llevado a cabo en 2010 muestra que, en Europa, las marcas de distribuidor han alcanzado un 40\% de cuota de mercado en 5 países europeos - Suiza, Reino Unido, Eslovaquia, España y Alemania, pero también es un fenómeno relevante en mercados emergentes tales como Polonia, Hungría y Turquía. En los Estados Unidos, las marcas de distribuidores representan uno de cada cuatro productos vendidos. El informe de ACNielsen (2011) confirma que las marcas de distribuidores han llegado para quedarse - en una investigación con más de 27.000 participantes, más de la mitad de los consumidores dicen que compran más marcas de distribuidores debido a la difícil situación económica actual, y el $91 \%$ de esos consumidores afirman que continuarán comprándolas cuando la economía mejore.

La importancia de los distribuidores y de sus marcas propias es tanta que algunos autores afirman que hemos pasado de la era de las marcas a la era de los distribuidores - un cambio que ha llevado a muchas marcas a un estado crónico de estrés y confusión (Thomassen, Lincoln y Aconis, 2006). Así mismo, las marcas de distribuidores han condenado al fracaso a las marcas secundarias no líderes (Dunne y Narasimhan, 1999) y algunas marcas propias de distribuidores se están haciendo tan fuertes como algunas marcas de fabricantes. Los fabricantes no solamente se están defendiendo del aumento en la penetración de las marcas de distribuidores sino también de una percepción y actitud cada vez más favorable hacia ellas por parte de los consumidores. Considerando además la reciente desaceleración de la economía en los mercados desarrollados, y consecuente impulso a las marcas de distribuidor, comprender el comportamiento del consumidor nunca ha sido tan importante como ahora (Puccinelli et al., 2009), 
Desde el artículo seminal de Meyer (1967), se ha intentado identificar y caracterizar al comprador de marcas de distribuidor. La mayoría de los estudios se han centrado en criterios socio-económicos y demográficos, siendo escasos los trabajos que han profundizado en el conocimiento de las motivaciones que subyacen en la compra (Ailawadi, Neslin y Gedenk, 2001; Burton et al., 1998; Martos-Partal y Gónzalez-Benito, 2009). La segmentación por beneficios buscados profundizan en las motivaciones y factores causales del consumo en lugar de analizar factores descriptivos $y$, consecuentemente, determinan de forma más precisa el comportamiento de compra (Haley, 1968). Por lo tanto, el primer objetivo de este estudio es conocer el perfil del comprador de marcas de distribuidor analizando sus motivaciones y beneficios buscados.

En sus orígenes, la principal motivación para la compra de la marca de distribuidor era el precio, debido al posicionamiento de estas marcas como alternativas baratas frente a las marcas de fabricante (Burt, 2000; Cunningham, Hardy e Imperia, 1982; Harris y Strang, 1985, Kumar y Steenkamp, 2007; Yelkur, 2000). Sin embargo, en la actualidad, el posicionamiento de las marcas de distribuidor ha evolucionado y ha dado lugar a una variada oferta en el continuo calidad-precio (Dunne y Narasimhan, 1999; Geyskens, Gielens y Gijsbrechts, 2010; Rubio y Yagüe, 2009). Por tanto, el fenómeno de la marca de distribuidor es ahora muy heterogéneo, y la respuesta de los consumidores depende de las particularidades que caracterizan a cada marca concreta. Es decir, las motivaciones y beneficios buscados por el comprador de marca de distribuidor deberían diferir conforme al posicionamiento de la marca de distribuidor.

Las marcas de distribuidor forman parte de la imagen del minorista. Los distribuidores tienden a comercializar marcas propias que son coherentes con su posicionamiento estratégico. De tal forma que el perfil del comprador de marca de distribuidor diferirá también conforme al posicionamiento del minorista. Por ese motivo, el segundo objetivo de este trabajo es analizar la influencia del posicionamiento en precio del distribuidor en el perfil del comprador de marca de distribuidor. Es escasa la literatura que se ha centrado en el papel moderador del posicionamiento en precio del distribuidor en el impacto de sus marcas de distribuidor (Dhar y Hoch, 1997, González-Benito y Martos- Partal, 2012). Este 
estudio contribuye al respecto en el marco de la caracterización por motivaciones y beneficios buscados del comprador de marca de distribuidor.

Este presente trabajo presenta algunas singularidades respecto a otras contribuciones previas en este campo. En primer lugar, va más allá de los clásicos criterios de segmentación demográficos y socioeconómicos, y pretende caracterizar al comprador de marcas propias en cuanto a los beneficios buscados en la compra de este tipo de productos. En segundo lugar, dada la creciente heterogeneidad de las marcas de distribuidor, se considera que el perfil del consumidor de marcas propias no puede plantearse de forma general, sino que depende del tipo de marca del distribuidor, cuyo posicionamiento estará alineado con el posicionamiento del distribuidor. En este caso concreto, el énfasis está en el posicionamiento respecto a la dimensión precio. En tercer lugar, este trabajo combina datos objetivos procedentes de datos de escáner con datos subjetivos sobre las motivaciones de los consumidores obtenidos a través de cuestionario. La combinación de distintas fuentes de información evita posibles sesgos y confiere al estudio una mayor validez. Finalmente, la muestra utilizada es una muestra representativa de uno de los mercados europeos en los que la marca de distribuidor ha experimentado un mayor desarrollo.

En los contenidos subsiguientes se aborda primeramente una revisión de las investigaciones previas con el fin de argumentar las hipótesis de trabajo. Seguidamente se describe la metodología seguida en el análisis empírico y se interpretan y comentan los resultados alcanzados. En una última sección se sintetizan las principales conclusiones e implicaciones.

\subsection{Marco Teórico e Hipótesis}

\subsubsection{Beneficios buscados por el comprador de marcas de distribuidor}

La caracterización del comprador de marcas de distribuidor ha sido una de las líneas de investigación pioneras en relación a este fenómeno. Principalmente, se ha estudiado las características demográficas y socio-económicas del comprador (Ailawadi y Keller, 2004; Baltas y Argouslidis, 2007; Sethuraman, 2006). Sin 
embargo y a pesar de la importancia de la caracterización por beneficios buscados, debido a que la verdadera razón de consumo de un determinado producto son los beneficios que ofrece (Haley, 1968), existe escasa generalización empírica sobre los beneficios que busca el comprador de marcas de distribuidor. Además, a veces los resultados 0 son pocos concluyentes 0 han sido escasamente investigados. A continuación pasamos a analizar algunos de los beneficios buscados que pueden ayudar a identificar al consumidor de marcas de distribuidor.

Sensibilidad al precio: Para algunos consumidores, el precio del producto es un factor decisivo en la compra de un producto y se enfocan casi exclusivamente en pagar precios bajos, ignorando otros atributos del producto (Martínez y Montaner, 2008). El precio bajo es un factor diferenciador entre marcas de distribuidor y marcas de fabricantes en la mente del consumidor (Nanycz-Thiel y Romaniuk, 2009) y resulta ser un determinante muy importante para la elección de este tipo de marcas (Ailawadi, Neslin y Gedenk, 2001; Baltas, 1997, Burton et al., 1998; Manzur et al., 2011; Méndez, Oubiña y Rubio, 2008; Sethuraman 2006). Por otro lado, son las categorías de producto que suscitan una mayor sensibilidad al precio por parte de los consumidores las que muestran una penetración mayor de las marcas de distribuidor (Batra y Sinha, 2000; Hoch, 1996). Los consumidores que no quieren o no pueden pagar un precio más alto por las marcas nacionales, van a comprar las marcas de distribuidores (Sethuraman, 2006). La literatura académica previa ha evidenciado repetidamente la relación entre la compra de marcas de distribuidor y la sensibilidad al precio de los consumidores (Baltas y Argouslidis, 2007; Cunningham, Hardy e Imperia., 1982; Dick, Jain y Richardson, 1995; Hansen, Singh y Chintagunta, 2006; Sinha y Batra, 1999). Por todo lo anterior se propone que:

\section{H1: La sensibilidad al precio del consumidor está relacionada positivamente con la compra de marcas de distribuidor.}

Propensión a la promoción: La propensión a la promoción está asociada a un bajo coste de búsqueda y una disposición a la búsqueda y utilización de cupones (Sudhir y Talukdar, 2004). Según Burton et al. (1998), para los consumidores con una actitud favorable hacia las marcas de distribuidor, la utilidad de la compra va más allá de pagar precios bajos per se, está relacionada con la realización de transacciones 
favorables a través de las promociones. Estos autores demuestran la existencia de una relación positiva entre la actitud hacia la marca de distribuidor y la propensión a la promoción. Sin embargo, en términos de comportamiento, sugieren y demuestran una relación negativa entre la compra de las marcas de distribuidor y la compra de productos en promoción (Baltas, 1997, Burton et al., 1998). El argumento subyacente es que, con el avance de marcas de distribuidores, los fabricantes utilizan cada vez más la promoción para evitar la migración de los consumidores hacia dichas marcas (Garretson, Fisher y Burton, 2002), y el consumidor propenso a las promociones se decanta por la compra de estos en lugar de por los productos de marca de distribuidor. En base a estos argumentos, se propone:

\section{H2: La sensibilidad a las promociones del consumidor está relacionada negativamente con la compra de marcas de distribuidor.}

Sensibilidad a la calidad del servicio: La búsqueda de calidad es una motivación clave en la elección de marca. Con el objetivo de diferenciarse, crear lealtad y desarrollar una ventaja competitiva, los distribuidores pueden proporcionar excelentes servicios al consumidor (Grawal y Levy, 2007). La calidad de los productos y servicios del establecimiento comercial es un componente muy importante de su imagen, y sirve como un indicativo del valor del distribuidor y, como consecuencia, del valor de sus marcas propias (Bao, Bao y Sheng, 2011; Dick, Jain y Richardson, 1995, Semeijin, van Riel y Ambrosini, 2004). Sin embargo, pocos estudios han tratado de caracterizar al comprador de marca de distribuidor en función de su sensibilidad a la calidad (Ailawadi, Neslin y Gedenk, 2001). Evidencias empíricas previas muestran una relación positiva entre imagen del establecimiento y actitud/compra de las marcas de distribuidor (Bao, Bao y Sheng, 2011; Liu y Wang 2008). Sin embargo, en el plano comportamental, Ailawadi y Keller (2004) definen al consumidor de marca de distribuidor como un consumidor no sensible a la calidad del servicio. Algunas contribuciones previas así lo demuestran (Ailawadi, Neslin y Gedenk, 2001; Ailawadi, Pauwels y Steenkamp, 2008). Por lo tanto, los consumidores más preocupados por el servicio serán menos propensos a comprar marca de distribuidor, es decir, se espera que aquellos consumidores leales a la 
marca de distribuidor sean menos sensibles a la prestación de servicios por parte del distribuidor, es decir:

\section{H3: La sensibilidad a la calidad del servicio del consumidor está relacionada negativamente con la compra de marcas de distribuidor}

Diversión en la compra: Hay consumidores que consideran la compra no como un medio para un fin, sino como un fin en sí mismo y que consideran la compra como una actividad recreativa. En definitiva, son consumidores que se divierten comprando (Williams, Slama y Rogers, 1985). Dado que las marcas propias forman parte de la experiencia total de compra en el establecimiento (De Wulf et al., 2005), pueden ayudar a generar diversión en el acto de compra. La literatura previa sobre la compra de marcas de distribuidor y la diversión en la compra muestra evidencias mixtas. Los consumidores que buscan diversión parecen comprar marcas nacionales en vez de marcas de distribuidor (Williams, Slama y Rogers, 1985). Ailawadi, Pauwels y Steenkamp (2008) confirman dicha relación negativa. Sin embargo, otros trabajos no han encontrado una relación significativa entre la diversión en la compra y la compra de marca de distribuidor (Ailawadi, Neslin y Gedenk, 2001; Martínez y Montaner, 2008). Por otro lado, Cox, Cox y Anderson (2005) sugieren que la búsqueda de gangas puede ser una de las mayores fuentes de diversión en la compra lo que afectaría positivamente la compra de marcas de distribuidor. Leischnig, Schwertfeger y Geigenmüller (2011) muestran evidencias en dicho sentido para la actitud hacia las marcas de distribuidor. En este trabajo se considera que, dado que la evolución de la estrategia de las marcas distribuidor hacia productos más divertidos es un fenómeno reciente, estas marcas se han centrado más en los atributos funcionales (Kumar y Steenkamp, 2007), por lo que las marcas de distribuidor puede que no satisfaga completamente el deseo de diversión del consumidor. Por lo tanto, se propone.

\section{H4: La diversión en la compra del consumidor está relacionada negativamente con la compra de marcas de distribuidor}

Propensión a la innovación: El grado de innovación del consumidor tiene que ver con su propensión a experimentar y comprar productos nuevos y diferentes (Xie, 
2008). En este caso las evidencias previas no son concluyentes. Las marcas de distribuidor son un fenómeno más reciente, y por lo tanto más novedoso, por eso habría una relación positiva entre propensión a la innovación y la compra de marcas de distribuidores. Por otro lado, Gómez y Rubio (2010) consideran que la propensión a la innovación puede alejar a los consumidores de dichas marcas, una vez que este comportamiento lleva a los consumidores a buscar constantemente alternativas a las marcas de distribuidores por considerar las marcas de fabricante como más novedosas. Sin embargo no encuentran un efecto significativo de la propensión a probar nuevos productos en la compra de marcas de distribuidor. En esa misma línea otros autores tampoco han encontrado evidencias de relación entre la propensión a la innovación y la compra de marcas de distribuidor (Ailawadi, Neslin y Gedenk, 2001, Baltas y Argouslidis, 2007, Martínez y Montaner 2008). En este trabajo creemos que las marcas de distribuidor están todavía evolucionando y reinventándose, de manera que pueden ser percibidas como algo relativamente nuevo y resultar atractivas para los más innovadores, es decir:

\section{H5: La propensión a la innovación del consumidor está relacionada positivamente con la compra de marcas de distribuidor}

Sensibilidad a la marca: La marca sirve como un indicativo de calidad en la medida que aporta al consumidor un conjunto de informaciones sobre el producto (Jacoby, Chestnut y Fisher, 1978). En general, los productos con marca reconocida reducen el riesgo de compra y se asocian con una orientación a la calidad o con la búsqueda de una imagen social. Park, Yu y Zhou (2010) definen al comprador sensible a la marca como aquél que, sin hacer demasiadas comparaciones sobre la calidad y atributos de los productos, compra las marcas más caras y conocidas. En general, las marcas de fabricante se venden a precios superiores que las marcas de distribuidor y son marcas más conocidas. Juhl et al. (2006) muestran una gran diferencia entre la notoriedad de las marcas de fabricante y las marcas de distribuidor a favor de las primeras. Además, los elevados gastos en publicidad de las marcas de fabricante, así como los controles de calidad de estos productos, conllevan una fuerte imagen de marca que apela a los consumidores sensibles a la marca (Richardson, Dick y Jain, 1994). La escasa evidencia a este respecto avala 
que los hogares que tienen una actitud más positiva hacia las marcas de distribuidor, así como los hogares que muestran mayor presencia de estas marcas en sus cestas de la compra son consumidores menos orientados a los productos de marca (Baltas y Argouslidis 2007). Por lo que se propone:

\section{H6: La sensibilidad a la marca del consumidor está relacionada negativamente con la compra de marcas de distribuidores}

\subsubsection{Papel moderador del posicionamiento en precios del distribuidor}

El precio es un elemento clave en el posicionamiento del distribuidor, y dicha imagen de precio puede ser influenciada por atributos como el nivel medio de precio, la variación de precios a lo largo del tiempo, la frecuencia e intensidad de las promociones y el posicionamiento del distribuidor como EDLP (Every Day Low Price) o como HILO (High-Low) (Ailawadi y Keller, 2004). En particular, las marcas de distribuidor están tendiendo a utilizarse como una herramienta para el posicionamiento del distribuidor (Ailawadi y Keller, 2004; Dekimpe et al., 2011). La imagen del distribuidor actúa como un indicador de la calidad de la marca del distribuidor (Dick, Jain y Richardson, 1995) y las marcas de distribuidor afectan a la imagen del establecimiento y permiten la diferenciación entre enseñas (Semeijin, van Riel y Ambrosini, 2004). La teoría de balance (Heider, 1944) y en concreto una versión más cuantitativa de la misma como es la teoría de la congruencia (Jacoby y Mazursky, 1984), mantiene que se produce inconsistencia o incongruencia cuando la fuente (el distribuidor) y el objeto (la marca propia del distribuidor) no son percibidas como igualmente asociadas, dicha incongruencia podría dañar la imagen del distribuidor. La congruencia entre el distribuidor y sus marcas propias también es habitual en lo que respecta al precio. De tal forma que un distribuidor con una elevada imagen podría verse dañado si se asocia con marcas de peor imagen.

La tendencia de las marcas de distribuidor a alinearse con el posicionamiento del distribuidor puede tener consecuencias en las motivaciones subyacentes a la compra de dichas marcas. Sin embargo, este efecto moderador del posicionamiento en precio del distribuidor es un aspecto que no ha sido analizado en profundidad por la literatura. 
Posicionamiento en precio-sensibilidad al precio: Las marcas de distribuidor han evolucionado en su posicionamiento, desde marcas posicionadas en precio hacia marcas más de calidad. Incluso algunos distribuidores posicionados en calidad ofrecen a sus consumidores múltiples marcas de distribuidor con distintos posicionamientos en el continuo precio-calidad (Geyskens, Gielens y Gijsbrechts, 2010; Kumar y Steenkamp, 2007). Las marcas propias tienden a ser coherentes con el posicionamiento del distribuidor, en particular, en su posición de calidad-precio (Luijten y Reijnders, 2009). Una estrategia de marca propia de alta calidad no sería congruente en un distribuidor que enfatiza el precio, de manera que, por ejemplo, los establecimientos que adoptan una estrategia EDLP tienden a comercializar marcas de distribuidores basadas en precio (Dhar y Hoch, 1997). Por el contrario, una estrategia de marca de distribuidor premium debería ser perseguida por los distribuidores menos orientados al precio (Huang y Huddleston, 2009). En los establecimientos más posicionados en calidad, aunque puede ofrecerse una cartera de marcas de distribuidor con distintos posicionamientos en precio, la marca insignia o más representativa del establecimiento tiende a buscar un posicionamiento en calidad. Por tanto basándonos la lógica de la teoría de la congruencia, es probablemente más atractivo para un distribuidor posicionado en calidad desarrollar marcas propias de calidad que beneficiaran tanto a la percepción del distribuidor como a la percepción de la marca (Huang y Huddleston, 2009). En este escenario, cabe esperar que el precio sea una motivación menos importante para la compra de marca de distribuidor cuando el establecimiento, y por tanto sus marcas de distribuidor, estén más orientadas a la calidad. Entonces, se espera que:

\begin{abstract}
H7: El posicionamiento en precio del distribuidor modera la relación entre la compra de marcas de distribuidor y la sensibilidad al precio, de manera que cuanto mayor es el nivel de precios del distribuidor, más desfavorable es la relación entre la orientación al precio y la compra de marca de distribuidor.
\end{abstract}

Posicionamiento en precio-propensión a la promoción: Los distribuidores más posicionados en precio, como es el caso de los establecimientos de descuento, suelen usar la estrategia de EDLP (IGD Research, 2007). Siendo coherentes con dicho posicionamiento, sus marcas mantienen unos precios bajos todos los días, y 
hacen escaso uso de las promociones (Kumar y Steenkamp, 2007). Sin embargo, los distribuidores posicionados en calidad, poseerán marcas propias de mayor calidad y precio, y podrán utilizar la promoción como una herramienta que incentive la compra de sus marcas. Consecuentemente, las marcas de distribuidor deberían resultar más atractivas para los consumidores más sensibles a las promociones a medida que los establecimientos están menos orientados al precio. Por tanto, se espera que:

H8: El posicionamiento en precio del distribuidor modera la relación entre la compra de marcas de distribuidor y la propensión a la promoción, de manera que cuanto mayor es el nivel de precios del distribuidor, más favorable es la relación entre la propensión a la promoción y la compra de marca de distribuidor.

Posicionamiento en precio-sensibilidad a la calidad del servicio: Los distribuidores menos orientados al precio están haciendo un mayor esfuerzo por desarrollar marcas de distribuidor con una calidad comparable a las marcas de fabricante (Kumar y Steenkamp, 2007; Soberman y Parker, 2006) Kumar, Radhakrishnan y Rao (2010) sugieren que, en los distribuidores que atienden a una clientela más sensible a la calidad, sus marcas de distribuidor deberían ser elaboradas por los fabricantes de marcas nacionales, lo que mejoraría su calidad percibida. De nuevo siguiendo la lógica de la teoría de la congruencia su énfasis en la calidad de servicio se traslada también a sus marcas de distribuidor. Sacrifican parte de las ventajas en precio a cambio de una mayor calidad en sus productos. Esto debería conllevar una actitud y comportamiento mucho más favorable hacia este tipo de marcas por parte de los consumidores que más aprecian la calidad. Por tanto:

H9: El posicionamiento en precio del distribuidor modera la relación entre la compra de marcas de distribuidor y la sensibilidad a la calidad del servicio, de manera que cuanto mayor es el nivel de precios del distribuidor, más favorable es la relación entre la sensibilidad a la calidad del servicio y la compra de marca de distribuidor. 
Posicionamiento en precio-diversión en la compra: En los establecimientos de mayor calidad, la oferta de marca de distribuidor tiene mayor dinamismo. Están haciendo un esfuerzo en desarrollar atributos más hedónicos y mejorar su marcas propias con un marketing más activo, como la mejora en los envases, la inversión en publicidad, etc. (Burt, 2000; Kumar y Steenkamp, 2007). Por tanto, en este contexto pueden ser percibidas como más divertidas, y resultar más atractivas para los clientes más sensibles a la diversión en la compra.

H10: El posicionamiento en precio del distribuidor modera la relación entre la compra de marcas de distribuidor y la diversión en la compra, de manera que cuanto mayor es el nivel de precios del distribuidor, más favorable es la relación entre la diversión en la compra y la compra de marca de distribuidor

Posicionamiento en precio-propensión a la innovación: Las marcas de distribuidor con un mayor énfasis en calidad, son marcas desarrolladas por los distribuidores para generar diferenciación con otros distribuidores y con las propias marcas de fabricante. Por ello, este tipo de marcas suele tener un mayor grado de innovación (Burt, 2000; Kumar y Steenkamp, 2007). Además, el posicionamiento en calidad de las marcas de distribuidor es más reciente y, por tanto más novedoso. Consecuentemente, este tipo de marcas de distribuidor tendrán más capacidad para atraer a los consumidores propensos a la innovación hacia la compra. Puesto que estas marcas con una mayor orientación a la calidad y con un carácter innovador son más propias de los distribuidores menos orientados al precio, cabe esperar que en este tipo de establecimientos los consumidores más sensibles a la innovación realicen un mayor consumo de marcas de distribuidor. Por tanto se espera que:

H11: El posicionamiento en precio del distribuidor modera la relación entre la compra de marcas de distribuidor y la propensión a la innovación, de manera que cuanto mayor es el nivel de precios del distribuidor, más favorable es la relación entre la propensión a la innovación y la compra de marca de distribuidor

Posicionamiento en precio-sensibilidad a la marca: Siguiendo de nuevo la lógica de la teoría de la congruencia: los establecimientos más orientados a la calidad e 
imagen posicionan sus marcas de distribuidor de forma coherente a dicho posicionamiento. Es decir, existe menos diferencia entre las marcas líderes reconocidas y las marcas de distribuidor porque han apostado por la mejora en la calidad para construir diferenciación basándose en un marketing más sofisticado (Burt, 2000; Corstjen y Lal, 2000; Kumar y Steenkamp, 2007; Soberman y Parker, 2006) En consecuencia, las marcas de distribuidor pueden resultar más atractivas para los consumidores que basan su elección en la notoriedad y reputación de la marca.

H12: El posicionamiento en precio del distribuidor modera la relación entre la compra de marcas de distribuidor y la sensibilidad a la marca, de manera que cuanto mayor es el nivel de precios del distribuidor, más favorable es la relación entre la sensibilidad a la marca y la compra de marca de distribuidor.

La tabla 3.1 presenta un resumen de las hipótesis planteadas en este trabajo.

Tabla 3.1. Resumo de hipótesis y resultados

\begin{tabular}{|c|c|c|c|c|}
\hline Relación & $\begin{array}{l}\text { Hipótesis } \\
\text { sobre } \\
\text { efecto } \\
\text { directo }\end{array}$ & Resultados & $\begin{array}{c}\text { Hipótesis sobre el } \\
\text { efecto de } \\
\text { moderación del } \\
\text { posicionamiento } \\
\text { de precio del } \\
\text { distribuidor }\end{array}$ & Resultados \\
\hline $\begin{array}{l}\text { Sensibilidad al precio } \\
\rightarrow \text { Cuota de gasto con } \\
M D\end{array}$ & $+(\mathrm{H} 1)$ & Confirmada & - $(\mathrm{H} 7)$ & Confirmada \\
\hline $\begin{array}{l}\text { Sensibilidad a la } \\
\text { promoción } \rightarrow \text { Cuota de } \\
\text { gasto con } M D\end{array}$ & - $(\mathrm{H} 2)$ & Rechazada & $+(\mathrm{H} 8)$ & Rechazada \\
\hline $\begin{array}{l}\text { Sensibilidad a la calidad } \\
\text { del servicio } \rightarrow \text { Cuota de } \\
\text { gasto con } M D\end{array}$ & - $(\mathrm{H} 3)$ & Confirmada & $+(\mathrm{H} 9)$ & Confirmada \\
\hline $\begin{array}{l}\text { Diversión en la compra } \\
\rightarrow \text { Cuota de gasto con } \\
M D\end{array}$ & - $(\mathrm{H} 4)$ & Rechazada & $+(\mathrm{H} 10)$ & Rechazada \\
\hline $\begin{array}{l}\text { Propensión a la } \\
\text { innovación } \rightarrow \text { Cuota de } \\
\text { gasto con } M D\end{array}$ & $+(\mathrm{H} 5)$ & Rechazada & $+(\mathrm{H} 11)$ & Rechazada \\
\hline $\begin{array}{l}\text { Sensibilidad a la marca } \\
\rightarrow \text { Cuota de gasto con } \\
M D\end{array}$ & $-(\mathrm{H} 6)$ & Confirmada & $+(\mathrm{H} 12)$ & Confirmada \\
\hline
\end{tabular}

Notas: MD (marcas de distribuidor) 


\subsection{Metodología}

Para analizar empíricamente el perfil del comprador de marcas de distribuidor y el efecto moderador del posicionamiento en precio del distribuidor en el perfil del comprador de marcas de distribuidor nos centramos en las doce principales cadenas de distribución minoristas que operan en el mercado español: Mercadona, Carrefour, Eroski, Alcampo, Dia, Hipercor, Caprabo, Lidl, Dinosol, Consum, Ahorramas y Miguel Alimentación. El Informe Anual de la Distribución Alimentaria de 2008 realizado por Alimarket sitúa a estas cadenas en las doce primeras posiciones en cuanto a ventas en el mercado español en 2007. Dentro de estas enseñas se pueden diferenciar dos grupos de establecimientos, los establecimientos de descuento y el resto de establecimientos. Los establecimientos de descuento son Día y Lidl. Lidl desarrolla una estrategia de descuento duro frente a Dia que desarrolla un descuento de tipo suave. Estos formatos se basan en estrategias de precios EDLP (todos los días precios bajos). Mercadona es una enseña que también sigue la estrategia de EDLP. Las otras nueve enseñas siguen estrategias HILO (precios altos y bajos debido a promociones).

Concretamente, se cuenta con datos del historial de compra en la categoría de productos de alimentación en una muestra de más de 2000 hogares representativos de la población española procedentes del panel de hogares de KANTAR WORLDPANEL (antes TNS). Los datos corresponden a un periodo temporal de un año comprendidos entre el segundo semestre de 2007 y el primer semestre de 2008. Para cada hogar se dispone de información sobre el gasto anual total y el gasto desagregado por cadenas minoristas (12 principales cadenas).

Los datos disponibles permiten calcular la distribución de presupuesto de cada hogar entre las enseñas comerciales. Para evitar los sesgos ocasionados por clientes muy ocasionales que sólo realizan compras aisladas en la enseña se eliminan de la muestra los clientes con una cuota de gasto en la enseña inferior al $1 \%$. Por tanto se consideran como clientes de la enseña a aquellos hogares con un gasto en la enseña superior al 1\%. La muestra de clientes varía en función de la penetración de cada enseña y va desde los 1050 clientes de Mercadona a los 27 de Miguel Alimentación tal y como se detalla en la Tabla 3.2. 
La variable dependiente, compra de marcas de distribuidor en cada enseña, se mide de forma global calculando la cuota de gasto en alimentación asignada a todas las marcas propias de la cadena (cuota de gasto en marcas de distribuidor) para cada cliente de la enseña. La información sociodemográfica de los hogares también procede del panel de hogares. Concretamente, se dispone de información sobre el tamaño familiar, la existencia de niños menores de 6 años en el hogar y la clase social. El tamaño familiar es una variable de recuento que toma valores de 1 a 8 , donde el 8 representa a hogares de 8 o más miembros. Presencia de niños es una variable indicador que identifica con un valor de 1 a los hogares con niños menores de 6 años. La clase social distingue cuatro niveles socioeconómicos: baja (clase social 1), media baja (clase social 2), media (clase social 3) y alta y media alta (clase social 4).

Para determinar el posicionamiento en precios de cada cadena se utilizan los niveles de precios facilitados por la OCU (2008). La OCU realiza anualmente una comparación de precios de supermercados en el mercado español. En el año 2008, el estudio se basó en una recogida de datos de 800 supermercados de 67 cadenas distribuidos por toda la geografía española. Para la comparación se analizan los precios de un conjunto de productos que conforma la cesta de compra de una familia media española y calculan un índice de precio a partir del coste de una cesta de compra formada por las marcas más baratas disponibles en el establecimiento. Con esos datos se elabora un índice para cada establecimiento y, por agregación, para cada cadena. El 100 corresponde al establecimiento más barato, mientras que los demás índices se asignan en relación a este. Así, un establecimiento con un índice 118 significa que la cesta en cuestión resulta un 18\% más cara que el establecimiento más barato. En la Tabla 3.2 se resume el perfil de gasto y el perfil sociodemográfico de los clientes de cada una de las enseñas así como los niveles de precio facilitados por OCU para las 12 cadenas estudiadas.

Adicionalmente se dispone de información procedente del cuestionario sobre opiniones y actitudes suministrado por Kantar Worldpanel a más de 4000 hogares (julio 2008). En relación a los beneficios buscados en la compra por el panelista, se partió de una selección de los ítems incluidos en dicho cuestionario, selección basada en el marco teórico establecido. Es decir, de las 160 preguntas planteadas en el cuestionario se consideraron únicamente los ítems que se correspondían con 
los beneficios buscados expuestos previamente. Los ítems se miden en una escala tipo likert de 5 puntos ( 1 - totalmente en desacuerdo, 5 - totalmente de acuerdo).

Sobre esta selección de ítems se realizó un análisis factorial de componentes principales con rotación Varimax para identificar las dimensiones de beneficios buscados subyacentes. Como resultado del análisis factorial se obtuvieron 6 factores consistentes con las motivaciones planteadas en el marco teórico. Dichos factores se interpretan como: 1) sensibilidad a precios; 2) propensión a la promoción; 3) sensibilidad a la calidad del servicio; 4) diversión en la compra; 5) propensión a la innovación; y 6) sensibilidad a la marca. En la Tabla 3.3 se detallan los ítems utilizados, sus descriptivos, las cargas factoriales, la varianza explicada y el Alpha de Cronbach para cada escala. La varianza explicada por los seis factores es superior al $62 \%$ y los valores del Alpha de Cronbach superan el 0.7 o están muy próximos a dicho valor (sensibilidad a la marca). En el análisis posterior, como medidas de los beneficios buscados se utilizarán las puntuaciones factoriales resultantes de este análisis.

Se combinan los datos factoriales del cuestionario con los datos de gastos y el perfil sociodemográfico de los clientes de cada enseña obtenidos del panel, utilizándose en los análisis posteriores únicamente los hogares presentes en ambas muestras y para los que se disponía de información completa. Esto supone una muestra de 5068 observaciones (cadena-cliente). 


\section{Tabla 3.2. Análisis Descriptivo}

\begin{tabular}{|c|c|c|c|c|c|c|c|c|c|c|c|c|c|c|c|c|c|c|c|c|c|c|c|c|}
\hline & \multicolumn{2}{|c|}{$\begin{array}{c}\text { MERCADONA } \\
\text { (CLIENTES= } \\
1050)\end{array}$} & \multicolumn{2}{|c|}{$\begin{array}{c}\text { CARREFOUR } \\
\text { (CLIENTES = } \\
854)\end{array}$} & \multicolumn{2}{|c|}{$\begin{array}{c}\text { EROSKI } \\
\text { (CLIENTES = } \\
595)\end{array}$} & \multicolumn{2}{|c|}{$\begin{array}{c}\text { ALCAMPO } \\
\text { (CLIENTES = } \\
506)\end{array}$} & \multicolumn{2}{|c|}{$\begin{array}{c}\text { DIA } \\
\text { (CLIENTES = } \\
\text { 925) }\end{array}$} & \multicolumn{2}{|c|}{$\begin{array}{c}\text { HIPERCOR } \\
\text { (CLIENTES = } \\
\text { 120) }\end{array}$} & \multicolumn{2}{|c|}{$\begin{array}{c}\text { CAPRABO } \\
\text { (CLIENTES = } \\
\text { 202) }\end{array}$} & \multicolumn{2}{|c|}{$\begin{array}{c}\text { LIDL } \\
\text { (CLIENTES = } \\
507)\end{array}$} & \multicolumn{2}{|c|}{$\begin{array}{c}\text { DINOSOL } \\
\text { (CLIENTES = } \\
59)\end{array}$} & \multicolumn{2}{|c|}{$\begin{array}{c}\text { CONSUM } \\
\text { (CLIENTES = } \\
118)\end{array}$} & \multicolumn{2}{|c|}{$\begin{array}{c}\text { AHORRAMAS } \\
\text { (CLIENTES = } \\
\text { 105) }\end{array}$} & \multicolumn{2}{|c|}{$\begin{array}{c}\text { MIGUEL } \\
\text { ALIMENTACION } \\
\text { (CLIENTES = } \\
\text { 27) }\end{array}$} \\
\hline & Media & D.T & Media & D.T & Media & D.T & Media & D.T & Media & D.T & Media & D.T & Media & D.T & Media & D.T & Media & D.T & Media & D.T & Media & D.T & Media & D.T \\
\hline $\begin{array}{ll}\text { Lealtad } & \text { al } \\
\text { establecimiento }\end{array}$ & 0,212 & 0,204 & 0,158 & 0,174 & 0,187 & 0,207 & 0,141 & 0,159 & 0,142 & 0,133 & 0,077 & 0,103 & 0,130 & 0,161 & 0,078 & 0,087 & 0,078 & 0,091 & 0,140 & 0,172 & 0,212 & 0,236 & 0,128 & 0,162 \\
\hline $\begin{array}{l}\text { Cuota de marcas } \\
\text { de distribuidor }\end{array}$ & 0,325 & 0,161 & 0,232 & 0,171 & 0,300 & 0,210 & 0,147 & 0,157 & 0,498 & 0,214 & 0,173 & 0,199 & 0,123 & 0,123 & 0,700 & 0,206 & 0,124 & 0,132 & 0,143 & 0,118 & 0,149 & 0,119 & 0,109 & 0,099 \\
\hline $\begin{array}{lll}\text { Clase } & \text { social } & 1 \\
\text { (baja) } & & \end{array}$ & 0,156 & 0,363 & 0,120 & 0,325 & 0,159 & 0,366 & 0,140 & 0,347 & 0,211 & 0,408 & 0,108 & 0,312 & 0,193 & 0,395 & 0,147 & 0,355 & 0,169 & 0,378 & 0,144 & 0,352 & 0,123 & 0,330 & 0,296 & 0,465 \\
\hline $\begin{array}{ll}\text { Clase social } & 2 \\
\text { (media-baja) } & \end{array}$ & 0,265 & 0,441 & 0,243 & 0,429 & 0,258 & 0,438 & 0,225 & 0,418 & 0,283 & 0,450 & 0,158 & 0,366 & 0,193 & 0,395 & 0,254 & 0,435 & 0,322 & 0,471 & 0,338 & 0,475 & 0,285 & 0,453 & 0,222 & 0,423 \\
\hline $\begin{array}{lll}\text { Clase social } & 3 \\
\text { (media) } & & \end{array}$ & 0,355 & 0,478 & 0,393 & 0,488 & 0,394 & 0,489 & 0,436 & 0,496 & 0,336 & 0,472 & 0,416 & 0,495 & 0,326 & 0,470 & 0,372 & 0,484 & 0,338 & 0,477 & 0,330 & 0,472 & 0,380 & 0,487 & 0,259 & 0,446 \\
\hline $\begin{array}{l}\text { Clase social } 4 \\
\text { (alta-media/alta) }\end{array}$ & 0,222 & 0,416 & 0,242 & 0,428 & 0,186 & 0,389 & 0,197 & 0,398 & 0,168 & 0,374 & 0,316 & 0,467 & 0,287 & 0,453 & 0,224 & 0,417 & 0,169 & 0,378 & 0,186 & 0,391 & 0,209 & 0,408 & 0,222 & 0,423 \\
\hline Tamaño del hogar & 3,066 & 1,117 & 3,108 & 1,089 & 3,062 & 1,116 & 3,075 & 1,091 & 3,092 & 1,120 & 2,883 & 1,153 & 2,886 & 1,176 & 3,057 & 1,144 & 3,440 & 1,102 & 3,059 & 1,200 & 3,219 & 1,100 & 2,629 & 0,926 \\
\hline $\begin{array}{l}\text { Presencia de } \\
\text { niños }\end{array}$ & 0,347 & 0,476 & 0,388 & 0,487 & 0,352 & 0,478 & 0,395 & 0,489 & 0,348 & 0,476 & 0,316 & 0,467 & 0,351 & 0,478 & 0,319 & 0,466 & 0,406 & 0,495 & 0,355 & 0,480 & 0,476 & 0,501 & 0,185 & 0,395 \\
\hline Nivel de precio & & & 1 & & & & 10 & & & & & & & & & & & & & & & & & \\
\hline
\end{tabular}


Tabla 3.3. Ítems descriptivos y análisis factorial exploratorio

\begin{tabular}{|c|c|c|c|c|c|c|}
\hline Factores & Ítem & Media & D.T & $\begin{array}{l}\text { Carga } \\
\text { Factori } \\
\text { al }\end{array}$ & V.E & $\begin{array}{l}\text { Alfa de } \\
\text { Cronbach }\end{array}$ \\
\hline $\begin{array}{l}\text { Sensibilidad } \\
\text { al precio }\end{array}$ & $\begin{array}{l}\text { Siempre comparo precios entre diferentes } \\
\text { marcas antes de elegir una } \\
\text { Comparo precios para aprovechar ofertas } \\
\text { especiales } \\
\text { Busco los productos en oferta } \\
\text { Visito diferentes tiendas para aprovechar los } \\
\text { mejores precios }\end{array}$ & $\begin{array}{l}3,698 \\
3,860 \\
3,576 \\
3,192\end{array}$ & $\begin{array}{l}0,821 \\
0,753 \\
0,807 \\
1,040\end{array}$ & $\begin{array}{l}0,775 \\
0,690 \\
0,662 \\
0,603\end{array}$ & 11,102 & 0,746 \\
\hline $\begin{array}{l}\text { Sensibilidad } \\
\text { a la } \\
\text { promoción }\end{array}$ & $\begin{array}{l}\text { Me gusta participar en las promociones que se } \\
\text { ofrecen en paquetes y etiquetas } \\
\text { Uso los cupones de descuento cuando tengo la } \\
\text { oportunidad } \\
\text { Me gusta participar en promociones que me } \\
\text { regalan cantidad extra de producto o un } \\
\text { producto diferente, } \\
\text { Me informo de las promociones a través de los } \\
\text { folletos de los establecimientos }\end{array}$ & $\begin{array}{l}3,387 \\
4,026 \\
3,652 \\
\\
3,658\end{array}$ & $\begin{array}{l}0,928 \\
0,822 \\
0,821 \\
0,831\end{array}$ & $\begin{array}{l}0,734 \\
0,649 \\
0,711 \\
\\
0,502\end{array}$ & 9,357 & 0,706 \\
\hline $\begin{array}{l}\text { Sensibilidad } \\
\text { a la calidad } \\
\text { del servicio }\end{array}$ & $\begin{array}{l}\text { No me importa de pagar más por la calidad } \\
\text { A la hora de hacer la compra, prefiero ir a una } \\
\text { tienda bien organizada, aunque sea un poco } \\
\text { más cara } \\
\text { A la hora de hacer la compra, prefiero ir a una } \\
\text { tienda más cuidada, aunque sea un poco más } \\
\text { cara } \\
\text { A la hora de hacer la compra, prefiero ir a una } \\
\text { tienda que me atienda bien, aunque sea un } \\
\text { poco más cara }\end{array}$ & $\begin{array}{l}3,525 \\
3,218 \\
3,268 \\
\\
3,357\end{array}$ & $\begin{array}{l}0,737 \\
0,829 \\
0,823 \\
0,827\end{array}$ & $\begin{array}{l}0,497 \\
0,887 \\
0,925 \\
0,875\end{array}$ & 12,384 & 0,845 \\
\hline $\begin{array}{l}\text { Diversión en } \\
\text { la compra }\end{array}$ & $\begin{array}{l}\text { Me gusta hacer la compra } \\
\text { Me gusta emplear el menor tiempo posible } \\
\text { cuando hago la compra }\end{array}$ & $\begin{array}{l}3,493 \\
3,317\end{array}$ & $\begin{array}{l}1,014 \\
0,929\end{array}$ & $\begin{array}{c}0,770 \\
-0,834\end{array}$ & 6,161 & $-0,359^{\star \star}$ \\
\hline $\begin{array}{l}\text { Propensión a } \\
\text { la innovación }\end{array}$ & $\begin{array}{l}\text { En general soy de los primeros que compran } \\
\text { productos nuevos cuando aparecen en el } \\
\text { mercado } \\
\text { Suelo ser de los primeros en probar marcas } \\
\text { nuevas } \\
\text { Me gusta probar nuevos productos } \\
\text { Me gusta probar nuevas marcas } \\
\text { Disfruto arriesgándome con la compra de } \\
\text { nuevos productos }\end{array}$ & $\begin{array}{l}2,508 \\
\\
2,511 \\
3,087 \\
3,080 \\
2,532\end{array}$ & $\begin{array}{l}0,802 \\
0,799 \\
0,756 \\
0,709 \\
0,749\end{array}$ & $\begin{array}{l}0,807 \\
0,811 \\
0,780 \\
0,782 \\
0,752\end{array}$ & 14,159 & 0,854 \\
\hline $\begin{array}{l}\text { Sensibilidad } \\
\text { a la marca }\end{array}$ & $\begin{array}{l}\text { Me considero leal a la marca } \\
\text { Tiendo a comprar productos de marca } \\
\text { Decido qué marcas comprar antes de salir a } \\
\text { hacer la compra } \\
\text { Para mí es importante que marca compro }\end{array}$ & $\begin{array}{l}3,088 \\
2,836 \\
2,705 \\
3,266\end{array}$ & $\begin{array}{l}0,898 \\
0,851 \\
0,916 \\
0,780\end{array}$ & $\begin{array}{l}0,714 \\
0,639 \\
0,662 \\
0,739\end{array}$ & 9,493 & 0,686 \\
\hline
\end{tabular}

Notas: M (media), D.T (desviación típica), V.E (varianza extraída) y * correlación. 


\subsection{Análisis y resultados}

La variable dependiente considerada en este trabajo es la cuota de gasto en marca de distribuidor de un hogar en cada establecimiento del que es cliente. Las variables independientes utilizadas hacen referencia al establecimiento en cuestión, y al perfil sociodemográfico y de beneficios buscados del hogar. Estas variables de beneficios buscados permiten testar las hipótesis $\mathrm{H} 1-\mathrm{H} 6$, y son: sensibilidad a precios, propensión a la promoción, sensibilidad a la calidad del servicio, diversión en la compra, propensión a la innovación y sensibilidad a la marca. Para testar las hipótesis $\mathrm{H} 7-\mathrm{H} 12$, se considera además la interacción de cada una de esas variables con el nivel de precios del establecimiento.

Puesto que la variable dependiente, cuota de gasto en marca de distribuidor, se define en forma de cuota, los análisis realizados se basan en una regresión logística adaptada al contexto de asignación de recursos. Concretamente, se propone la siguiente relación:

$$
\pi_{i j}=\frac{e^{\alpha+\delta+\lambda+\lambda Z_{i}+\beta B_{i}+\chi B_{i}^{*} P_{j}}}{1+e^{\alpha+\delta+\lambda Z_{i}+\beta B_{i}+\chi B_{i}{ }^{*} P_{j}}}
$$

donde $\pi_{i j}$ denota la cuota de gasto en marca de distribuidor por parte de cada hogar $i$ en cada cadena $j$ de la que es cliente; $\alpha$ denota un parámetro a estimar que cuantifica el grado de lealtad a la marca de distribuidor; $\delta j$ denota otro parámetro a estimar que cuantifica el efecto diferencial sobre la lealtad a la marca de distribuidor de la cadena $j$ (una de las cadenas debe tomarse como referencia con parámetro nulo $\mathrm{y}$, por tanto, nivel de lealtad equivalente dado por $\alpha$ ); $Z_{i}$ es el vector de las variables sociodemográficas para el hogar $i ; \lambda$ denota un vector de parámetros a estimar que recoge el efecto de la variables sociodemográficas (una de las clases sociales debe tomarse como referencia con parámetro nulo); $B_{i}$ es el vector de las variables de beneficios buscados del hogar $i, B_{i}^{*} P_{j}$ es el vector de variables de interacción entre los beneficios buscados $y$ el nivel de precios de la cadena; $\beta y x$ son dos vectores de parámetros a estimar correspondientes respectivamente a los efectos de las 
variables anteriores. Debe señalarse que no se considera el efecto directo de $P_{j}$ porque es redundante.

La Tabla 3.4 resume los resultados de estimación. Se estimaron dos modelos: en el primer modelo se incorporan las constantes de la cadena, las variables sociodemográficas y de beneficios buscados. En el segundo modelo, además de esas variables, se incorporan los efectos de interacción del nivel de precios de la cadena con cada uno de los beneficios buscados.

El efecto de los parámetros por enseña (modelo 1) indica diferencias significativas en el consumo de marcas de distribuidor a través de las enseñas. El peso de la marca de distribuidor es mucho mayor en las cadenas de descuento, Dia y Lidl. También es más elevado en las cadenas Mercadona, Eroski y Carrefour, que han realizado un esfuerzo especialmente notable en el desarrollo de este tipo de marcas (Alimarket 2007, Eleconomista, 2010; KantarWorldPanel, 2010).

En cuanto al perfil sociodemográfico del comprador de marca de distribuidor sólo dos variables son significativas, detectándose un efecto negativo de la clase social alta y un efecto positivo del tamaño del hogar. La compara de marca de distribuidor parece estar más asociada con hogares de mayor tamaño y no pertenecientes a las clases sociales más altas.

En cuanto a los efectos directos de los beneficios buscados en la compra de marcas de distribuidor, los resultados confirman tres de las seis hipótesis propuestas. La sensibilidad al precio tiene un efecto positivo y significativo en la compra de marcas de distribuidor $(\mathrm{H} 1)$ y un efecto significativo pero negativo con la sensibilidad a la calidad del servicio $(\mathrm{H} 3)$ y la sensibilidad a la marca (H6). Dos hipótesis, la relación negativa de la propensión a la promoción $(\mathrm{H} 2)$ y de la propensión a la innovación (H5) con la compra de esas marcas, no pueden ser confirmados debido a que los efectos de dichas variables no son significativos. En cuanto a la relación negativa ente diversión en la compra y compra de marcas de distribuidor $(\mathrm{H} 4)$, el resultado obtenido indica un efecto opuesto al propuesto, positivo, aunque significativo sólo a un nivel de confianza 
Tabla 3.4. Estimación de resultados

\begin{tabular}{|c|c|c|}
\hline & Modelo 1 & Modelo 2 \\
\hline Constante & $-1,923^{\star * *}$ & $-1,928^{* * *}$ \\
\hline Mercadona & $1,292^{* * *}$ & $1,339^{\star * *}$ \\
\hline Carrefour & $0,702^{\star \star *}$ & $0,736^{\star * \star}$ \\
\hline Eroski & $1,033^{\star \star *}$ & $1,071^{\star \star \star}$ \\
\hline Alcampo & 0,165 & 0,201 \\
\hline Dia & $1,867^{\star \star \star}$ & $1,901^{\star \star \star}$ \\
\hline Hipercor & 0,299 & 0,287 \\
\hline Caprabo & $-0,049$ & $-0,005$ \\
\hline Lidl & $2,739^{\star * *}$ & $2,770^{* * *}$ \\
\hline Dinosol & $-0,088$ & $-0,027^{\star * *}$ \\
\hline Consum & 0,071 & 0,134 \\
\hline Ahorramas & 0,133 & 0,175 \\
\hline Miguel alimentación & -- & -- \\
\hline \multicolumn{3}{|l|}{ SOCIODEMOGRÁFICOS } \\
\hline Clase Social 2 (media-baja) & $-0,058$ & $-0,064$ \\
\hline Clase Social 3 (media) & $-0,046$ & $-0,054$ \\
\hline Clase Social 4 (alta-media/alta) & $-0,171^{* \star *}$ & $-0,183^{\star \star *}$ \\
\hline Tamaño del hogar & $0,033^{* * *}$ & $0,033^{* * *}$ \\
\hline Presencia de niños & 0,035 & 0,037 \\
\hline \multicolumn{3}{|l|}{ RASGOS MOTIVACIONALES } \\
\hline Sensibilidad al precio & $0,103^{\star \star *}$ & $0,557^{\star \star *}$ \\
\hline Propensión a la promoción & $-0,011$ & 0,002 \\
\hline Sensibilidad a la calidad del servicio & $-0,076^{* * *}$ & $-0,741^{* * *}$ \\
\hline Diversión en la compra & $0,023^{*}$ & 0,279 \\
\hline Propensión a la innovación & $-0,017$ & $-0,080$ \\
\hline Sensibilidad a la marca & $-0,109^{\star \star \star}$ & $-0,675^{\star \star *}$ \\
\hline Sensibilidad al precio *Nivel de precio & & $-0,004^{\star \star}$ \\
\hline $\begin{array}{l}\text { Propensión a la promoción * Nivel de } \\
\text { precio }\end{array}$ & & $-0,0001$ \\
\hline Sensibilidad a la calidad del servicio * & & $0,006^{\star * *}$ \\
\hline \multicolumn{3}{|l|}{ Nivel de precio } \\
\hline Diversión en la compra * Nivel de precio & & $-0,002$ \\
\hline $\begin{array}{l}\text { Propensión a la innovación * Nivel de } \\
\text { precio }\end{array}$ & & 0,0005 \\
\hline Sensibilidad a la marca * Nivel de precio & & $0,005^{\star \star \star}$ \\
\hline \multicolumn{3}{|l|}{ BONDAD DEL AJUSTE } \\
\hline$\rho^{2}$ & 0,141 & 0,142 \\
\hline Test Razón de Verosimilitud & $* * *$ & $* * *$ \\
\hline
\end{tabular}

Notas: -- enseña de referencia, ${ }^{*} p<0,10$; ${ }^{* *} p<0,05 ;{ }^{* * *} p<0,01$. 
del $90 \%$. Este resultado está en línea con los resultados obtenidos por Leischnig, Schwertfeger y Geigenmüller (2011), y parece indicar que los consumidores que se divierten comprando podrían cubrir dicha motivación con la compra de este tipo de marcas. Por tanto, el comprador de marca de distribuidor se perfila motivacionalmente como un hogar más sensible a

precios, y menos sensible a la calidad del servicio y a las marcas reconocidas. Además, podría caracterizarse por una mayor búsqueda de diversión en la compra, aunque esta última asociación resulta menos evidente y debe asumirse con mayor cautela.

En lo que respecta al efecto moderador del posicionamiento en precio del distribuidor en el perfil del comprador de marca de distribuidor (modelo 2), también se confirman tres de las hipótesis propuestas tal y como se resume en la Tabla 3.1. A mayor nivel de precios del distribuidor, menor es la relación positiva entre la sensibilidad al precio y la compra de marca de distribuidor $(\mathrm{H} 7)$, el efecto negativo y significativo de la variable de interacción entre el nivel de precios y la sensibilidad al precio permite confirmar dicha hipótesis. Por otro lado, los efectos positivos y significativos de las variables de interacción del nivel de precios con la sensibilidad al servicio y la sensibilidad a la marca nos lleva a confirmar que, a mayor nivel de precios del distribuidor, menor es la relación negativa entre la sensibilidad a la calidad del servicio y la compra de marca de distribuidor (H9), y menor es la relación negativa entre la sensibilidad a la marca y la compra de marca de distribuidor. Los efectos no son significativos para la interacción del nivel de precios con la propensión a la promoción, la diversión en la compra y la propensión a la innovación, por lo que los resultados no permiten confirmar las hipótesis H8, H10 y H11. A la vista de los hallazgos obtenidos podemos concluir que el posicionamiento en precio del distribuidor modera la relación entre la compra de marcas de distribuidor y el perfil motivacional del comprador de marca de distribuidor. En las cadenas menos orientadas al precio, la compra de marcas de distribuidor parece estar menos motivada por la búsqueda de precios ventajosos, y más por la calidad, reconocimiento y reputación de las mismas. Este resultado corrobora además 
la congruencia entre el posicionamiento de las marcas de distribuidor y el posicionamiento de los propios distribuidores en el continuo precio versus calidad.

En la tabla 3.1 también se incluye un resumen de los resultados obtenidos en relación a las hipótesis planteadas en este trabajo.

\subsection{Conclusiones e implicaciones}

Aunque la caracterización del comprador de marca de distribuidor ha sido un tema pionero, el extraordinario crecimiento de sus ventas, así como la evolución de las estrategias de los distribuidores en los últimos años, posiblemente han afectado el perfil del comprador de este tipo de marcas. Por este motivo, este trabajo revisa esta cuestión de investigación. Un primer reto ha sido abordar la caracterización del comprador de marca de distribuidor considerando las motivaciones y beneficios buscados por el consumidor en la compra de estas marcas. Los resultados empíricos obtenidos indican que el comprador de marcas de distribuidor puede caracterizarse motivacionalmente como un consumidor más sensible a precios, y menos sensible a la calidad del servicio y a las marcas reconocidas. También, aunque la evidencia es menos rotunda, podría perfilarse por una mayor búsqueda de diversión en la compra. Además, los resultados obtenidos confirman que los beneficios buscados resultan más útiles para caracterizar al comprador que las características sociodemográficas.

Por otro lado, la evolución y creciente heterogeneidad de las marcas de distribuidor hace inapropiado hablar del perfil del comprador sin diferenciar las distintas estrategias competitivas seguidas por los distribuidores. En este contexto, y puesto que la evolución de las marcas de distribuidor también parece en gran medida motivada por la alineación de las marcas de distribuidor con la estrategia de posicionamiento del distribuidor, el perfil de comprador de marca de distribuidor también debería estar condicionado por el 
posicionamiento competitivo del propio distribuidor, en particular, el posicionamiento en precios. Por ello, un segundo desafío de este trabajo ha sido ha sido abordar la influencia del posicionamiento en precios del distribuidor en el perfil del comprador de sus marcas de distribuidor. Los resultados empíricos obtenidos confirman esta influencia sobre el perfil motivacional del comprador. En las cadenas menos orientadas al precio, la compra de marcas de distribuidor parece estar menos motivada por la búsqueda de precios ventajosos, y más por la calidad, reconocimiento y reputación de las mismas. Este resultado está en línea con la teoría de la congruencia que subyace a las cuestiones e hipótesis de investigación planteadas: el distribuidor alinea sus marcas de distribuidor con la estrategia de imagen y posicionamiento pretendida para sus establecimientos.

Los resultados obtenidos conducen a una serie de interpretaciones e implicaciones para los distintos agentes implicados en el sector de la distribución. En su estrategia de marcas de distribuidor, las cadenas deben estar atentas al perfil del comprador de este tipo de marcas. A pesar de la evolución en la estrategia de marcas de distribuidor, se sigue manteniendo como una de las principales motivaciones de compra la mayor sensibilidad al precio, la menor sensibilidad al servicio y a la reputación de marca de los compradores de este tipo de productos. El esfuerzo de muchos distribuidores en los últimos años ha estado orientado a mejorar la percepción de sus marcas de distribuidor. Como consecuencia, los diferenciales de precios entre las marcas de distribuidor y las marcas de fabricante se han venido reduciendo (Steenkamp, van Heerde y Geykens, 2010). Sin embargo, los resultados encontrados parecen indicar que todavía queda camino por recorrer y que la venta de marca de distribuidor todavía depende en gran medida del atractivo de sus precios.

No obstante, y a pesar de tratarse todavía de un proceso inacabado, los resultados encontrados parecen indicar que los esfuerzos de los distribuidores más orientados al servicio y a la calidad están en el buen camino. Parece que estos distribuidores menos orientados al precio están venciendo la arraigada percepción de las marcas de distribuidor como marcas centradas 
exclusivamente en ofrecer precios bajos en detrimento de su calidad. El atractivo de sus marcas de distribuidor ya reside menos en un precio ventajoso y más en su capacidad para satisfacer los clientes más exigentes.. Esto implica que, las marcas de distribuidor no sólo constituyen una herramienta para la competencia en precios sino que también pueden constituir una herramienta para forjar la imagen del minorista e incluso diferenciarse del resto. No obstante, debe apuntarse que la utilización de la marca de distribuidor como elemento diferenciador no solamente requiere apostar por la imagen, sino que también debe vencer otras barreras. Por ejemplo, la tendencia de los consumidores a generalizar sus experiencias con las marcas de distribuidor a través de las distintas cadenas (Szymanowski y Gijsbrechts, 2012).

Los resultados obtenidos también parecen indicar que el desarrollo de una cartera de marcas de distribuidor con distintos posicionamientos en el continuo calidad-precio resulta más apropiada a medida que el distribuidor se aleja de una orientación precio. Por un lado, el desarrollo de una marca de distribuidor coherente con el posicionamiento en calidad de la cadena atrae a los consumidores más exigentes y permite competir directamente con las marcas líderes de fabricante. Además, por su venta en exclusividad, puede contribuir a la diferenciación de la cadena y a la fidelización de los clientes. Por otro lado, la oferta de una marca genérica, orientada al precio, permite atraer a los consumidores más sensibles al precio y, consecuentemente, competir con formatos de establecimiento más agresivos en precio, como los establecimientos de descuento. Además, puede jugar un papel relevante en la credibilidad de las marcas de distribuidor más orientadas a calidad (Palmeira y Thomas, 2011). Esta última marca, puesto que no aporta a la diferenciación del establecimiento, puede sustituirse por una línea de precios bajos garantizados. Por ejemplo, esta estrategia está siendo utilizada por Alcampo (Grupo Auchan) con sus "productos económicos Alcampo" (Alcampo 2011). La estrategia de marca de distribuidor debe tener muy en cuenta los segmentos de consumo a los que atiende el distribuidor.

Este estudio no está exento de limitaciones que requieren investigaciones futuras. Cabe destacar que las medidas utilizadas pueden ser mejoradas 
sustancialmente. Por ejemplo, las medidas de beneficios buscados y de compra de marcas de distribuidor se han cuantificado en general, y no para cada categoría de productos concreta. En la misma línea, el posicionamiento en precio del distribuidor es un concepto complejo y multidimensional (Zielke, 2010) que ha sido cuantificado de manera simple y unidimensional. Por otro lado, el trabajo ha obviado otros rasgos motivacionales como: restricciones presupuestarias o búsqueda de variedad (Ailawadi, Neslin y Gedenk, 2001). Si bien el presente trabajo se ha centrado en la clasificación de los distribuidores en función de su imagen de precio sería interesante analizar otros atributos del distribuidor que podrían moderar la caracterización del comprador de marcas de distribuidor (servicio, surtido, etc). 


\subsection{Referencias}

Alimarket (2008), Informe Anual de la Distribución. Disponible en http://alimarket.es (Acesso el 30 Mayo 2009)

ACNielsen (2011) "The rise of the value-conscious shopper". Disponible en http://au.nielsen.com/site/documents/PrivateLabelGlobalReportMar2011.pdf (Acesso el 30 Maio 2011).

Ailawadi, Kusum L., Scott A. Neslin y Karen Gedenk, (2001), "Pursuing the value-conscious consumer: store brands versus national brand promotions", Journal of Marketing, 65 (1): 71-89

Ailawadi Kusum L. y Kevin L. Keller (2004), "Understanding Retail Branding: conceptual insights and research priorities", Journal of Retailing, 80 (4): 331 342

Ailawadi, Kusum L., Koen Pauwels y Jan-Benedict E.M. Steenkamp (2008), "Private label use and store loyalty", Journal of Marketing, 72 (3): 19-30

Alcampo (2011). Disponble en http://www.alcampo.es/web/guest/primer-precio, (Acesso el 30 Semptembre 2011)

Baltas, George (1997), "Determinants of store brand choice: a behavioral analysis," The Journal of Product and Brand Management, 6 (5): 315-324

Baltas, George y Paraskevas C. Argouslidis (2007) "Consumer characteristics and demand for store brands", International Journal of Retail \& Distribution Management, 35 (5): 328-341

Bao, Yongchuan, Yeqing Bao y Shibin Sheng (2011), "Motivating purchase of private brands: effects of store image, product signatureness, and quality variation", Journal of Business Research, 64 (2): 220-226 
Batra, Rajee y Indrajit Sinha (2000), "Consumer-level factors moderating the success of private label brands", Journal of Retailing, 76 (2): 175-191

Burt, Steve (2000), "The strategic role of retail brands in British grocery retailing", European Journal of Marketing, 34 (8): 875-890

Burton, Scot, Donald R. Lichtenstein, Richard G. Netemeyer y Judith A. Garretson (1998): "A scale for measuring attitude toward private label products and an examination of its psychological and behavioral correlates", Journal of the Academy of Marketing Science, 26 (4): 293-306

Corstjens, Marcel y Rajiv Lal (2000), "Building store loyalty through store brands”, Journal of Marketing Research, 37 (3): 281-291

Cox, Anthony D., Dena Cox y Ronald D. Anderson (2005), "Reassessing the pleasures of store shopping", Journal of Business Research, 58 (3): 250-259

Cunningham, Isabella C. M., Andrew P. Hardy y Giovanna Imperia (1982), "Generic brands versus national brands and store brands: a comparison of consumers' preferences and perceptions", Journal of Advertising Research, 22 (7-8): 25-32

De Wulf, Kristof, Gaby Odekerken-Schröder, Frank Goedertier y Gino Van Ossel (2005), "Consumer perception of store brands versus national brands", Journal of Consumer Marketing, 24 (4): 223-32

Dick, Alan, Arun Jain y Paul Richardson (1995), "Correlates of store brand proneness: some empirical observations", The Journal of Product \& Brand Management, 4 (4): 15-22

Dhar, Sanjay K. y Stephen J. Hoch (1997), "Why store brand penetration varies by retailer?", Marketing Science, 16 (3): 208-227

Dunne, David y Chakravarthi Narasimhan (1999), "The new appeal of private label", Harvard Business Review, 77 (May/Jun): 41-52 
Eleconomista (2010), La marca propia de Eroski creció tres puntos en 2009, hasta lograr el $33 \%$ del total de las ventas. Disponible en http://www.eleconomista.es/economia/noticias/2196796/06/10/EconomiaEmpresas-La-marca-propia-de-Eroski-crecio-tres-puntos-en-2009-hasta-lograrel-33-del-total-de-las-ventas.html, (Acesso el 30 Septiembre 2011)

Garretson, Judith A., Dan Fisher y Scot Burton (2002), "Antecedents of private label attitude and national brand promotion attitude: similarities and differences", Journal of Retailing, 78 (2): 91-99

Geyskens, Inge, Katrijn Gielens y Els Gijsbrechts (2010), "Proliferating privatelabel portfolios: how introducing economy and premium private labels influences brand choice", Journal of Marketing Research, 47 (5): 791-807

Gómez, Mónica y Natalia Rubio (2010), "Re-thinking the relationship between store brand attitude and store brand loyalty: a simultaneous approach", The International Review of Retail, Distribution and Consumer Research, 20 (5): 515- 534

González-Benito, Óscar y Mercedes Martos-Partal (2012), "Price sensitivity versus perceived quality: moderating effects of retailer positioning on privatelabel consumption", Working paper, Universidad de Salamanca

Grawal Dhruv y Michael Levy (2007), "Retailing research: past, present and future", Journal of Retailing, 83 (4): 447-464

Haley, Russel I. (1968), "Benefit segmentation: a decision-oriented research tool," Marketing Management, 32 (3): 30-35

Hansen, Karsten, Vishal Singh y Pradeep Chintagunta (2006), "Understanding store-brand purchase behaviour across categories", Marketing Science, 25 (1): $75-90$

Harris, Brian F. y Roger A. Strang (1985), "Marketing strategies in the age of generics", Journal of Marketing, 49 (4): 70-81 
Heider, Fritz (1944), "Social perception and phenomenal causality", Journal of Psychology, 21: 107-112

Hoch, Stephen J. (1996), "How should national brands think about private labels?", Sloan Management Review, 37 (2): 89-102.

Huang, Ying y Patricia Huddleston (2009), "Retailer premium own-brands: creating customer loyalty through own-brand products advantage", International Journal of Retail \& Distribution Management, 37 (11): 975-992

IGD Research (2007), "European discount retailing". Disponible en http://www.igd.com (Acesso el 30 Septiembre 2009)

Jacoby, Jacob, Robert W. Chestnut y William A. Fisher (1978), "A behavioral process approach to information acquisition in non-durable purchasing", Journal of Marketing Research, 15 (4): 532-544

Jacoby, Jacob y David Mazursky (1984), "Linking brand and retailer images do the potential risks outweigh the potential benefits?", Journal of Retailing, 60 (2): $105-22$

Juhl, Hans Jorn, Lans Esbjerg, Klaus G. Grunert, Tino Bech-Larsen y Karen Brunso (2006), "The fight between store brands and national brands - what's the score?", Journal of Retailing and Consumer Services, 13 (5): 331-338

KantarWorldPanel, (2010), La distribución en tiempos difíciles, Reacciones y resultados

Kumar, Nirmalya y Jan-benedict E. M. Steenkamp (2007) "Private label strategy: how to meet the store brand challenge", Harvard Business School Press

Kumar, Nanda, Suresh Radhakrishnan y Ram Rao (2010), "Private label vendor selection in a supply chain: quality and clientele effects", Journal of Retailing, 86 (2): $148-158$ 
Leischnig, Alexander, Marko Schwertfeger y Anja Geigenmüller (2011), 'Shopping events, shopping enjoyment, and consumers' attitudes toward retail brands - an empirical examination", Journal of Retailing and Consumer Services, 18 (3): 218-223

Luijten, Ton y Will Reijnders (2009), "The development of store brands an store as a brand in supermarkets in the Netherlands", International Review of Retail, Distribution \& Consumer Research, 19 (1): 45-58

Liu, Tsung-Chi y Chung-Yu Wang (2008), "Factors affecting attitudes toward private labels and promoted brands", Journal of Marketing Management, 24 (34): $283-298$

Martínez, Eva y Teresa Montaner (2008), "Characterization of Spanish store brand consumers", International Journal of Retail \& Distribution Management, 36 (6): 477 - 493

Martos-Partal, Mercedes y Oscar González-Benito, (2009), “¿Qué busca el comprador de marcas de distribuidor? Caracterización del comprador de marca de distribuidor por beneficios buscados", Universia Business Review, 24: 76-95

Manzur Maciej, Sergio Olavarrieta, Pedro Hidalgo, Pablo Farías, y Rodrigo Uribe (2011), "Store brand and national brand promotion attitudes antecedents", Journal of Business Research, 64 (3): 286-291

Méndez, José Luis, Javier Oubiña y Natalia Rubio (2008), "Expert quality evaluation and price of store vs, manufacturer brands: an analysis of the Spanish mass market", Journal of Retailing and Consumer Services, 15 (3): 144-155

Meyer, John G. (1967), "Determinants of private brand attitude", Journal of Marketing Research, 4 (1): 73-81 
Nanycz-Thiel Magda y Jenni Romaniuk (2009), "Perceptual categorization of private labels and national brands", Journal of Product and Brand Management, $18(4): 251-261$

Palmeira, Mauricio M. y Dominic Thomas, (2011) "Two-tier store brands: the benefic impact of a value brand on perceptions of premium brand", Journal of Retailing, 87 (4): 540-548

Park, Ji E., Jun Yu y Joyce Xin Zhou (2010), "Consumer innovativeness and shopping styles“, The Journal of Consumer Marketing, 27 (5): 437-446

$\begin{array}{llll}\text { PLMA (2012), } & \text { Disponible }\end{array}$ http://www.plmainternational.com/es/private label es2.htm. (Acesso el 10 febrero 2012)

Puccinelli, Nancy M., Ronald C. Goodstein, Dhruv Grewal, Robert Price y David Stewart (2009), "Customer experience management in retailing: understanding the buying process", Journal of Retailing, 85 (1): 15-30

Richardson, Paul, Alan S. Dick, y Arun K. Jain (1994), "Extrinsic and intrinsic cue effects on perceptions of store brand quality", Journal of Marketing, 58 (4): 28-36

Rubio, Natalia y María Jesús Yagüe (2009), "Alternative panel models to evaluate the store brand market share: evidence from the Spanish market", European Journal of Marketing, 43 (1-2): 110-138

Semeijn, Janjaap, Allard C. R. van Riel y Ana Beatriz Ambrosini (2004), "Consumer evaluations of store brands: effects of store image and product attributes," Journal of Retailing and Consumer Services, 11 (4): 247-58

Sethuraman, Raj (2006): "Private label marketing strategies in packaged goods: management beliefs and research insights", Marketing Science Institute Working Paper, 27-44 
Sinha, Indrajit y Batra, Rajee (1999), "The effect of consumer price consciousness on private label purchase", International Journal of Research in Marketing, 16 (3): 237-251

Soberman, David A. y Philip M. Parker (2006), "The economics of qualityequivalent store brands", International Journal of Research in Marketing, 23 (June): 125-139

Steenkamp, Jan-Benedict E,M, Harald J. van Heerde y Inge Geykens (2010), "What makes consumers willing to pay a price premium for national brands over private labels?", Journal of Marketing Research, 47 (6): 1011-1024

Sudhir K. y Debabrata Talukdar (2004), "Does store brand patronage improve store patronage?", Review of Industrial Organization, 24 (2): 143-160

Szymanowski, Maciej y Els Gijsbrechts, (2012), "Consumption-based crossbrand learning: Are private labels really private?", Journal of Marketing Research, 49 (2)

Thomassen, Lars, Ketih Lincoln y Anthony Aconis (2006), "Retailization: brand survival in the age of retailer power", Great Britain: Kogan Page

Xie, Yu Henry (2008) "Consumer innovativeness and consumer acceptance of brand extensions", Journal of Product and Brand Management, 14 (4): 235-243

Yelkur, Rama (2000), "Consumer perceptions of generic products: a Mexican study," The Journal of Product and Brand Management, 9 (7): 446-456.

Williams, Tarrel G., Mark Slama y John Rogers (1985), "Behavioral characteristics of the recreational shoppers and implications for retail management", Journal of the Academy of Marketing Science, 13 (3): 307-16

Zielke, Stephan (2010), "How price image dimensions influence shopping intentions for different store formats", European Journal of Marketing, 44 (6): 748-770 


\section{VALOR DE MARCA Y CARTERAS}

\section{DE MARCAS DE DISTRIBUIDOR}




\section{VALOR DE MARCA Y CARTERAS DE MARCAS DE DISTRIBUIDOR}

\subsection{Introducción}

Construir y gestionar el valor de las marcas se ha convertido en una prioridad para las empresas de todos los tamaños, industrias y mercados (Keller, 2000). De hecho, las marcas de alto valor son consideradas un activo intangible valioso para las empresas (Kotler y Armstrong, 1995). Los beneficios de mantener una marca fuerte son la generación de flujo de caja marginal, el aumento de la probabilidad de elegir la marca, mayores niveles de lealtad y menor vulnerabilidad a acciones de marketing de los competidores, oportunidades adicionales de extensión de marca y posibilidad de licenciar su nombre, logo y otros aspectos a otras empresas (Aaker, 1993; Keller, 1998). También, altos niveles de conocimiento de marca y una imagen de marca positiva tienen implicaciones específicas favorables en el precio, distribución y actividades promocionales ligados a la marca (Farquhar, 1990; Keller, 1993). Estas ventajas se deben a que, para los consumidores, las marcas de alto valor ofrecen seguridad y garantizan un nivel de calidad, facilitan el proceso de elección, reducen el riesgo, crean confianza y comunican un status social (Aaker, 1994; Keller, 1998; Keller y Lehmann, 2006; Wilke y Zaichkowsky, 1999). En este contexto, comprender cómo la marca contribuye a la experiencia con el producto es una prioridad para gestores e investigadores (Christodoulides y Chernatony, 2010)

El siglo XX ha sido el siglo de las marcas de fabricante. Sin embargo, también se ha caracterizado por el avance de las marcas de distribuidor. En los años 70, los distribuidores empezaron a desarrollarse globalmente y a comercializar sus marcas propias (Kumar y Steenkamp, 2007a). Al principio, las marcas de distribuidor eran un producto genérico de poca calidad, que incluso no usaban el nombre del distribuidor, o eran productos imitadores que copiaban las características de las marcas nacionales. Sin embargo, las marcas de distribuidor han evolucionado a lo largo de los años, mejorando en 
calidad y ganando la confianza de los consumidores. Una investigación llevada a cabo para la PLMA (Private Label Manufacturers Association, 2010) muestra que la relación del consumidor con las marcas de distribuidor va más allá de razones como precio, condiciones económicas y formato del distribuidor. En la actualidad los distribuidores ofrecen líneas de productos con marca de distribuidor de calidad comparable o incluso superior a las marcas nacionales (Dunne y Narasimhan, 1999; Geyskens, Gielens y Gijsbrechts 2010; Soberman y Parker, 2006). Además, gestionan sus marcas de manera más estratégica, utilizando distintos criterios de segmentación para ofrecer marcas con distintos posicionamientos y distintas propuestas de valor dentro de su cartera de marcas de distribuidor (Kumar y Steenkamp, 2007b).

La cuota de mercado de las marcas de distribuidor es creciente y amenaza a las grandes marcas de fabricante (Ailawadi y Keller, 2004; Quelch y Harding, 1996). Según la PLMA (2010), las marcas de distribuidor están más fuertes que nunca. Dichas marcas alcanzaron un $40 \%$ de cuota de mercado en 5 países europeos. Mientras, en Estados Unidos, uno de cada cuatro productos vendidos es marca de distribuidor.

La investigación académica sobre el valor de marca se ha centrado en cómo desarrollar y mantener marcas fuertes (Aaker, 1994; Keller, 2001), sobretodo en el ámbito de las marcas de fabricante. Sin embargo, en este nuevo contexto competitivo, es relevante así como interesante investigar en mayor profundidad el valor de las marcas del distribuidor. Para así conocer si el esfuerzo realizado por los distribuidores en su estrategia de marcas de distribuidor está dando sus frutos y está generando valor a sus marcas propias. Son escasos los trabajos que han analizado conjuntamente el valor de marcas de distribuidor y marcas de fabricante y los resultados obtenidos no son concluyentes. Por tanto, un primer objetivo de este trabajo consiste en analizar de forma comparada el valor de las marcas de distribuidor y de las marcas de fabricante en un contexto reciente.

Por otro lado, las investigaciones previas que han estudiado el valor de las marcas de distribuidor lo han hecho de forma agregada, sin diferenciar entre 
marcas de distribuidor con distintos posicionamientos. En los últimos años se ha producido una evolución en la calidad de las marcas de distribuidor y un cambio de estrategia por parte de los distribuidores que ya no ofrecen una única marca de distribuidor sino que incluso ofrecen una cartera de marcas. De hecho, es habitual diferenciar entre marca genérica, estándar o premium para referirse, respectivamente, niveles crecientes en el posicionamiento en calidad de las marcas de distribuidor (Kumar y Steenkamp, 2007b). Este cambio de estrategia está generando una línea de investigación emergente centrada en el efecto moderador del posicionamiento de la marca de distribuidor (e.j., Geyskens, Gielens y Gijsbrechts 2010; Kumar y Steenkamp 2007a). En línea con esta nueva tendencia de investigación en el ámbito de las marcas de distribuidor, nos planteamos como segundo objetivo de este trabajo analizar el efecto del posicionamiento de las marcas de distribuidor en el valor de dichas marcas. Es decir, este trabajo persigue estudiar si el valor de las marcas de distribuidor depende del tipo de marca que se considere, en particular, marca genérica, estándar o premium. A pesar de los esfuerzos de los distribuidores en gestionar una cartera de marcas de distribuidor y lanzar marcas de mayor calidad para competir con las marcas líderes, se desconoce hasta qué punto los consumidores perciben esa diferenciación. Este tema no ha sido abordado previamente por la literatura, brecha que el presente trabajo pretende subsanar.

En los contenidos subsiguientes se aborda primeramente una revisión de las investigaciones previas con el fin de argumentar las hipótesis de trabajo. Seguidamente se describe la metodología seguida en el análisis empírico y se interpretan y comentan los resultados alcanzados. En una última sección se sintetizan las principales conclusiones e implicaciones. 


\subsection{Marco Teórico e Hipótesis}

\subsubsection{Valor de las marcas de distribuidor y marcas de fabricante}

La marca es un nombre y/o símbolo distintivo que identifica los productos o servicios de un fabricante y que los diferencia de los de la competencia (Aaker, 1994). En el marketing moderno, sin embargo, las marcas son más que una herramienta de identificación y diferenciación. Las marcas son uno de los activos intangibles más importantes que poseen las empresas (Keller y Lehmann, 2006) y se han convertido en el elemento central en las estrategias de marketing (McEnally y Hawes, 1984). Representan información acerca de una variedad de atributos vinculados al producto, como características, significado y calidad, que constituye el valor de la marca (Wilke y Zaichkowsky, 1999).

Existen muchas definiciones de valor de marca que adoptan distintas perspectivas. Desde la perspectiva del consumidor, Farquhar (1990) define el valor de marca como el aumento en la fuerza de la actitud del consumidor en relación a un producto que lleva un nombre de marca específico. Keller (1993), también bajo esa misma perspectiva, lo define como el efecto diferencial del conocimiento de marca en las respuestas del consumidor al marketing de una marca. Es decir, el valor de marca basado en el consumidor involucra las reacciones del consumidor a un elemento del mix de marketing para la marca en comparación con sus reacciones al mismo elemento del mix de marketing de una versión del producto o servicio con una marca ficticia o sin marca. Siguiendo ese mismo enfoque Keller y Lehmann (2006) definen el valor de marca como la parte de la atracción hacia un producto particular generada por la parte no objetiva de la oferta del producto (no por los atributos del producto per se). Por tanto, se puede decir que la valoración percibida que hace un consumidor de un producto (VP) se puede descomponer en el valor del producto per se o valor objetivo percibido del producto (VO) y el valor del producto subjetivo o valor de marca percibido (VM). De tal forma que:

$$
V P=V O+V M
$$


La propuesta de este trabajo es que, aislando el papel del precio, la valoración percibida (VP) es mayor para las marcas de fabricante que para las marcas de distribuidor, pero la razón de dicha diferencia no se debe a que el valor objetivo percibido (VO) es mayor para las marcas de fabricante que para las marcas de distribuidor, sino a que el valor de marca percibido (VM) es mayor para las marcas de fabricante que para las marcas de distribuidor. Diversas evidencias previas permiten argumentar esta propuesta.

Aunque dentro de la línea de investigación de las marcas de distribuidor se ha prestado poca atención al estudio de las percepciones de los consumidores respecto a las marcas de distribuidor, los resultados previos muestran que los consumidores perciben diferencias entre las marcas de distribuidor y las marcas de fabricante en las dimensiones de precio, calidad, valor y riesgo (Nenycz-Thiel y Romaniuk, 2009). Las marcas de distribuidor han sido percibidas tradicionalmente como alternativas de calidad inferior compensada con precios bajos (Bellizi et al., 1981; Cunningham, Hardy e Imperia, 1982, Richardson, Dick y Jain, 1994, Sethuraman 2006). Las marcas de distribuidor han tenido un precio inferior a las marcas de fabricante y éste ha sido uno de los factores determinantes para su compra (Sethuraman 2006). Dicho de otro modo, las deficiencias en calidad percibida se suplen con precios más atractivos, resultando así más útiles, o con mayor valor global, para los consumidores que deciden comprarlas. En consecuencia, cabe esperar que, asilando el papel del precio, la valoración percibida (VP) sea mayor para las marcas de fabricante que para las marcas de distribuidor.

Es preciso apuntar, no obstante, que la tendencia está cambiando. Las marcas de distribuidor están evolucionando positivamente respecto a la calidad percibida (Quelch y Harding, 1996; Steenkamp, van Heerde y Geykens, 2010), y cada vez más se perciben como marcas con calidad comparable a las marcas de fabricante pero con precios más atractivos (Sethuraman y Cole, 1999) Según el estudio global realizado por ACNielsen (2005) dos tercios de los consumidores consideran que las marcas de distribuidor son una buena alternativa en términos de calidad, valor, empaquetado y posicionamiento frente a otras marcas. Recientemente la PLMA (2010) ha mostrado que los 
compradores creen que las marcas de distribuidor funcionan tan bien como las marcas de fabricantes. El hecho de que las diferencias de precios entre marcas de distribuidor y marcas de fabricante tiendan a reducirse es otra evidencia clara de esta convergencia en términos de calidad (Steenkamp, van Heerde y Geykens, 2010). Sin embargo, considerando la marca de distribuidor en conjunto, todavía parecen existir diferencias importantes con respecto a la marca de fabricante.

La cuestión es si estas diferencias en la percepción de las marcas de distribuidor se deben a una valoración objetiva de sus cualidades y prestaciones o están influidas por la credibilidad, reputación y notoriedad que conlleva la marca. Jacoby, Olson y Haddock (1971) muestran que los consumidores se basan en señales intrínsecas (ej., ingredientes, sabor) y extrínsecas (ej., precio, nombre de marca, publicidad) cuando hacen los juicios sobre la calidad de las marcas. En el contexto de las marcas de distribuidor, Richardson, Dick y Jain (1994) atribuyen un mayor peso a las señales extrínsecas. En su estudio, dado que las marcas de distribuidor analizadas tenían precios bajos, un empaquetado pobre y no sé publicitaban, estas señales extrínsecas se usaban para inferir una baja calidad del producto, sin reparar en los ingredientes del producto y otras señales intrínsecas. Esto conduce a pensar que el valor de marca (VM) juega un papel más relevante que el valor objetivo (VO) en la percepción de las marcas de fabricante respecto a las marcas de distribuidor.

Respecto al valor objetivo, Apelbaum,Gerstner y Naik (2003), en el contexto americano, y Mendéz, Oubiña y Rubio (2008), en el contexto español, encuentran que la calidad objetiva en la actualidad de las marcas de distribuidor, mostrada a través de evaluaciones a expertos, es comparable a las marcas nacionales pero se venden a precios inferiores. Incluso, en algunos casos, tienen una calidad superior a las marcas nacionales. Davies y Brito (2004), De Wulf et al (2005) y (Fornerino y d'Hauteville, (2010) confirman también estos resultados usando evaluaciones basadas en test ciegos a consumidores. Cuando los consumidores desconocen las marcas, no se aprecian diferencias en sus preferencias. También la PLMA (2011) señala que, 
en términos de calidad objetiva, no se encuentran diferencias entre las marcas de distribuidor y las marcas nacionales. De 29 categorías analizadas mediante test ciegos, 23 tienen una valoración igual o superior a las marcas nacionales. Además, los estudios muestran una evolución positiva de la calidad objetiva de las marcas de distribuidor (e.j; Mendéz, Oubiña y Rubio, 2008, Soberbam y Parker, 2006). Estos resultados conducen a pensar que en el contexto actual, y aislando el valor del precio, las diferencias de valor objetivo percibido en las marcas de fabricante y de distribución es escaso. Por ello, se propone la siguiente hipótesis:

\section{H1: El valor objetivo (VO) percibido en las marcas de distribuidor es igual al valor objetivo percibido en las marcas de fabricante}

Centrados exclusivamente en el valor de marca, son escasos los trabajos que han analizado esta cuestión para las marcas de distribuidor. La mayoría de los estudios se han centrado en estudiar el valor de las marcas de fabricante. Una excepción es el trabajo de Erdem, Zhao y Valenzuela (2004). Estos autores miden el valor de marca examinando las percepciones sobre la calidad de las marcas de distribuidor. Las marcas contribuyen a las percepciones de calidad de los clientes, de tal forma que la reputación de una marca se convierte en una señal creíble para el mercado sobre la calidad del producto (Erdem y Swait, 1998). Sus resultados muestran que la diferencia en el éxito entre las marcas de distribuidor en Europa y EEUU se explica parcialmente por las mejores percepciones de calidad de estas marcas en Europa y, por tanto, el mayor valor de marca de las marcas de distribuidor en Europa. Sin embargo, aunque el valor de las marcas de distribuidor sea mayor en Europa, otras evidencias parecen indicar que su valor está todavía lejos del valor de las marcas de fabricante líderes. De Wulf et al (2005) utiliza la comparación de test ciegos y no ciegos para investigar hasta qué punto la valoración de marcas de fabricante y distribuidor tras una degustación cambia como consecuencia de conocer dichas marcas. Sus resultados muestran que la valoración de las marcas de distribuidor era menor cuando los consumidores eran conscientes 
de la marca. Mientras que ocurría lo contrario en el caso de las marcas de fabricante reconocidas. También Fornerino y d'Hauteville (2010) utilizan este tipo de test para comparar el valor de marcas de fabricante y de distribuidor. Concluyen que el conocimiento de la marca tiene un efecto positivo sobre la valoración del producto en el caso de marcas líderes, pero carece de efecto en el caso de marcas de distribuidor. Igualmente, Davies y Brito (2004) concluyen que el valor de marca es la única explicación del sobreprecio pagado por las marcas de fabricante respecto a las marcas de distribuidor. De nuevo, mediante test ciegos, encuentran que la preferencia por las marcas de fabricante mostrada por los consumidores desaparece cuando se aísla el efecto de la marca y las evaluaciones se basan exclusivamente en la calidad intrínseca percibida. Juhl et al (2006) obtienen resultados similares utilizando la notoriedad de la marca como indicador del valor de marca. Sus resultados muestran una gran diferencia entre la notoriedad de las marcas de fabricante y las marcas de distribuidor a favor de las primeras. En esta misma línea, Richardson (1997) encuentra que las marcas de distribuidor no se diferencian en la mente del consumidor, se perciben sólo como otra marca en el mercado. Esta escasa capacidad de diferenciación conlleva un reducido valor de marca. Todas estas evidencias previas conducen a pensar que el valor de las marcas de distribuidor es todavía menor que el de las marcas de fabricante tradicionales que compiten en una categoría de producto. Por tanto, se propone la siguiente hipótesis:

\section{H2 El valor de marca (VM) percibido en las marcas de fabricante es mayor que el valor de marca percibido en las marcas de distribuidor}

\subsubsection{Posicionamiento de las marcas de distribuidor}

El posicionamiento se define como el lugar que la marca o el producto ocupa en la mente de los consumidores con relación a sus competidores (Kotler y Armstrong, 1995). En la actualidad, los minoristas no comercializan una única marca de distribuidor sino que gestionan una cartera de marcas de 
distribuidor con el objetivo de atender a distintos segmentos de mercado de manera simultánea con marcas que usan distintos posicionamientos (Geyskens, Gielens y Gijsbrechts, 2010; Kumar y Steenkamp, 2007a). Una de las estrategias más comunes de posicionamiento adoptada por los distribuidores dentro de su cartera de marcas es la estrategia en tres escalones. En esa estrategia el minorista ofrece una marca económica, una marca estándar y una marca premium, ocupando tres posicionamientos distintos en la mente de los consumidores en cuanto a la propuesta de valor al consumidor (Geyskens, Gielens y Gijsbrechts, 2010; Kumar y Steenkamp, 2007a). Las marcas genéricas o económicas surgieron en ámbito de la alimentación en los años setenta (Davies, 1990) y enfatizan el uso básico del producto posicionándose como la alternativa más barata, gracias a sus actividades promocionales limitadas, a envases más sencillos y ahorros en los ingredientes más costosos (Yelkur, 2000; Cunningham, Hardy e Imperia, 1982; Harris y Strang, 1985; Geyskens, Gielens y Gijsbrechts 2010). Se utilizan para competir en precio pero son marcas cuidadosamente seleccionadas y gestionadas por los distribuidores (Burt, 2000). Han resurgido en los últimos años en los distribuidores europeos como una herramienta para competir con los establecimientos de descuento (Kumar y Steenkamp, 2007a). Las marcas tipo estándar o copia son las marcas tradicionales y se posicionan como la alternativa equilibrada en términos de calidad y precio (Geyskens, Gielens y Gijsbrechts, 2010). Normalmente siguen una estrategia de imitación frente a las marcas de fabricante tratando de ofrecer una calidad similar al fabricante pero a un precio más ventajoso (Kumar y Steenkamp, 2007a). Finalmente, las marcas premium son un fenómeno más reciente que pretende una calidad igual o incluso superior a la de las marcas líderes (Quelch y Harding, 1996). Entre otros objetivos, el distribuidor pretende diferenciarse y mejorar su imagen (Kumar y Steenkamp, 2007a). Dunne y Narasimham (1999) consideran las marcas premium como substitutas cercanas de las marcas de fabricante líderes.

Las investigaciones empíricas previas sobre el posicionamiento de las marcas de distribuidor se han centrado en analizar la elección del posicionamiento óptimo con relación a las marcas nacionales (ej., Choi y 
Coughlan, 2006; Sayman, Hoch y Raju, 2002). También existe una línea de investigación emergente en torno a las carteras de marcas de distribuidor configuradas con distintos posicionamientos competitivos. Por ejemplo, Geyskens, Gielens y Gijsbrechts (2010) analizan como la introducción de marcas de distribuidor genéricas y premium afectan la elección de marca por parte de los consumidores. Martos-Partal y González-Benito (2011) también analizan el efecto de los distintos posicionamientos de la marca de distribuidor en la lealtad de los consumidores hacia el distribuidor. Sin embargo, no existen estudios empíricos que investiguen explícitamente el valor de las marcas de distribuidor en función de los distintos posicionamientos.

El posicionamiento de un producto y el precio se usan por los consumidores como una señal de calidad (Richardson, Dick y Jain, 1994). Estos mismos autores señalan que un mayor enfoque de las marcas de distribuidor en la calidad podría producir unas mejores percepciones de las marcas de distribuidor. Algunos estudios pioneros que analizaron las percepciones de las marcas genéricas frente a las marcas de distribuidor estándar ponían de manifiesto que la calidad percibida de las marcas de distribuidor estándar era superior a la calidad percibida de las marcas genéricals (Bellizi et al., 1981; Cunningham, Hardy e Imperia., 1982). Consecuentemente, cabe esperar que la evolución experimentada al respecto en los últimos años tenga su reflejo en la calidad percibida por los consumidores. Por tanto, cabe esperar que, una vez aislado el papel del precio, la valoración percibida (VP) de las marcas de distribuidor premium sea mayor que la valoración percibida de las marcas estándar, y que la valoración percibida de las marcas estándar sea superior que en las marcas genéricas.

Sin embargo, en este trabajo sugerimos que estas diferencias en la calidad percibida de las distintas marcas de distribuidor se deben más al esfuerzo realizado por los distribuidores para forjar una imagen de calidad, credibilidad y reputación en sus marcas de distribuidor que a la percepción de una mejora en los atributos y cualidades intrínsecas u objetivas de los productos. Por ejemplo la cadena francesa Carrefour ha desarrollado en los últimos años un gran esfuerzo en este sentido. En España Carrefour realizó una campaña para 
redefinir el posicionamiento de sus marcas propias renovando la imagen de 7.500 artículos y lanzando 1.600 artículos nuevos, cuyo coste suponía 10 millones de euros. El objetivo de dicho plan era mejorar la imagen de sus marcas propias e innovar con nuevas líneas de productos especializados para atender necesidades concretas de los consumidores (Alimarket, 2007). Otros distribuidores importantes muestran una historia similar como es el caso del distribuidor británico Tesco. En dos décadas dicho distribuidor ha pasado de ser un distribuidor seguidor con imagen de precios bajos a ser el líder de la industria, posición que ha alcanzado gracias a su cartera de marcas de distribuidor, cartera que a lo largo de los años ha ido mejorando en imagen hasta el punto de que su marca Tesco Finest se comercializa con precios superiores a las marcas de fabricante (Kumar y Steenkamp, 2007a).

Si previamente se ha argumentado que las diferencias entre marcas de distribuidor y fabricante están fundamentalmente explicadas por las diferencias en el valor de marca, y no en el valor objetivo, la propuesta aquí es que las diferencias entre los distintos posicionamientos de marca de distribuidor también se deben fundamentalmente al valor ligado a la marca. En definitiva, la evaluación que hacen los consumidores de estas marcas se basa en credibilidad atribuida a la marca, más que en un análisis de sus características y prestaciones. Por tanto, proponemos las siguientes hipótesis:

\section{H3: El valor objetivo (VO) percibido en las marcas de distribuidor premium, estándar y genérica son iguales entre sí}

H4: El valor de marca (VM) percibido en las marcas de distribuidor premium es mayor que el valor de marca percibido en las marcas estándar, y el valor de marca percibido en las marcas estándar es mayor que el valor de marca percibido en las marcas genéricas. 


\subsection{Metodología}

\subsubsection{Contexto y Diseño de la investigación}

Con el fin de aportar evidencia empírica en torno a las hipótesis planteadas, se ha realizado un experimento orientado a comparar las valoraciones de los productos en función de si se conoce o no la marca de los mismos. Básicamente, se solicita a los consumidores colaboradores que evalúen un producto mientras se controlan dos variables: por un lado la marca a evaluar, y por otro lado el conocimiento o no de dicha marca. El tratamiento ciego sirve para evaluar como las características percibidas objetivamente influyen en las preferencias, mientras que el tratamiento no ciego desvela la realidad de mercado (Ghose y Lowengart, 2001). Estos experimentos han probado ser un método efectivo para entender el posicionamiento y el valor de marca, en particular en el contexto de la marca de distribuidor (De Wulf et al 2005; Fornerino y d'Hauteville, 2010; Richardson, Dick y Jain, 1994; Davies y Brito, 2004).

Para este experimento, se ha utilizado una muestra de estudiantes universitarios. Los estudiantes son una parte importante de los consumidores más propensos a comprar marcas de distribuidor en el marco de sus compras de alimentación y, por lo tanto, pueden ser considerados experimentados con relación a elecciones entre marcas de fabricante y marcas de distribuidor (Simejin, 2004). La utilización de muestras de estudiantes se ha probado útil en estudios sobre el valor de marca (Fornerino y d'Hauteville, 2010; Yoo, Donthu y Lee, 2000). Siguiendo a De Wulf et al (2005), se realizó un pre-test con 15 estudiantes de postgrado que permitió hacer pequeños ajustes en el procedimiento.

No obstante, se seleccionó una categoría de producto adaptada al perfil de la muestra. Concretamente, se eligió la categoría de tabletas de chocolate con leche. Se trata de un producto muy conocido y accesible. Además, las tabletas de chocolate son una categoría de producto interesante para un estudio de marcas de distribuidor (Lybeck, Holmlund-Rytkonen y Saaksjarvi, 2006). A 
diferencia de los productos comúnmente estudiados como arroz, pañuelos y detergentes, las tabletas de chocolate pueden implicar emociones y satisfacción de carácter hedónico (Mowen, 1995, p. 205). Como productos típicamente hedónicos, ofrecen más oportunidades de diferenciación en la mente de los consumidores, y los aspectos simbólicos y emocionales tienen un papel más importante (Sloot, Verhoef y Franses, 2005; Suh, 2009). Además, De Wulf et al (2005) sugieren que los atributos del chocolate están más relacionados con la experiencia que con la búsqueda, es decir, sus atributos se evalúan mediante el uso o la prueba (Batra y Sinha, 2000), siendo especialmente apropiados para un test que conlleva la degustación.

Se seleccionaron cinco marcas dentro de ésta categoría de producto. Por un lado se seleccionaron dos marcas de fabricante reconocidas, Nestle y Lindt. Lindt es la marca líder en Europa, y Nestlé es internacionalmente conocida. Por otro lado se seleccionaron tres marcas bien conocidas de un reconocido distribuidor (Carrefour), Número 1, Carrefour y Carrefour Selección. Estas tres marcas se corresponden respectivamente con los posicionamientos genérico, estándar y premium.

Cada participante evaluó dos marcas de chocolate. En el primer caso desconocía la marca y solo disponía de la degustación y de la ficha técnica del producto (ingredientes) para su valoración. En el segundo caso conocía además la marca. Las marcas fueron seleccionadas aleatoriamente de manera que no había ninguna relación entre la marca utilizada en el test-ciego y la marca utilizada en el test-no ciego.

Como resultado, 311 estudiantes participaron en el experimento, resultando finalmente 307 válidos por haber respondido a todas las preguntas planteadas, esto es, $98 \%$ de respuestas válidas. 


\subsubsection{Medidas y escalas}

La valoración de los productos después de su degustación se cuantificó utilizando la escala sugerida por Cunningham, Hardy e Imperia (1982). En concreto se valoró la calidad, la nutrición de los ingredientes, la apariencia, el sabor y la textura de las marcas. Además, se incorporó otro ítem en el que se pregunta por una evaluación general del producto. Las respuestas fueron codificadas en una escala tipo Likert de cinco puntos ( $1=$ "mala" y $5=$ "excelente"). La Tabla 4.1 resume el análisis de la escala. Tanto el análisis de componentes principales como el alpha de Cronbach permiten asumir unidimensionalidad en los distintos aspectos de valoración. Por ello, el análisis subsiguiente se ha centrado exclusivamente en el ítem de evaluación general del producto. Es preciso apuntar, no obstante, que el análisis se ha repetido considerando otras alternativas sin encontrarse variaciones sustanciales en los resultados y conclusiones

\section{Tabla 4.1. Escala de valoración después de la degustación}

\begin{tabular}{lccccc} 
& Media & $\begin{array}{c}\text { Desviación } \\
\text { Típica }\end{array}$ & $\begin{array}{c}\text { Carga } \\
\text { Factorial }\end{array}$ & $\begin{array}{c}\text { Alpha de } \\
\text { Cronbach }\end{array}$ & $\begin{array}{c}\text { Varianza } \\
\text { Extraída }\end{array}$ \\
\hline Calidad & 3,423 & 0,892 & 0,879 & & \\
Nutrición/Ingredientes & 3,179 & 0,766 & 0,645 & & \\
Apariencia & 3,326 & 0,970 & 0,692 & 0,894 & 66,532 \\
Sabor & 3,492 & 1,045 & 0,865 & & \\
Textura & 3,433 & 1,020 & 0,834 & & \\
Evaluación General & 3,438 & 0,863 & 0,938 & & \\
\hline
\end{tabular}

Además de la información relativa a la valoración de las marcas, se solicitó información relativa al perfil demográfico de los participantes. Básicamente, la edad, sexo y el rango de ingresos anuales de la familia. Entre ellos, 67,2\% eran mujeres, la edad media fue de 22 años y $58,6 \%$ de los hogares tienen una renta entre 20.001 - 50.000 euros. El nivel de ingresos ha sido interpretado como una variable métrica con cinco niveles: menos de $20.000 €$, de $20.001 €$ a $50.000 €$, de $50.001 €$ a $100.000 €$, de $100.001 €$ a $200.000 €$ y más de $200.001 €$, 
Puesto que la edad presentaba muy pocas variaciones y su papel ha sido irrelevante en los análisis realizados, no ha sido tenida en cuenta en la exposición subsiguiente.

\subsection{Análisis y resultados}

\subsubsection{Marca de distribuidor versus marca de fabricante}

Una primera fase de análisis se ha centrado exclusivamente en el análisis del valor de marca considerando únicamente dos grupos de marca: las marcas de fabricante y las marcas de distribuidor. El efecto de los las dos variables controladas, la marca y el conocimiento de la marca, sobre las valoraciones realizadas por los consumidores participantes en el experimento ha sido llevado a cabo estimando el siguiente modelo:

$$
Y=\beta_{O}+\beta_{1} M D+\beta_{2}(M F x C)+\beta_{3}(M D x C)
$$

donde $\mathrm{Y}$ es la valoración realizada por los participantes; MD y MF son variables binarias que toman valor 1 cuando el consumidor ha degustado marca de distribuidor y marca de fabricante, respectivamente; y $\mathrm{C}$ es otra variable binaria que toma valor 1 cuando el consumidor es consciente de la marca degustada.

La estimación del modelo permite cuantificar las magnitudes de interés en este estudio. El valor objetivo (VO) viene dado por la valoración realizada por los participantes cuando desconocen la marca, es decir:

\footnotetext{
$V O($ marca de fabricante $)=\beta_{0}$

$V O($ marca de distribuidor $)=\beta_{0}+\beta_{1}$
} 
El valor de marca (VM) viene dado por la diferencia de valoración que conlleva el conocimiento de la marca, es decir:

$$
\begin{gathered}
V M(\text { marca de fabricante })=\beta_{2} \\
V M(\text { marca de distribuidor })=\beta_{3}
\end{gathered}
$$

$Y$ finalmente, el valor percibido (VP) viene dado por la suma de los anteriores 0 , lo que es igual, por las valoraciones dadas cuando se conoce la marca. Es decir:

$$
\begin{gathered}
V P(\text { marca de fabricante })=\beta_{0}+\beta_{2} \\
V P(\text { marca de distribuidor })=\beta_{0}+\beta_{1}+\beta_{3}
\end{gathered}
$$

La Tabla 4.2 muestra los resultados de estimación de este modelo. Se incorporaron, como variables de control, el nivel de ingresos y el sexo de los participantes, aunque su papel no resultó significativo. Adicionalmente, el Gráfico 4.1 representa los valores estimados para las magnitudes de interés en este estudio: valor objetivo, valor de marca y valor percibido.

Tabla 4.2. Marca de distribuidor vs. fabricante: resultados de estimación

\begin{tabular}{lc} 
& Coeficientes \\
\hline Constante & $3,410^{\star \star *}$ \\
MD & $-0,181^{* *}$ \\
MFxC & $0,672^{\star \star *}$ \\
MDxC & $-0,061$ \\
Sexo & 0,040 \\
Ingresos & $-0,003$ \\
\hline$R^{2}$ & $0,403^{* * *}$ \\
$F$ & $23,864^{* * *}$ \\
\hline${ }^{* * *} p<0,01 ;{ }^{* *} p<0,05 ;{ }^{*} p<0,10$ &
\end{tabular}




\section{Gráfico 4.1. Valores percibido, objetivo y de marca estimados}

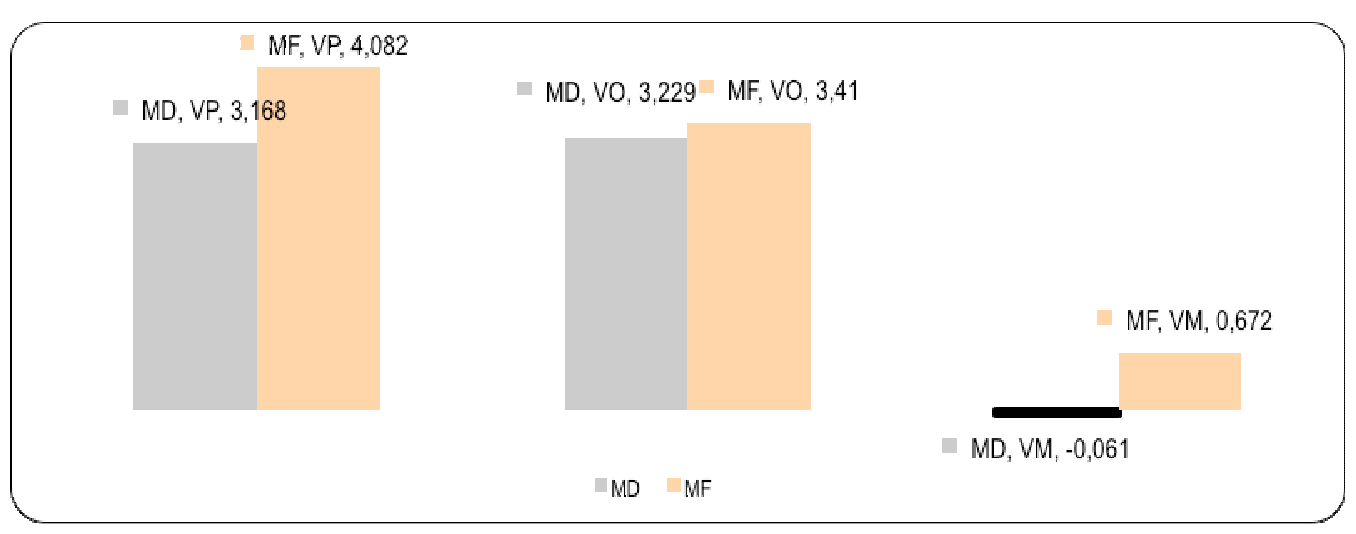

El análisis de los resultados relativos al valor objetivo (VO) permite apreciar que la valoración de la marca de distribuidor es significativamente inferior a la de la marca de fabricante. Es decir, cuando los consumidores degustan del producto desconociendo la marca y conociendo únicamente los ingredientes, la valoración asignada a las marcas de fabricante es superior a la valoración asignada a las marcas de distribuidor. Este resultado sugiere rechazar H1. Parece que la calidad objetiva de las marcas de distribuidor es inferior a la de las marcas de fabricante.

Por otro lado, los resultados relativos al valor de marca (VM) evidencian claramente que el valor de la marca de distribuidor es inferior al de la marca de fabricante. El efecto de conocer la marca es positivo para la marca de fabricante y negativo para la marca de distribuidor, aunque solo es significativo en el primer caso. Por tanto, para la marca de fabricante, el conocimiento de la marca supone un incremento significativo de la valoración de las marcas de fabricante. Por el contrario, para la marca de distribuidor, el conocimiento de la marca no conlleva una variación significativa de la valoración. Estos resultados están en línea con $\mathrm{H} 2$.

Puesto que la marca de fabricante parece significativamente beneficiada en ambos aspectos del valor, el valor objetivo y el valor de marca, los resultados para el valor percibido (VP) evidencian una clara ventaja de la marca de 
fabricante respecto a la marca de distribuidor. La degustación del producto conociendo la marca conlleva una mejor valoración de la marca de fabricante.

\subsubsection{Cartera de marcas de distribuidor versus marcas nacionales}

Una segunda fase de análisis ha profundizado en el análisis previo estudiando el valor de marca para las distintas marcas de distribuidor y fabricante consideradas en el diseño experimental. El efecto de las dos variables controladas, la marca y el conocimiento de la marca, sobre las valoraciones realizadas por los consumidores participantes en el experimento ha llevado a cabo estimando el siguiente modelo:

$$
\begin{gathered}
Y=\beta_{O}+\beta_{1} L I N D T+\beta_{2} N 1+\beta_{3} C A R R+\beta_{4} C A R R S E L \\
+\beta_{5}(N E S T L E x C)+\beta_{6}(\text { LINDTxC })+\beta_{7}(N 1 x C)+\beta_{8}(C A R R x C)+\beta_{9}(C A R R S E L x C)
\end{gathered}
$$

donde $Y$ sigue siendo la valoración realizada por los participantes; NESTLE, LINDT, N1, CARR y CARRSEL son variables binarias que toman valor 1 cuando el consumidor ha degustado, respectivamente, la marca Nestle, Lindt, Numero 1, Carrefour y Carrefour Selección; y $C$ denota de nuevo una variable binaria que toma valor 1 cuando el consumidor es consciente de la marca degustada.

La estimación del modelo permite cuantificar las magnitudes de interés en este estudio. El valor objetivo (VO) viene dado por la valoración realizada por los participantes cuando desconocen la marca, es decir:

$$
\begin{gathered}
V O(\text { Nestle })=\beta_{0} \\
V O(\text { Lindt })=\beta_{0}+\beta_{1} \\
V O(\text { Numero } 1)=\beta_{0}+\beta_{2} \\
V O(\text { Carrefour })=\beta_{0}+\beta_{3} \\
V O(\text { Carrefour Selección })=\beta_{0}+\beta_{4}
\end{gathered}
$$


El valor de marca (VM) viene dado por la diferencia de valoración que conlleva el conocimiento de la marca, es decir:

$$
\begin{gathered}
V M(\text { Nestle })=\beta_{5} \\
V M(\text { Lindt })=\beta_{6} \\
V M(\text { Numero } 1)=\beta_{7} \\
V M(\text { Carrefour })=\beta_{8} \\
V M(\text { Carrefour Selección })=\beta_{9}
\end{gathered}
$$

$Y$ finalmente, el valor percibido (VP) viene dado por la suma de los anteriores 0 , lo que es igual, por las valoraciones dadas cuando se conoce la marca. Es decir:

$$
\begin{gathered}
V P(\text { Nestle })=\beta_{0}+\beta_{5} \\
V P(\text { Lindt })=\beta_{0}+\beta_{1}+\beta_{6} \\
V P(\text { Numero })=\beta_{0}+\beta_{2}+\beta_{7} \\
V P(\text { Carrefour })=\beta_{0}+\beta_{3}+\beta_{8} \\
V P(\text { Carrefour Selección })=\beta_{0}+\beta_{4}+\beta_{9}
\end{gathered}
$$

La Tabla 4.3. muestra los resultados de estimación de este modelo. Se incorporaron, como variables de control, el nivel de ingresos y el sexo de los participantes, aunque su papel no resultó significativo. Adicionalmente, el Gráfico 4.2 representa los valores estimados para las magnitudes de interés en este estudio: valor objetivo, valor de marca y valor percibido. Para facilitar el análisis, la Tabla 4.4 incluye además los contrastes de diferencias entre marcas. 
Tabla 4.3. Marcas de distribuidor vs. fabricante: resultados de estimación

\begin{tabular}{lc}
\hline Constante & Coeficientes \\
LINDT & $3,447^{* * *}$ \\
N1 & $-0,109$ \\
CARR & $-0,183$ \\
CARRSEL & $-0,409^{* *}$ \\
NESTLExC & $-0,099$ \\
LINDTxC & $0,665^{\star * *}$ \\
N1xC & $0,687^{* * *}$ \\
CARRxC & $-0,303^{* *}$ \\
CARRSELxC & 0,082 \\
Sexo & 0,035 \\
Ingresos & 0,053 \\
\hline$R^{2}$ & $-0,001$ \\
F & $0,428^{* * *}$ \\
\hline${ }^{* * *} p<0,01 ;{ }^{* *} p<0,05 ;{ }^{*} p<0,10$ & $12,409^{* * *}$
\end{tabular}

Gráfico 4.2. Valores percibido, objetivo y de marca estimados

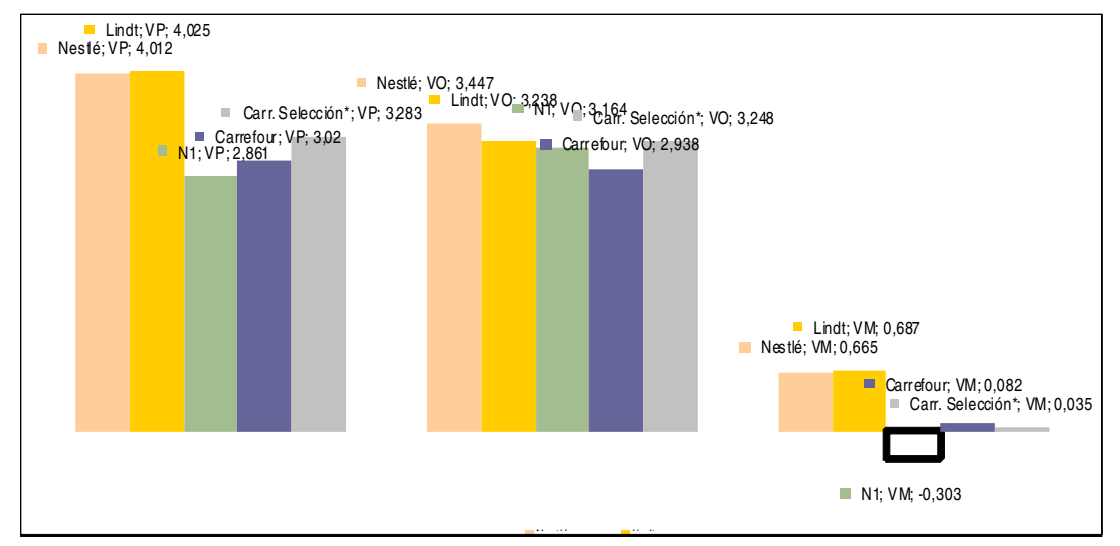


Tabla 4.4. Diferencias entre marcas

\begin{tabular}{|c|c|c|c|c|c|c|c|c|}
\hline & \multicolumn{4}{|c|}{ Valor Objetivo (VO) } & \multicolumn{4}{|c|}{ Valor de Marca (VM) } \\
\hline & Lindt & $\begin{array}{c}\text { Numero } \\
1\end{array}$ & Carrefour & $\begin{array}{l}\text { Carrefour } \\
\text { Selección }\end{array}$ & Lindt & $\begin{array}{c}\text { Numero } \\
1\end{array}$ & Carrefour & $\begin{array}{l}\text { Carrefour } \\
\text { Selección }\end{array}$ \\
\hline Nestle & n.s. & n.s. & ** & n.s. & n.s. & ${ }^{* \star *}$ & ** & ** \\
\hline Lindt & & n.s. & ** & n.s. & & $* \star *$ & ** & $* * *$ \\
\hline $\begin{array}{l}\text { Numero } \\
1\end{array}$ & & & * & n.s. & & & ** & * \\
\hline Carrefour & & & & $\star \star *$ & & & & n.s. \\
\hline
\end{tabular}

Este análisis no solamente permite evaluar las diferencias entre posicionamientos de marca de distribuidor, sino también estudiar con mayor profundidad las cuestiones analizadas en la fase previa. Atendiendo al valor objetivo (VO), únicamente la marca Carrefour recibe una valoración significativamente inferior al resto de marcas. No hay diferencias significativas en la valoración objetiva del resto de marcas. Este resultado pone en duda el rechazo generalizado de H1. Los resultados solo sugieren el rechazo para una de las tres marcas de distribuidor analizada. En el resto de casos, los consumidores no aprecian diferencias objetivas entre la marca de distribuidor y las marcas de fabricante.

Los resultados encontrados sugieren también el rechazo de $\mathrm{H} 3$, porque hay diferencias significativas en la valoración objetiva de los distintos posicionamientos de marca de distribuidor. Sin embargo, sorprende que las diferencias observadas no sigan el patrón que cabría esperar. En línea con el 
posicionamiento en calidad de las marcas de distribuidor, cabría esperar la peor valoración para la marca genérica, esto es Número 1. Por el contrario, como ya se ha apuntado, no se aprecian diferencias significativas respecto a las marcas de fabricante. Tampoco en el caso de la marca premium, esto es Carrefour Selección. Por tanto, el resultado evidencia que, aunque existen diferencias en la valoración objetiva de las marcas, estas no se corresponden necesariamente con el posicionamiento de las marcas.

Atendiendo al valor de marca (VM), el valor de todas las marcas de distribuidor es significativamente inferior al de todas las marcas de fabricante. Este resultado evidencia aun más claramente lo propuesto en H2. Las marcas de distribuidor siguen teniendo una desventaja en cuanto al valor de marca, incluso en lo que respecta a las marcas premium.

Los resultados relativos a la marca genérica evidencian el posicionamiento pretendido. Cuando los participantes son conscientes de que degustan la marca genérica, ésta resulta significativamente penalizada. Sin embargo, no se aprecian diferencias significativas entre las marcas estándar y premium, esto es Carrefour y Carrefour Selección. Consecuentemente, los resultados soportan $\mathrm{H} 4$ respecto a la diferencias entre marca genérica y las otras marcas de distribuidor, pero sugieren rechazar $\mathrm{H} 4$ respecto a las diferencias entre marca premium y las otras marcas de distribuidor. Este resultado pone además de manifiesto la dificultad que implica desarrollar marcas de distribuidor premium.

Atendiendo al valor percibido (VP), esto es, a la valoración asignada por los consumidores participantes cuando conocen la marca de los productos degustados, las diferencias reflejan fundamentalmente las diferencias en cuanto al valor de marca. En definitiva, el valor de marca parece ser el aspecto más determinante en la valoración de las distintas marcas que integran una categoría de productos. La notoriedad, imagen y reputación de la marca parece estar por encima de los atributos intrínsecos de los productos. 


\subsection{Conclusiones e implicaciones}

Este trabajo ha tratado de aportar evidencia empírica sobre el valor objetivo, valor de marca y valor percibido de las marcas de distribuidor frente a las marcas de fabricante. Asimismo, también se han comparado algunos posicionamientos habituales en la cartera de marcas de distribuidor, concretamente la estrategia de tres escalones: marca genérica, estándar y premium, analizando cómo afectan al valor objetivo, valor de marca y valor percibido.

Los resultados de este trabajo muestran que, aislando el papel del precio, las marcas de distribuidor tienen un valor percibido inferior a las marcas de fabricante. Esta diferencia se debe principalmente a que las marcas de fabricante tienen mayor valor de marca que las marcas de distribuidor. Aunque también se aprecia una valoración objetiva de las marcas de distribuidor inferior a la de las marcas de fabricante. Sin embargo, la realización de un análisis más detallado diferenciando distintos tipos de marca de distribuidor desvela que esta diferencia en el valor objetivo no es necesariamente consistente con el posicionamiento de las marcas. En la categoría de productos analizada, el valor objetivo de la marca estándar resultó inferior al de la marca genérica. La consistencia con el posicionamiento competitivo es mayor en el caso del valor de marca. Las marcas genéricas resultan claramente penalizadas en el valor de marca. Aunque en este caso no se aprecian diferencias entre las marcas estándar y premium, que además presentan una clara desventaja respecto a la marcas de fabricante. En cualquier caso, se aprecia que la valoración percibida está más condicionada por el valor de marca que por una evaluación objetiva de las cualidades de los productos.

Los resultados obtenidos conducen a una serie de implicaciones tanto para los distribuidores como para los fabricantes. La posesión de marcas fuertes, marcas de alto valor, se ha demostrado que reporta beneficios a la empresa; por ejemplo, la mayor lealtad de los consumidores o la menor vulnerabilidad de esas marcas a las acciones de la competencia (Aaker, 1993; Keller, 1998). Por ello, tanto distribuidores como fabricantes están interesados en desarrollar 
estrategias que les permitan potenciar la reputación y credibilidad de sus marcas. Los resultados obtenidos acentúan la importancia de estas estrategias: el valor de marca determina en gran medida la valoración percibida por los consumidores, mucho más que una valoración objetiva de sus características.

Los distribuidores parecen estar todavía en desventaja respecto a las marcas de fabricante en términos de la creación de reputación de marca. Si bien han conseguido vencer la percepción inicial de las marcas de distribuidor como alternativas de baja calidad con el éxito obtenido en las marcas estándar o copia, parece que el desarrollo de marcas premium capaces de competir en los niveles más altos de calidad no resulta una tarea sencilla. Para que las marcas premium alcancen mayor reputación y credibilidad, los distribuidores tendrán que desarrollar un marketing más intenso, invirtiendo para conseguir desligar sus marcas premium de las asociaciones que tradicionalmente han acompañado a las marcas de distribuidor. Se trata de crear marcas de alta calidad e imagen con asociaciones fuertes en la mente del consumidor, a través de una estrategia que las diferencie de la competencia, tanto de fabricantes como de otros minoristas. Un ejemplo de marca premium exitosa es President's Choice desarrollada por la cadena de supermercados canadiense Loblaws. Esta marca tiene un mensaje de marketing que enfatiza la calidad de los ingredientes y la preparación de los productos. Esta marca es tan popular que la cadena la ha licenciado a otros distribuidores en Estados Unidos para su venta (Dunne y Narasimhan, 1999).

Otro elemento clave para los distribuidores es la dificultad que tienen los consumidores para valorar de forma objetiva los productos, y la escasa importancia que parece tener en la valoración global. Los minoristas tendrán que seguir trabajando para conseguir el aprendizaje de los consumidores con respecto a los elementos objetivos de los productos, a través de distintas herramientas como, por ejemplo, la prueba de marcas de distribuidor en sus establecimientos (Beldona y Scott ,2007) o la entrega de muestras de productos para mejorar la valoración de sus marcas. 
Respecto a las marcas de fabricante, se observa que al menos las marcas líderes siguen conservando una ventaja de imagen y reputación. Beldona y Scott (2007) señalan que los fabricantes invierten mucho más que los distribuidores en el desarrollo de sus marcas. Eso provoca un mayor conocimiento y una mayor preferencia de los consumidores hacia las marcas de fabricante. Sin embargo, dada la evolución de las marcas de distribuidor en términos de cuota y sofisticación en la estrategia de marcas de distribuidor (Martos-Partal y González-Benito, 2009), la ventaja se está reduciendo (Steenkamp, van Heerde y Geykens, 2010) y los fabricantes tendrán que seguir invirtiendo en sus marcas para al menos mantener las distancias usando estrategias que ayuden a mantener su reputación construyendo valor al consumidor. Las estrategias de inversión en innovación parecen estar dando buenos resultados para competir con las marcas de distribuidor (Kumar y Steenkamp, 2007b; Quelch y Harding, 1996; Martos-Partal, 2012; Steiner, 2004; Steenkamp, van Heerde y Geykens, 2010), así como el uso combinado de innovación y publicidad (Steenkamp, van Heerde y Geykens, 2010).

Este estudio no está exento de limitaciones que requieren una investigación futura. En el trabajo se ha analizado una única categoría, tabletas de chocolate con leche, y un único minorista, Carrefour. En cuanto a las marcas de fabricante, únicamente se han considerado marcas de alta reputación. Un análisis en otras enseñas, en otras categorías, utilitarias o de búsqueda, y que considere otras marcas de fabricante con menor reputación podría llevar a resultados diferentes a los obtenidos en este trabajo. Otra limitación se debe al uso de una muestra de conveniencia, estudiantes universitarios, que puede dar a una visión parcial de la realidad en cuanto a la compra de productos de gran consumo. Por otro lado, en el diseño experimental únicamente se han controlado dos variables, el tipo de marca y el conocimiento de la marca. No se han considerado otras posibles variables de interés ( $p$. e., niveles de ingredientes, sabores, envases, etc). Además, no se ha considerado la posibilidad de comparación entre las marcas en lo que respecta a sus características técnicas. Los consumidores no suelen evaluar los ingredientes de un producto en términos absolutos, sino comparándolos con los de otras marcas. 
También se han obviado una serie de factores que pueden influir en la valoración de la marca. Por ejemplo, la familiaridad con la marca (Richardson, Jain y Dick, 1996, De Wulf et al 2005), la actitud hacia las marcas de distribuidor (Zielke y Dobbelstein, 2007; Puccinelli et al, 2009), la lealtad hacia el establecimiento (Kumar y Steenkamp 2007b, Ailawadi, Neslin y Gedenk, 2001 y Ailawadi y Keller 2004), o la imagen del establecimiento (Semeijn, van Riel y Ambrosini , 2004). Una línea de investigación futura podría analizar el efecto de estas variables sobre la valoración de marcas de distribuidor con distintos posicionamientos. 


\subsection{Referencias}

ACNielsen. (2005): "The Power of Private Label in Europe. An Insight into Consumer Attitudes". http://www2.acnielsen.com/reports/documents/2005_cc_privatelabel.pdf.

Aaker, David A. (1994), "Gestión Del Valor De La Marca: Capitalizar El Valor De La Marca". Madrid: Díaz de Santos.

Ailawadi, Kusum L. (2001), "The retail power performance conundrum: what have we learned?" Journal of Retailing, 77 (3): 299-318

Ailawadi Kusum L. y Kevin L. Keller (2004), "Understanding retail branding: conceptual insights and research priorities", Journal of Retailing, 80 (4): 331342

Apelbaum, Eidan, Eitan Gerstner y Prasad A. Naik (2003), "The effects of expert quality evaluations versus brand name on price premiums," The Journal of Product and Brand Management, 12 (3): 154-165

Alimarket (2007). "Carrefour inaugura nueva era en marcas propias". http://alimarket.es/noticia/mr204010/CARREFOUR-INAUGURA-NUEVA-ERAEN-MARCAS-PROPIAS

Batra, Rajeev y Indrajit Sinha (2000), "Consumer-level factors moderating the success of private label brands," Journal of Retailing, 76 (2): 175-191

Beldona, Sri y Scott Wysong (2007), "Putting the "brand" back into store brands: an exploratory examination of store brands and brand personality," The Journal of Product and Brand Management, 16 (4): 226-235.

Bellizi, Joseph A., Harry Krueckeberg, John Hamilton y Martin, W. (1981). "Consumer perceptions of national, private, and generic brands", Journal of Retailing, 57 (4), 56-70. 
Burt, Steve (2000), "The strategic role of retail brands in british grocery retailing," European Journal of Marketing, 34 (8): 875-890

Christodoulides, George y Leslie de Chernatony (2010), "Consumer based brand equity conceptualization and measurement: a literature review" International Journal of Market Research 52(1): 43-66.

Choi, S. Chan. y Anne T. Coughlan (2006), "Private label positioning: quality versus feature differentiation from the national brand," Journal of Retailing, 82 (2): 79-93.

Cunningham, Isabella C. M., Andrew P. Hardy y Giovanna Imperia (1982), "Generic brands versus national brands and store brands: a comparison of consumers' preferences and perceptions", Journal of Advertising Research, 22 (7-8): 25-32

Davies, Gary (1990), "Marketing to retailers: a battle for distribution?" Long Range Planning, 23 (6): 101-108.

Davies, Gary y Eliane Brito (2004), "Price and quality competition between brands and own brands: a value systems perspective," European Journal of Marketing, 38 (1): 30-55.

De Wulf, Kristof, Gaby Odekerken-Schröder, Frank Goedertier y Gino Van Ossel (2005), "Consumer perceptions of store brands versus national brands," The Journal of Consumer Marketing, 22 (4): 223-232.

Dunne, David y Chakravarthi Narasimhan (1999), "The new appeal of private labels," Harvard Business Review, 77 (May/Jun), 41-52

Erdem, Tulin, Ying Zhao y Ana Valenzuela (2004), "Performance of store brands: a cross-country analysis of consumer store-brand preferences, perceptions, and risk", Journal of Marketing Research, 41 (Feb), 86-100. 
Erdem, Tulin y Joffre Swait (1998), "Brand equity as a signaling phenomenon", Journal of Consumer Psychology, 7 (2): 131-157.

Farquhar, Peter H. (1990), "Managing brand equity," Journal of Advertising Research, 30 (4): 7-11

Fornerino, Marianela y François d'Hauteville (2010), "How good does it taste? Is it the product or the brand? A contribution to brand equity evaluation," The Journal of Product and Brand Management, 19 (1): 34-43

Geyskens, Inge, Katrijn Gielens y Els Gijsbrechts (2010): "Proliferating privatelabel portfolios: how introducing economy and premium private labels influences brand choice", Journal of Marketing Research, 47 (5), 791-807.

Ghose, Sanjoy y Oded Lowengart (2001), "Taste tests: impacts of consumer perceptions and preferences on brand positioning strategies," Journal of Targeting, Measurement and Analysis for Marketing, 10 (Aug), 26-41.

Harris, Brian F. y Roger A. Strang (1985), "Marketing strategies in the age of generics," Journal of Marketing, 49 (Fall), 70-81.

Jacoby, Jacob, Jerry C. Olson y Rafael A Haddock (1971). "Price, brand name, and product characteristics as determinants of perceived quality", Journal of Applied Psychology, 55 (6): 570-579.

Juhl, Hans. Jorn, Lars Esbjerg, Klaus G. Grunert y Tino Bech-Larsen (2006), "the fight between store brands and national brands-what's the score?" Journal of Retailing \& Consumer Services, 13 (09): 331-338.

Keller, Kevin L. (1993), "Conceptualizing, measuring, and managing customerbased brand equity," Journal of Marketing, 57 (Jan), 1-22

Keller, Kevin L. (1998), "Strategic brand management: building, measuring and managing brand equity," Prentice Hall. 
Keller, Kevin L. (2000), "The brand report card," Harvard Business Review, 78 (Jan/Feb): 147-157

Keller, Kevin L. (2001), "Building customer-based brand equity," Marketing Management, 10 (Jul/Aug): 14-19.

Keller, Kevin L. y Donald R. Lehmann (2006), "Brands and branding: research findings and future priorities," Marketing Science, 25 (6): 740-759.

Kotler, Philip y Gary Armstrong (1995), “Princípios de Marketing”, Prentice Hall

Kumar, Nirmalya y Jan-Benedict E. M. Steenkamp (2007a), "Private label strategy: how to meet the store brand challenge," Harvard Business School Press.

Kumar, Nirmalya y Jan-Benedict E. M. Steenkamp (2007b), "Brand versus brand," International Commerce Review, 7 (1): 47-53

Lybeck, Annika, Maria Holmlund-Rytkonen y Maria Saaksjarvi (2006), "Store brands vs. manufacturer brands: consumer perceptions and buying of chocolate bars in finland". Int. Rev. of Retail, Distribution and Consumer Research, 16 (4): $471-492$

Martos-Partal, Mercedes (2012), "Innovation and the market share of private labels", Journal of Marketing Management, 28 (5-6): 695-715

Martos-Partal, Mercedes y Óscar González-Benito (2009), “¿Qué busca el comprador de marcas de distribuidor? Caracterización del comprador de marca de distribuidor por beneficios buscados", Universia Business Review, 24: 76-95

Martos-Partal, Mercedes y Óscar Gónzalez-Benito (2011), "Store brand and store loyalty: the moderating role of store brand positioning". Marketing Letters, 22 (3): 297-313 
McEnally, Martha R. (1984), "The market for generic brand grocery products: a review and extension," Journal of Marketing 48 (Winter), 75-83.

Mendéz, José Luiz, Javier Oubiña y Natalia Rubio (2008), "Expert quality evaluation and price of store vs. manufacturer brands: an analysis of the spanish mass market," Journal of Retailing and Consumer Services, 15 (3):144155

Mowen, John C. (1995), "Consumer Behaviour", 4th edn, Prentice Hall

Nenycz-Thiel, Magda y Jenni Romaniuk (2009), "Perceptual categorization of private labels and national brands," The Journal of Product and Brand Management, 18 (4): 251-261.

Private Label Manufacturers Association, PLMA (http://plma.com/storeBrands/sbt10.html-accesed 24-1-2011)

Puccinelli, Nancy M, Ronald C. Goodstein, Dhruv Grewal, Robert Price, Priya Raghubir y David Stewartf (2009), "Customer experience management in retailing: understanding the buying process," Journal of Retailing, 85 (1), 15-30.

Quelch, John A. y David Harding (1996), "Brands versus private labels: fighting to win," Harvard Business Review, 74 (Jan/Feb), 99.

Richardson, Paul S. (1997), "Are store brands perceived to be just another brand?" The Journal of Product and Brand Management, 6 (6): 388-404

Richardson, Paul S., Alan S. Dick, y Arun K. Jain (1994), "Extrinsic and intrinsic cue effects on perceptions of store brand quality," Journal of Marketing, 58 (4): 28-36

Richardson, Paul S., Arun K. Jain, y Alan Dick (1996), "Household store brand proneness: a framework," Journal of Retailing, 72 (2): 159-185 
Sayman, Serdar, Stephen J. Hoch, y Jagmohan S. Raju (2002), "Positioning of store brands," Marketing Science, 21 (4): 378-397

Semeijn, Janjaap, Allard C. R. van Riel y Ana Beatriz Ambrosini (2004), "Consumer evaluations of store brands: effects of store image and product attributes," Journal of Retailing and Consumer Services, 11 (4): 247-58.

Sethuraman, Raj (2006), "Private-label marketing strategies in packaged goods: management beliefs and research insights," Marketing Science Institute Working Paper, 27-44.

Sethuraman, Raj y Catherine Cole (1999), "Factors influencing the price premiums that consumers pay for national brands over store brands," The Journal of Product and Brand Management, 8 (4): 340-351

Sloot, Laurens M., Peter C. Verhoef y Philip H. Franses (2005), "The impact of brand equity and the hedonic level of products on consumer stock-out reactions," Journal of Retailing, 81 (1): 15-34.

Soberman, David A. y Philip M. Parker (2006), "The Economics of qualityequivalent store brands," International Journal of Research in Marketing, 23 (Jun), 125-139

Steenkamp, J-B, van Heerde, H.J y Geykens, I. (2010). "What Makes Consumers Willing to Pay a Price Premium for National Brands over Private Labels?", Journal of Marketing Research, 47 (6), 1011-1024

Steiner, Robert L. (2004), "The nature and benefits of national brand/private label competition", Review of Industrial Organization, 24 (105): 105-127

Suh, Jung-Chae (2009), "The role of consideration sets in brand choice: the moderating role of product characteristics," Psychology \& Marketing, 26 (6): 534-550. 
Wilke, Ricky y Judith L. Zaichkowsky (1999), "Brand imitation and its effects on innovation, competition, and brand equity," Business Horizons, 42 (6): 9-18.

Yelkur, Rama (2000), "Consumer perceptions of generic products: a Mexican study," The Journal of Product and Brand Management, 9 (7): 446-456.

Yoo, Boonghee, Naveen Donthu y Sungho Lee (2000), "An examination of selected marketing mix elements and brand equity," Academy of Marketing Science.Journal, 28 (2): 195-211.

Zielke, Stephan y Thomas Dobbelstein (2007), "Customers' willingness to purchase new store brands," The Journal of Product and Brand Management, 16 (2): 112-121. 
CARACTERIZACIÓN MOTIVACIONAL DEL COMPRADOR DE MARCA DE DISTRIBUIDOR: DIFERENCIAS ENTRE POSICIONAMIENTOS 


\section{CARACTERIZACIÓN MOTIVACIONAL DEL COMPRADOR DE MARCA DE DISTRIBUIDOR: DIFERENCIAS ENTRE POSICIONAMIENTOS}

\subsection{Introdución}

El crecimiento de las marcas de distribuidor representa una de las tendencias más notables en el mercado minorista en las últimas décadas (Szymanowski y Gijsbrechts, 2012). Según la PLMA (Private Label Manufacturers Association, 2010), las marcas de distribuidor están más fuertes que nunca. Estas marcas han alcanzado un $40 \%$ de cuota de mercado en 5 países Europeos. Asimismo, en los Estados Unidos, uno en cada cuatro productos vendidos es marca de distribuidor.

Las marcas de distribuidor surgieran originariamente como alternativas baratas a las marcas nacionales. Este posicionamiento inicial, reforzado por años de precios bajos, ha llevado los consumidores a asociar las marcas de distribuidor con un nivel de calidad más bajo que el de las marcas nacionales líderes (Soberman y Parker 2006). Sin embargo, esa tendencia ha ido cambiando. Tal y como señala Corstjens y Lal (2000), muchos distribuidores ofrecen para marcas de distribuidor de mayor calidad debido a la mayor capacidad de para mejorar la rentabilidad. Esta evolución en la calidad también ha sido percibida por los consumidores: una investigación global realiza por Nielsen en 2011, 37\% a internautas pone de manifiesto que los consumidores perciben las marcas de distribuidor como una buena alternativa frente a las marcas nacionales (ACNielsen, 2011). Otros estudios, como Baltas y Argouslidis (2007), muestran que las preferencias de los consumidores de marcas de distribuidor provienen de un amplio proceso de evaluación en que la calidad tiene un papel principal, de tal forma los fabricantes no pueden asumir que las marcas de distribuidor son sólo alternativas baratas compradas por quienes no pueden pagar las marcas nacionales. Por tanto, es importante resaltar el extraordinario cambio tanto en la calidad como en las percepciones 
de las marcas de distribuidor que son vistas como alternativas atractivas a los productos de marcas nacionales.

Con la creciente popularidad de las marcas de distribuidor, muchos minoristas manejan una cartera de marcas propias que incorpora múltiples propuestas de valor con una oferta de varios escalones, diseñada para atender una demanda diferenciada en términos de calidad y precio de distintos consumidores. Esta estrategia es común entre los minoristas Europeos y está empezando a cruzar el Atlántico, puesto que tener una cartera de marcas propias permite al distribuidor penetrar en distintos segmentos de consumidores de manera simultánea (IRI 2007; Kumar y Steenkamp 2007). La tendencia más reciente en el mercado minorista es la oferta de una marca de distribuidor premium junto con las marcas genéricas y estándar, que son los tipos de marcas de distribuidor más comunes y dominantes en el mercado. Las marcas de distribuidor premium deben ofrecer alta calidad y representar productos únicos y tienen un precio similar o superior a las marcas nacionales (Kumar y Steenkamp, 2007; Quelch y Harding, 1996). Considerando este nuevo escenario competitivo, las marcas de distribuidor no pueden ser analizadas de manera agregada. Tal y como señalan Palmeira y Thomas (2011) es sorprendente que esa realidad de múltiples escalones no haya recibido más atención por la investigación en marketing.

En este nuevo contexto, la caracterización de los compradores de marcas de distribuidores, a pesar de haber sido uno de los temas de investigación pioneros en esta área, permanece como un tema de relevancia y de actualidad. El extraordinario crecimiento en ventas de dichas marcas así como su creciente heterogeneidad hace necesario revisar este tema para explorarlo más profundamente. En ese sentido, la caracterización motivacional y por beneficios buscados de los compradores de marcas de distribuidor parece adecuada puesto que revela la verdadera razón de consumo para cada tipo de marca (Haley, 1968). La caracterización motivacional de comprador de marcas de distribuidor a través de los distintos posicionamientos en precio-calidad ha recibido poca atención, especialmente cuando se habla del nivel más alto de calidad (marcas premium). El objetivo de este artículo es comprehender como 
el posicionamiento de la marca de distribuidor afecta el perfil del consumidor de estas marcas analizando sus motivaciones y beneficios buscados.

A pesar de la aparente simplicidad de la propuesta, investigaciones empíricas previas no han analizado esta cuestión de manera explícita. Además, este artículo es único en una serie de aspectos. En primer lugar, el artículo analiza el efecto del posicionamiento competitivo de la marca de distribuidor genérica, estándar y premium. Segundo, se consideran minoristas con una estrategia de marcas propias con múltiples escalones, es decir, minoristas que ofrecen simultáneamente distintas marcas propias con diferentes posicionamientos en calidad-precio, y se comparan las marcas propias ofrecidas por el mismo minorista $y$, por lo tanto, se minimiza el efecto del posicionamiento del minorista. Tercero, este estudio utiliza datos objetivos sobre el comportamiento de compra y datos subjetivos para analizar la motivación de compra. Cuarto, puesto que la variable dependiente consiste en la cuota de gasto asignada a los distintos tipos de marcas, el análisis se basa en un modelo logit fraccional multinomial.

En los contenidos subsiguientes se aborda primeramente una revisión de las investigaciones previas con el fin de argumentar las hipótesis de trabajo. Seguidamente se describe la metodología seguida en el análisis empírico y se interpretan y comentan los resultados alcanzados. En una última sección se sintetizan las principales conclusiones e implicaciones.

\subsection{Marco Teórico e Hipótesis}

\subsubsection{Cartera de marcas de distribuidor}

Las marcas de distribuidor fueron tradicionalmente percibidas como alternativas de calidad inferior con por precios bajos (Bellizi et al. 1981; Cunningham, Hardy e Imperia, 1982; Richardson, Dick y Jain, 1994; Sethuraman 2006), no obstante, esa percepción ha cambiado en los últimos 
años. Resultados recientes muestran que el efecto del precio en la calidad percibida ha disminuido (Völckner y Hofmann, 2007) y a pesar de que las marcas de distribuidor son vendidas a precios inferiores (Sethuraman y Cole 1999), cada vez más estas marcas son vistas como marcas con nivel de calidad que puede ser comparable a las marcas nacionales. Las marcas de distribuidor han evolucionado de manera positiva en términos de la calidad percibida (Quelch y Harding 1996; Steenkamp, van Heerde y Geykens 2010), evolución que ha sido puesta de manifiesto tanto por expertos (Apelbaum, Gerstner y Naik, 2003; Méndez, Oubiña y Rubio, 2008) como por consumidores. Según la investigación global online realizada por ACNielsen en 2011, más de uno en cada tres encuestados (37\%) perciben las marcas de distribuidor como una buena alternativa a las marcas de fabricantes (ACNielsen, 2011). Davies y Brito (2004), De Wulf et al. (2005), y Fornerino y d'Hauteville (2010) confirman tal mejora en la calidad a través de testes ciegos: cuando los consumidores no conocen la marca, no difieren en sus percepciones entre marcas de distribuidor y marcas nacionales.

La oferta de marcas de distribuidor ha evolucionado hasta tal nivel que los minoristas no comercializan solamente una marca, sino una cartera de marcas a fin de atender, simultáneamente, a distintos segmentos de mercado con marcas de distribuidor con diferentes posicionamientos en calidad y precio (Geyskens, Gielens y Gijsbrechts, 2010; Kumar y Steenkamp 2007). Una de las estrategias más comunes adoptadas por los minoristas en su cartera de marca es la estrategia de tres escalones. Esta estrategia de marcas de distribuidor en tres niveles sigue una aproximación de "bueno, mejor, lo mejor": se incluye una línea de marcas económicas y otra premium adicionalmente a la marca estándar tradicional propia del distribuidor que lleva tiempo en el mercado (Ailawadi y Keller, 2004).

En concreto, las marcas estándar son las marcas tradicionales posicionadas como una alternativa equilibrada en términos de calidad y precio (Geyskens, Gielens y Gijsbrechts, 2010). Normalmente siguen una estrategia de imitación de las marcas nacionales, ofreciendo calidad similar, pero a un precio más bajo (Kumar y Steenkamp, 2007). Estas marcas son las más 
rápidas en lanzar las versiones copiadas porque tienen una mayor probabilidad de imitar y necesitan menos tiempo para llegar al mercado (Sinapuelas y Robinson, 2009). Las marcas genéricas, a su vez, enfatizan el uso básico del producto, posicionándose como la alternativa más barata debido a sus actividades promocionales limitadas, envases más sencillos y economías en los ingredientes más caros (Yelkur 2000; Cunningham, Hardy e Imperia, 1982; Harris y Strang 1985; Geyskens, Gielens y Gijsbrechts, 2010). Estas marcas son especialmente usadas en las guerras de precios puesto que enfatizan y destacan la sensibilidad al precio (Corstjens y Lal, 2000). El cambio más importante de las marcas de distribuidores, ha sido tal y como apuntaban Dunne y Narasimhan (1999), las marcas posicionadas como las mejores del mercado. Minoristas Europeos y Americanos están introduciendo marcas propias cuya calidad es comparable e incluso excede a la de los de productos de marcas conocidas, aún cuando a veces se comercializan con un precio ligeramente más bajo. Las marcas premium se posicionan en el nivel más alto del mercado con una calidad igual a las marcas nacionales de calidad premium (Geyskens, Gielens y Gijsbrechts, 2010; Kumar y Steenkamp, 2007). Uno de los objetivos de los distribuidores al usar marcas premium es diferenciarse de sus competidores y mejorar su imagen (Kumar y Steenkamp, 2007). En resumen, los posicionamientos de marcas de distribuidor en el continuo calidad-precio son: las marcas genéricas, seguidas por las marcas estándar y las marcas premium como las marcas con el nivel más alto en la cartera de marcas del distribuidor.

Dada la oferta actual de marcas de distribuidor, es evidente que estas marcas no pueden ser analizadas de manera agregada. Cada tipo de marca atiende a un segmento de consumidores distintos y, por lo tanto, su adquisición deberá ser motivada por aspectos distintos. El efecto moderador del posicionamiento de la marca en la motivación y beneficios buscados en la compra de marcas de distribuidor es un tema que todavía no ha sido analizado por las investigaciones precedentes. 


\subsubsection{Perfil motivacional de los compradores de marcas de distribuidor}

Inicialmente las características demográficas y socioeconómicas fueron las más usadas para caracterizar a los compradores de marcas de distribuidores, sin embargo el impacto de características personales como género, ingresos, edad, tamaño del hogar y educación han mostrado evidencias débiles e incluso opuestas (Baltas y Argouslidis, 2007). De tal forma que las motivaciones subyacentes a la compra empezaron a ser consideradas. El énfasis en la caracterización basada en motivaciones y beneficios buscados se debe a que estas constituyen la verdadera razón de consumo (Haley, 1968). A pesar de su importancia, hay escasa evidencia sobre la las motivaciones y su relación con la compra de marcas de distribuidor.

Además, teniendo en cuenta la evolución de las marcas de distribuidor y la amplia oferta de estas marcas en el continuo calidad-precio, resulta inapropiado hacer un único perfil de comprador de marcas de distribuidores. El posicionamiento de cada marca de distribuidor debe ser considerado y este debe afectar a las motivaciones subyacentes y beneficios buscados en la compra de cada tipo de marca de distribuidor. Palmeira y Tomas (2011) enfatizan este tema señalando que "que cuando a los consumidores se les ofrecen dos marcas de la misma compañía en la misma categoría, estos van pensar que debe haber alguna diferencia entre ellas, sino ¿por qué habrían de tener dos marcas?" Los resultados de dicho estudio muestran que, por ejemplo, la expectativa de calidad de los consumidores para una marca de distribuidor premium es más elevada cuando el distribuidor tiene también una marca propia posicionada en valor además de la marca estándar. Por lo tanto, se espera que otros aspectos motivacionales también difieran para marcas de distribuidor genéricas, estándar y premium. Hasta la fecha, pocas investigaciones han comparado las motivaciones del consumidor entre los distintos posicionamientos en calidad-precio de las marcas de distribuidor (Bellizi et al., 1981, Cunningham, Hardy e Imperia, 1982), y se han enfocado casi exclusivamente en comparaciones entre marcas genéricas y estándar. 
Sensibilidad al precio: El diferencial de precio entre marcas de distribuidor y marcas de fabricantes todavía aún es una base importante para vender marcas de distribuidor. Se cree que las marcas de distribuidor ganan ventas ofreciendo la marca a precios más bajos que las marcas de fabricantes (Raju, Sethurama y Dhar, 1995). En media, las marcas de distribuidor son entre un 10-30 por ciento más baratas que marcas de fabricantes en la categoría de alimentación (Baltas, 1997). Por eso la sensibilidad al precio es una motivación importante entre los compradores de marcas de distribuidor (Baltas y Argouslidis, 2007; Cunningham, Hardy e Imperia, 1982; Dick, Jain y Richardson, 1995; Hansen, Singh y Chintagunta, 2006; Sinha y Batra, 1999). Respecto a la cartera de marcas de distribuidor y su diferencial de precios respecto a las marcas de fabricantes, las marcas de distribuidor se posicionan de manera diferenciada en el continuo calidad-precio. La alternativa más barata disponible es la marca genérica; las marcas estándar se posicionan en el nivel medio (Burt, 2000) mientras que las marcas premium son vendidas con el menor diferencial de precio e incluso algunas veces, con ninguna diferencia de precio (por ejemplo la marca premium de Tesco "Tesco's Finest", se vende a precios más elevados que algunas marcas de fabricantes - Kumar y Steenkamp, 2007). Tal posicionamiento en calidad-precio debe afectar a la elección de los consumidores sensibles a precio: se espera que consumidores sensibles a precio prefieran la alternativa más barata disponible - las marcas genéricas, seguida de las marcas estándar y marcas premium.

H1: El posicionamiento de las marcas de distribuidor modera la relación entre la compra de marcas de distribuidor y la sensibilidad al precio, de manera que la sensibilidad al precio para marcas genéricas es más elevada que para marcas estándar, y la sensibilidad al precio para marcas estándar es más elevada que para marcas premium

Propensión a la promoción: La propensión a la promoción está asociada a un bajo coste de búsqueda y a una disposición a la búsqueda y utilización de cupones (Sudhir y Talukdar, 2004). Con el avance de las marcas de 
distribuidor, los fabricantes usan las promociones para evitar la migración de los consumidores hacia esas marcas (Garretson, Fisher y Burton, 2002), y el consumidor propenso a la promoción es atraído a comprar estos ítems en lugar de comprar marcas de distribuidor. Por lo tanto, en general, tal aspecto motivacional debería ser negativamente relacionado a la compra de marcas de distribuidor (Baltas 1997, Burton et al., 1998). No obstante, los minoristas que ofrecen marcas propias de calidad más elevada a precios más elevados pueden usar la promoción como herramienta para motivar la compra de esas marcas. Por otro lado, las marcas de distribuidor genérica raramente son promocionadas (Kumar y Steenkamp, 2007). Por esa razón, se espera que las marcas de distribuidor posicionadas en calidad y precio más elevados sean más atractivas para los compradores que buscan promociones que las marcas posicionadas en menor calidad/menor precio.

H2: El posicionamiento de las marcas de distribuidor modera la relación entre la compra de marcas de distribuidor y la propensión a la promoción, de manera que la propensión a la promoción para marcas genéricas y estándar es menor que para marcas premium

Sensibilidad a la calidad del servicio: La búsqueda de calidad de servicio está relacionada también con la búsqueda de calidad en los productos. En este sentido, consumidores sensibles a la calidad son disuadidos a la hora de comprar marcas de distribuidor, puesto son percibidas como marcas de calidad inferior (Cunningham, Hardy e Imperia, 1982; Richardson, Jain y Dick, 1996). Estudios empíricos previos confirman tal afirmación (Ailawadi, Neslin y Gedenk, 2001; Ailawadi, Pauwels y Steenkamp, 2008). Sin embargo, estos estudios previos no consideran el posicionamiento de las marcas de distribuidor. En este trabajo se asume que la sensibilidad a la calidad de servicio está relacionada con la búsqueda de calidad en los productos. De tal forma que los, consumidores motivados por la calidad de servicio deberán ser más atraídos por marcas de distribuidor posicionadas en calidad, y no en precio. 
H3: El posicionamiento de las marcas de distribuidor modera la relación entre la compra de marcas de distribuidor y la sensibilidad a la calidad de servicio, de manera que la sensibilidad a la calidad de servicio para marcas genéricas es más baja que para marcas estándar, y la sensibilidad a la calidad de servicio para marcas estándar es más baja que para marcas premium

Diversión en la compra: Hay consumidores que consideran la compra no como un medio para un fin, sino como un fin en sí mismo y que consideran la compra como una actividad recreativa (Williams, Slama y Rogers, 1985). No existen resultados concluyentes sobre la diversión en la compra; algunos estudios han encontrado una relación negativa (Ailawadi, Pauwels, y Steenkamp 2008) y otros no han encontrado una relación significativa entre la diversión en la compra y la compra de marcas de distribuidor (Ailawadi, Neslin y Gedenk, 2001; Martínez y Montaner, 2008). El análisis de diferentes marcas de distribuidor en el continuo calidad-precio puede esclarecer estas inconsistencias. Williams, Slama y Rogers (1985) muestran que los consumidores buscadores de diversión prefieren productos y servicios asociados a precios más elevados como marcas de fabricantes y tiendas reconocidas. En general, no son consumidores de descuentos. En este sentido, los consumidores buscadores de diversión deberán sentirse menos atraídos por las marcas genéricas y más atraídos por las marcas premium. Por otro lado, Cox, Cox y Anderson (2005) sugieren que la búsqueda de gangas puede ser una de las mayores fuentes de diversión en la compra, lo que afectaría positivamente la compra de marcas de distribuidor. Siguiendo tal razonamiento, por su diferencial de precio, en este caso las marcas genéricas deberían ser las preferidas en lugar de las marcas premium. En este trabajo, sin embargo, se considera que dado que las marcas genéricas enfatizan el uso básico del producto y son más comúnmente encontradas en el área de ítems de alimentación de baja implicación (Prendergast y Marr, 1997), estas marcas deberán estar menos relacionadas con la diversión en la compra. Por otro lado, los minoristas están haciendo un esfuerzo para desarrollar atributos hedónicos 
y mejorar sus marcas propias con un marketing más atractivo, como envases más agradables e inversiones en publicidad, etc (Burt, 2000; Kumar y Steenkamp, 2007). Este esfuerzo debería ser especialmente notable en las marcas premium. Por lo tanto, se propone que:

H4: El posicionamiento de las marcas de distribuidor modera la relación entre la compra de marcas de distribuidor y la diversión en la compra, de manera que la diversión en la compra para marcas genéricas es más baja que para marcas estándar, y la diversión en la compra para marcas estándar es más baja que para marcas premium

Propensión a la innovación: El grado de innovación del consumidor tiene que ver con su propensión a experimentar y comprar productos nuevos y diferentes (Xie, 2008). Además, consumidores innovadores sirven como modelos y líderes fuerte de opinión en el mercado, llevando parte del mercado a seguirles (Schreier, Oberhauser y Prügl 2007). Las evidencias previas no son concluyentes acerca de la relación entre la propensión a la innovación de los consumidores y la compra de marcas de distribuidores. Gómez y Rubio (2010) sugieren una relación negativa mientras que otros autores no han encontrado evidencias de relación (Ailawadi, Neslin y Gedenk, 2001, Baltas y Argouslidis, 2007, Martínez y Montaner 2008). No obstante, la literatura previa afirma que las marcas de distribuidor premium son un fenómeno reciente y pretenden ofrecer calidad similar o superior respecto a las marcas de fabricantes líderes (Quelch y Harding, 1996). Considerando tal nivel de novedad, debería esperarse que los consumidores innovadores se sientan más atraídos hacia dichas marcas en lugar de hacia las marcas tradicionales estándar y genérica. Entonces:

H5: El posicionamiento de las marcas de distribuidor modera la relación entre la compra de marcas de distribuidor y la propensión a la innovación, de manera que la propensión a la innovación para marcas genéricas es 
más baja que para marcas estándar, y la propensión a la innovación para marcas estándar es más baja que para marcas premium

Sensibilidad a la marca: Park, Yu y Zhou (2010) definen los compradores sensibles a la marca como aquéllos más orientados a las marcas más caras y conocidas y que no hacen demasiadas comparaciones sobre la calidad y atributos de los productos. La marca sirve como un indicador de calidad en la medida que aporta al consumidor un conjunto de informaciones sobre el producto (Jacoby, Chestnut y Fisher, 1978). Shannon y Mandhachitara (2008) destacan que hay una creencia común de que las marcas reconocidas ofrecen mayor calidad y que cuanto mayor es el precio mayor es la calidad del producto. La sensibilidad a la marca y la compra de marcas de distribuidor ha sido escasamente investigada. Algunas evidencias indican que consumidores con actitudes más positivas hacia las marcas de distribuidor y aquellos con más marcas de distribuidor en su cesta de la compra están menos orientados a la marca (Baltas y Argouslidis, 2007). Eso sugiere que la sensibilidad a la marca está inversamente relacionada con la elección de marcas de distribuidor. Sin embargo, debería esperarse que consumidores sensibles a la marca prefieran a las marcas de distribuidor tipo premium, puesto que dichas marcas están posicionadas en calidad, tienen precio superior y los minoristas están invirtiendo más en el marketing de estas marcas premium (Kumar y Steenkamp, 2007). Un buen ejemplo es la marca "President's Choice", del supermercado Canadiense Loblaws: este minorista ha creado una marca de alta calidad y buena imagen, con asociaciones fuertes en la mente de los consumidores a través de una estrategia de diferenciación. El mensaje de marketing enfocado a la calidad de los ingredientes y en la preparación del producto, y la marca se ha vuelto tan popular que Loblaws ha licenciado la marca licencia para otros minoristas de Estados Unidos mientras que las marcas tradicionales genéricas y estándar son vistas como "category killers" baratas e imitaciones (Dunne y Narasimhan, 1999), y por tanto, deberían ser menos preferidas por los consumidores sensibles a la marca. 
H5: El posicionamiento de las marcas de distribuidor modera la relación entre la compra de marcas de distribuidor y la sensibilidad a la marca, de manera que la sensibilidad a la marca para marcas genéricas es más baja que para marcas estándar, y la sensibilidad a la marca para marcas estándar es más baja que para marcas premium

\subsection{Metodología}

Para analizar empíricamente el papel del posicionamiento de la marca de distribuidor en la caracterización motivacional de sus compradores nos centramos en cadenas de distribución minoristas que comercialicen una cartera de marcas de distribuidor con distintos posicionamientos. De esta manera, comparando las marcas propias de un mismo distribuidor, es posible aislar el papel del posicionamiento de la marca de distribuidor del papel del posicionamiento del propio distribuidor.

Concretamente, el estudio se centra en dos cadenas de distribución minorista que operan en el mercado español: Carrefour y Eroski. El Informe Anual de la Distribución Alimentaria de 2008 realizado por Alimarket situaba a estas cadenas en segundo y tercer lugar en cuanto a ventas en el mercado español en 2007 (Alimarket, 2008). Ambas cadenas han operado tradicionalmente con el formato de hipermercado, aunque en los últimos años también han abierto establecimientos de menor tamaño clasificables como supermercados. Ambas cadenas están posicionadas en servicio frente a la apuesta en precio de los establecimientos de descuento.

Dentro de la cartera de marcas propias de Carrefour destacan las marcas "Número 1", "Carrefour" y "De nuestra tierra" (en la actualidad Carrefour Discount, Carrefour y Carrefour Selección, respectivamente), que corresponden respectivamente a los posicionamientos genérico, estándar y premium. En la cartera de marcas propias de Eroski también destacan tres marcas propias, "Eroski", "Eroski Selección" y "Eroski Deleitte de nuestra tierra" (en la actualidad 
estas dos últimas marcas se comercializan respectivamente como Eroski SeleQtia y Eroski Natur Selección). Esas tres marcas se corresponden con los posicionamientos estándar (Eroski) y premium (Eroski Selección y Eroski Deleitte de nuestra tierra).

Para realizar el análisis empírico, se cuenta con datos del historial de compra en la categoría de productos de alimentación en una muestra de más de 2000 hogares representativos de la población española procedentes del Panel de Hogares de TNS (ahora KantarWorldPanel). Dentro de la categoría de alimentación se engloban las categorías de: alimentación seca, conservas, leche y batidos, bebidas, productos frescos no perecederos y productos frescos perecederos, congelados, derivados lácteos, quesos, pastelería y bollería y platos cocinados. Los datos corresponden a un periodo temporal de un año comprendidos entre el segundo semestre de 2007 y el primer semestre de 2008. Los miembros del panel usan un escáner en casa para registrar todas las compras del hogar en todos los establecimientos de distribución españoles para posteriormente enviar electrónicamente todos los datos a TNS.

Los datos disponibles permiten calcular la distribución del presupuesto de cada hogar entre las enseñas comerciales, pudiéndose definir los clientes de una enseña como aquellos hogares con un gasto en la enseña superior o igual al $1 \%$ de sus compras durante el periodo estudiado. La caracterización motivacional de la compra de marca de distribuidor se realiza independiente para Carrefour y Eroski considerando respectivamente estas muestras de clientes.

Los datos también permiten calcular la distribución del presupuesto de cada hogar cliente de una enseña comercial entre las distintas marcas de distribuidor comercializadas por la enseña. Esta distribución de gasto constituye las variables dependientes del estudio. La relación entre estas cuotas de gasto y las características del consumidor permiten establecer un perfil del comprador de cada marca de distribuidor y compararlo a través de los distintos posicionamientos. 
Adicionalmente se dispone de información procedente del cuestionario sobre opiniones y actitudes suministrado por KantarWorldPanel a más de 4000 panelistas (julio 2008). Esta información sirve para cuantificar las motivaciones o beneficios buscados en la compra por el panelista. Se partió de una selección de los ítems incluidos en dicho cuestionario conforme al marco teórico establecido. Es decir, de las 160 preguntas planteadas en el cuestionario se consideraron únicamente los ítems que se correspondían con los beneficios buscados expuestos previamente. Los ítems se miden en una escala tipo likert de 5 puntos ( 1 - totalmente en desacuerdo, 5 - totalmente de acuerdo).

Sobre esta selección de ítems se realizó un análisis factorial de componentes principales con rotación Varimax para identificar las dimensiones de beneficios buscados subyacentes. Como resultado del análisis factorial se obtuvieron 6 factores consistentes con las motivaciones planteadas en el marco teórico. Dichos factores se interpretan como: 1) sensibilidad a precios; 2) propensión a la promoción; 3) sensibilidad a la calidad del servicio; 4) diversión en la compra; 5) propensión a la innovación; y 6) sensibilidad a la marca. En la Tabla 5.1 se detallan los ítems utilizados, sus estadísticos descriptivos y los resultados de una análisis de componentes principales. La varianza explicada por los seis factores es superior al $62 \%$ y los valores del Alpha de Cronbach superan el 0.7 o están muy próximos a dicho valor (sensibilidad a la marca). En el análisis posterior, como medidas de los beneficios buscados se utilizarán las puntuaciones factoriales resultantes de este análisis.

Los datos de panel también proporcionan información sociodemográfica de los hogares, que es tenida en cuenta en el estudio a modo de variables de control. Concretamente, se dispone de información sobre el tamaño del hogar, la existencia de niños menores de 6 años en el hogar y la clase social. El tamaño del hogar es una variable de recuento que toma valores de 1 a 8 , donde el 8 representa a hogares de 8 o más miembros. Presencia de niños es una variable indicador que identifica con un valor de 1 a los hogares con niños menores de 6 años. La clase social distingue cuatro niveles socioeconómicos: baja (clase social 1), media baja (clase social 2), media (clase social 3 ) y alta y media alta (clase social 4). 
Tabla 5.1. Ítems descriptivos y análisis factorial exploratorio

\begin{tabular}{|c|c|c|c|c|c|c|}
\hline Factores & Ítem & Media & D.T & $\begin{array}{l}\text { Carga } \\
\text { Factori } \\
\text { al }\end{array}$ & V.E & $\begin{array}{c}\text { Alfa de } \\
\text { Cronbac } \\
\mathbf{h}\end{array}$ \\
\hline $\begin{array}{l}\text { Sensibilidad } \\
\text { al precio }\end{array}$ & $\begin{array}{l}\text { Siempre comparo precios entre diferentes } \\
\text { marcas antes de elegir una } \\
\text { Comparo precios para aprovechar ofertas } \\
\text { especiales } \\
\text { Busco los productos en oferta } \\
\text { Visito diferentes tiendas para aprovechar los } \\
\text { mejores precios }\end{array}$ & $\begin{array}{l}3,698 \\
3,860 \\
3,576 \\
3,192\end{array}$ & $\begin{array}{l}0,821 \\
0,753 \\
0,807 \\
1,040\end{array}$ & $\begin{array}{l}0,775 \\
0,690 \\
0,662 \\
0,603\end{array}$ & $\begin{array}{c}11,10 \\
2\end{array}$ & 0,746 \\
\hline $\begin{array}{l}\text { Sensibilidad } \\
\text { a la } \\
\text { promoción }\end{array}$ & $\begin{array}{l}\text { Me gusta participar en las promociones que se } \\
\text { ofrecen en paquetes y etiquetas } \\
\text { Uso los cupones de descuento cuando tengo la } \\
\text { oportunidad } \\
\text { Me gusta participar en promociones que me } \\
\text { regalan cantidad extra de producto o un } \\
\text { producto diferente, } \\
\text { Me informo de las promociones a través de los } \\
\text { folletos de los establecimientos }\end{array}$ & $\begin{array}{l}3,387 \\
4,026 \\
3,652 \\
3,658\end{array}$ & $\begin{array}{l}0,928 \\
0,822 \\
0,821 \\
0,831\end{array}$ & $\begin{array}{l}0,734 \\
0,649 \\
0,711 \\
0,502\end{array}$ & 9,357 & 0,706 \\
\hline $\begin{array}{l}\text { Sensibilidad } \\
\text { a la calidad } \\
\text { del servicio }\end{array}$ & $\begin{array}{l}\text { No me importa de pagar más por la calidad } \\
\text { A la hora de hacer la compra, prefiero ir a una } \\
\text { tienda bien organizada, aunque sea un poco } \\
\text { más cara } \\
\text { A la hora de hacer la compra, prefiero ir a una } \\
\text { tienda más cuidada, aunque sea un poco más } \\
\text { cara } \\
\text { A la hora de hacer la compra, prefiero ir a una } \\
\text { tienda que me atienda bien, aunque sea un } \\
\text { poco más cara }\end{array}$ & $\begin{array}{l}3,525 \\
3,218 \\
3,268 \\
3,357\end{array}$ & $\begin{array}{l}0,737 \\
0,829 \\
0,823 \\
0,827\end{array}$ & $\begin{array}{l}0,497 \\
0,887 \\
0,925 \\
0,875\end{array}$ & $\begin{array}{c}12,38 \\
4\end{array}$ & 0,845 \\
\hline $\begin{array}{l}\text { Diversión en } \\
\text { la compra }\end{array}$ & $\begin{array}{l}\text { Me gusta hacer la compra } \\
\text { Me gusta emplear el menor tiempo posible } \\
\text { cuando hago la compra }\end{array}$ & $\begin{array}{l}3,493 \\
3,317\end{array}$ & $\begin{array}{l}1,014 \\
0,929\end{array}$ & $\begin{array}{l}0,770 \\
-0,834\end{array}$ & 6,161 & $-0,359^{* *}$ \\
\hline $\begin{array}{l}\text { Propensión a } \\
\text { la innovación }\end{array}$ & $\begin{array}{l}\text { En general soy de los primeros que compran } \\
\text { productos nuevos cuando aparecen en el } \\
\text { mercado } \\
\text { Suelo ser de los primeros en probar marcas } \\
\text { nuevas } \\
\text { Me gusta probar nuevos productos } \\
\text { Me gusta probar nuevas marcas } \\
\text { Disfruto arriesgándome con la compra de } \\
\text { nuevos productos }\end{array}$ & $\begin{array}{l}2,508 \\
2,511 \\
3,087 \\
3,080 \\
2,532\end{array}$ & $\begin{array}{l}0,802 \\
0,799 \\
0,756 \\
0,709 \\
0,749\end{array}$ & $\begin{array}{l}0,807 \\
0,811 \\
0,780 \\
0,782 \\
0,752\end{array}$ & $\begin{array}{c}14,15 \\
9\end{array}$ & 0,854 \\
\hline $\begin{array}{l}\text { Sensibilidad } \\
\text { a la marca }\end{array}$ & $\begin{array}{l}\text { Me considero leal a la marca } \\
\text { Tiendo a comprar productos de marca } \\
\text { Decido qué marcas comprar antes de salir a } \\
\text { hacer la compra } \\
\text { Para mí es importante que marca compro }\end{array}$ & $\begin{array}{l}3,088 \\
2,836 \\
2,705 \\
3,266\end{array}$ & $\begin{array}{l}0,898 \\
0,851 \\
0,916 \\
0,780\end{array}$ & $\begin{array}{l}0,714 \\
0,639 \\
0,662 \\
0,739\end{array}$ & 9,493 & 0,686 \\
\hline
\end{tabular}

Notas: D.T (desviación típica), V.E (varianza extraída) y * correlación. 
Se combinaron los datos motivacionales del cuestionario con los datos de gasto y perfil sociodemográfico de los clientes de cada enseña obtenidos del panel, utilizándose en los análisis posteriores únicamente los hogares presentes en ambas muestras. Esto supone una muestra de 838 clientes para Carrefour y 595 clientes para Eroski. La Tabla 5.2 contiene estadísticos descriptivos para todas las variables construidas e implicadas en el estudio.

\section{Tabla 5.2. Analisis descriptivo}

\begin{tabular}{|c|c|c|c|c|c|c|c|c|}
\hline & \multicolumn{4}{|c|}{$\begin{array}{c}\text { CARREFOUR } \\
\text { (CLIENTES: } 838 \text { ) }\end{array}$} & \multicolumn{4}{|c|}{$\begin{array}{c}\text { EROSKI } \\
\text { (CLIENTES: } 595 \text { ) }\end{array}$} \\
\hline & Media & D.T & Min. & Max. & Media & D.T & Min. & Max. \\
\hline \multicolumn{9}{|c|}{ COMPORTAMIENTO DE COMPRA } \\
\hline Lealtad al establecimiento & 0,160 & 0,175 & 0,010 & 0,848 & 0,185 & 0,206 & 0,010 & 0,900 \\
\hline Lealtad MD global & 0,222 & 0,163 & 0 & 0,949 & 0,139 & 0,147 & 0 & 0,911 \\
\hline Lealtad MD genérica & 0,023 & 0,041 & 0 & 0,321 & & & & \\
\hline Lealtad MD estándar & 0,195 & 0,151 & 0 & 0,949 & 0,138 & 0,146 & 0 & 0,911 \\
\hline Lealtad MD premium & 0,002 & 0,020 & 0 & 0,462 & 0,001 & 0,005 & 0 & 0,070 \\
\hline \multicolumn{9}{|c|}{ SOCIODEMOGRÁFICOS } \\
\hline Clase social 1 (baja) & 0,119 & 0,324 & 0 & 1 & 0,156 & 0,363 & 0 & 1 \\
\hline $\begin{array}{l}\text { Clase social } 2 \text { (media- } \\
\text { baja) }\end{array}$ & 0,243 & 0,429 & 0 & 1 & 0,265 & 0,441 & 0 & 1 \\
\hline Clase social 3 (media) & 0,394 & 0,489 & 0 & 1 & 0,392 & 0,488 & 0 & 1 \\
\hline $\begin{array}{l}\text { Clase social } 4 \text { (alta- } \\
\text { media/alta) }\end{array}$ & 0,242 & 0,428 & 0 & 1 & 0,186 & 0,389 & 0 & 1 \\
\hline Tamaño del hogar & 3,130 & 1,124 & 1 & 8 & 3,092 & 1,134 & 1 & 8 \\
\hline Presencia de niños & 0,441 & 0,496 & 0 & 1 & 0,434 & 0,496 & 0 & 1 \\
\hline \multicolumn{9}{|c|}{ RASGOS MOTIVACIONALES } \\
\hline Sensibilidad al precio & 0,056 & 0,994 & $-3,243$ & 3,555 & $-0,008$ & 1,001 & $-3,606$ & 2,960 \\
\hline $\begin{array}{l}\text { Sensibilidad a la } \\
\text { promoción }\end{array}$ & 0,100 & 0,985 & $-3,360$ & 3,014 & 0,032 & 0,958 & $-3,360$ & 2,758 \\
\hline $\begin{array}{l}\text { Sensibilidad a la calidad } \\
\text { del servicio }\end{array}$ & $-0,035$ & 1,001 & $-3,336$ & 2,823 & 0,004 & 0,991 & $-3,060$ & 2,594 \\
\hline Diversión en la compra & 0,001 & 1,027 & $-3,009$ & 2,826 & 0,048 & 1,041 & $-3,001$ & 2,658 \\
\hline $\begin{array}{l}\text { Propensión a la } \\
\text { innovación }\end{array}$ & 0,065 & 1,020 & $-3,204$ & 4,011 & 0,010 & 0,984 & $-2,968$ & 3,548 \\
\hline Sensibilidad a la marca & $-0,033$ & 1,003 & $-2,893$ & 3,504 & $-0,075$ & 0,998 & $-3,130$ & 3,464 \\
\hline
\end{tabular}

Notas: MD (marca de distribuidor), D.T (desviación típica) 


\subsection{Análisis y resultados}

Las variables dependientes consideradas en este trabajo vienen dadas por la distribución del gasto de los hogares entre las distintas marcas de distribuidor ofrecidas por el minorista. Las variables independientes utilizadas hacen referencia a las motivaciones o beneficios buscados por los hogares. También se considera el perfil sociodemográfico de los hogares como variables de control.

Puesto que la variable dependiente viene dada por las cuotas de gasto asignadas a las distintas marcas, es decir, son valores comprendidos entre $0 \mathrm{y}$ 1 , y suman 1 a través de todos los tipos de marcas diferenciadas, los análisis realizados se basan en un modelo logit multinomial fraccional (fractional multinomial logit model). Específicamente, se propone la siguiente relación:

$$
\begin{aligned}
& \pi_{i j}=\frac{e^{\alpha_{j}+\lambda_{j} Z_{i}+\beta_{j} B_{i}}}{1+\sum_{j} e^{\alpha_{j}+\lambda_{j} Z_{i}+\beta_{j} B_{i}}} \\
& \pi_{i 0}=\frac{1}{1+\sum_{j} e^{\alpha_{j}+\lambda_{j} Z_{i}+\beta_{j} B_{i}}}
\end{aligned}
$$

donde $\pi \mathrm{ij}$ denota la cuota de gasto del hogar i en la marca de distribuidor $\mathrm{j}$ (donde j recorre los distintos posicionamientos de marca de distribuidor) y $\pi$ io denota la cuota de gasto del hogar i en marcas de fabricante; $\alpha$ j denota un parámetro a estimar que cuantifica la tendencia de gasto en la marca de distribuidor j; Zi es el vector de las variables sociodemográficas para el hogar $\mathrm{i}$; $\lambda \mathrm{j}$ denota un vector de parámetros a estimar que recoge el efecto de la variables sociodemográficas (una de las clases sociales debe tomarse como referencia con parámetro nulo); Bi es el vector de las variables de beneficios buscados del hogar $\mathrm{i} ; \beta \mathrm{j}$ denota un vector de parámetros a estimar correspondiente a los efectos de los beneficios buscados. Nótese que las 
marcas de fabricante se toman como referencia y que el efecto de las características de los hogares en la compra de las distintas marcas de distribuidor se cuantifica respecto a dichas marcas de fabricante.

Para la estimación del modelo se utilizó la rutina fmlogit de Stata (Maarten, 2008). Las tablas 5.3 y 5.4 contienen los resultados de estimación para Carrefour y Eroski respectivamente. Estas tablas también incluyen algunos test comparando los parámetros a través de los diferentes tipos de marcas de distribuidores.

Primero señalar que la constante es significativa con signo negativo; es decir, se observa una baja cuota de gasto en las marcas propias en ambos minoristas. Los resultados de la estimación también indican que entre las marcas de distribuidores, la marca estándar es la más consumida, esto es un resultado esperado dado que son las marcas de distribuidor con más tradición.

Los modelos indican algunas diferencias y semejanzas en el perfil sociodemográfico de los consumidores a través de los tipos de marcas de distribuidores. En general, el consumo de marcas de distribuidor tiende a disminuir cuando el nivel socioeconómico del hogar crece. Adicionalmente, esta relación inversa tiende a ser más intensa a medida en que la orientación en precio de las marcas de distribuidor aumenta. Con respecto al tamaño del hogar, el efecto es significativo solamente para Carrefour y tiende a ser negativo a medida que la calidad y precio de las marcas de distribuidor aumenta; en otras palabras, hogares más grandes revelan una mayor preferencia por marcas genéricas, seguidas de marcas estándar mientras que las marcas premium son las menos preferidas. También en Carrefour se detecta un efecto significativo de los hogares con niños; estos hogares tienden a comprar más marcas estándar y en mayor medida marcas premium. 
Tabla 5.3. Resultados de la estimación para Carrefour

\begin{tabular}{|c|c|c|c|c|c|c|c|}
\hline \multirow[b]{3}{*}{ Constante } & \multicolumn{4}{|c|}{ Parámetros } & \multicolumn{3}{|c|}{$\begin{array}{l}\text { Comparativo entre tipos de } \\
\text { marcas }\end{array}$} \\
\hline & Genérica & Estándar & $\begin{array}{l}\text { Premiu } \\
\text { m }\end{array}$ & $\begin{array}{c}\text { Marca } \\
\text { de } \\
\text { fabricant } \\
\text { e }\end{array}$ & $\begin{array}{c}\text { Genéric } \\
\text { a vs. } \\
\text { Estánda } \\
\text { r }\end{array}$ & $\begin{array}{c}\text { Genérica } \\
\text { vs. } \\
\text { Premium }\end{array}$ & $\begin{array}{c}\text { Estándar } \\
\text { vs. } \\
\text { Premium }\end{array}$ \\
\hline & $-3,562^{\star \star \star}$ & $-1,416^{\star * *}$ & ${ }^{-}-661^{\star \star *}$ & $0^{\mathrm{a}}$ & $* * *$ & * & *** \\
\hline \multicolumn{8}{|c|}{ VARIABLES DE CONTROL (sociodemográficos) } \\
\hline $\begin{array}{l}\text { Clase social } 2 \text { (media- } \\
\text { baja) }\end{array}$ & $-0,387^{*}$ & $-0,076$ & $-1,370^{* *}$ & $0^{\mathrm{a}}$ & & & ** \\
\hline Clase social 3 (media) & $-0,416^{\star \star}$ & $-0,070$ & $-0,962^{*}$ & $0^{\mathrm{a}}$ & & & * \\
\hline $\begin{array}{l}\text { Clase social } 4 \text { (alta- } \\
\text { Media/alta) }\end{array}$ & $-0,656^{* * *}$ & $-0,227^{*}$ & $-0,524$ & $0^{\mathrm{a}}$ & * & & \\
\hline Tamaño del hogar & $0,110^{*}$ & 0,013 & $-0,509^{* *}$ & $0^{\mathrm{a}}$ & * & *** & $* * *$ \\
\hline Presencia de niños & 0,075 & $0,148^{*}$ & $1,201^{*}$ & $0^{\mathrm{a}}$ & & * & * \\
\hline \multicolumn{8}{|c|}{ RASGOS MOTIVACIONALES } \\
\hline Sensibilidad al precio & $0,302^{\star \star \star}$ & $0,123^{\star \star *}$ & $\begin{array}{c}- \\
0,553^{* \star *}\end{array}$ & $0^{\mathrm{a}}$ & $* \star *$ & $* \star *$ & $* * *$ \\
\hline $\begin{array}{l}\text { Sensibilidad a la } \\
\text { promoción }\end{array}$ & 0,001 & 0,018 & 0,142 & $0^{\mathrm{a}}$ & & & \\
\hline $\begin{array}{l}\text { Sensibilidad a la } \\
\text { calidad del servicio }\end{array}$ & $-0,178^{* * *}$ & $-0,140^{* * *}$ & $0,906^{* * *}$ & $0^{\mathrm{a}}$ & & $* \star *$ & $* * *$ \\
\hline Diversión en la compra & 0,057 & 0,030 & 0,283 & $0^{\mathrm{a}}$ & & & \\
\hline $\begin{array}{l}\text { Propensión a la } \\
\text { innovación }\end{array}$ & 0,016 & $-0,022$ & $-0,272^{*}$ & $0^{\mathrm{a}}$ & & * & \\
\hline $\begin{array}{l}\text { Sensibilidad a la } \\
\text { marca }\end{array}$ & $-0,113^{\star *}$ & $-0,091^{\star \star \star}$ & $-0,367$ & $0^{\mathrm{a}}$ & & & \\
\hline
\end{tabular}

Bondad del ajuste

Test Razón de Verosimilitud: ***

${ }^{*} p<0,1 ;{ }^{* *} p<0,05 ;{ }^{* * *} p<0,01$

${ }^{a}$ Tipo de marca tomado como referencia con parámetros nulos. 
Tabla 5.4. Resultados de la estimación para Eroski

\begin{tabular}{|c|c|c|c|c|c|c|c|}
\hline \multirow[b]{3}{*}{ Constante } & \multicolumn{4}{|c|}{ Parámetros } & \multicolumn{3}{|c|}{$\begin{array}{c}\text { Comparativo entre tipos de } \\
\text { marcas }\end{array}$} \\
\hline & Genérica & Estándar & Premium & $\begin{array}{l}\text { Marca de } \\
\text { fabricante }\end{array}$ & $\begin{array}{c}\text { Genérica } \\
\text { vs. } \\
\text { Estándar }\end{array}$ & $\begin{array}{c}\text { Genérica } \\
\text { vs. } \\
\text { Premium }\end{array}$ & $\begin{array}{c}\text { Estándar } \\
\text { vs. } \\
\text { Premium }\end{array}$ \\
\hline & & $-2,125^{\star \star *}$ & $-6,337^{\star \star \star}$ & $0^{\mathrm{a}}$ & - & - & 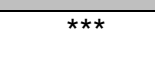 \\
\hline \multicolumn{8}{|c|}{ VARIABLES DE CONTROL (sociodemográficos) } \\
\hline $\begin{array}{l}\text { Clase social } 2 \text { (media- } \\
\text { baja) }\end{array}$ & & $-0,021$ & $-0,565$ & $0^{a}$ & - & - & \\
\hline Clase social 3 (media) & & 0,090 & $-0,815$ & $0^{a}$ & - & - & ** \\
\hline $\begin{array}{l}\text { Clase social } 4 \text { (alta- } \\
\text { media/alta) }\end{array}$ & & $-0,294^{*}$ & $-0,974$ & $0^{a}$ & - & - & \\
\hline Tamaño del hogar & & 0,060 & 0,101 & $0^{a}$ & - & - & \\
\hline Presencia de niños & & 0,171 & 0,146 & $0^{a}$ & & & \\
\hline \multicolumn{8}{|c|}{ RASGOS MOTIVACIONALES } \\
\hline Sensibilidad al precio & & $0,136^{* *}$ & $-0,104$ & $0^{\mathrm{a}}$ & - & - & ** \\
\hline $\begin{array}{l}\text { Sensibilidad a la } \\
\text { promoción }\end{array}$ & & $-0,012$ & 0,089 & $0^{a}$ & - & - & \\
\hline $\begin{array}{l}\text { Sensibilidad a la calidad } \\
\text { del servicio }\end{array}$ & & $-0,108^{\star *}$ & 0,109 & $0^{a}$ & - & - & ** \\
\hline Diversión en la compra & & 0,020 & $0,134^{*}$ & $0^{a}$ & - & - & \\
\hline $\begin{array}{l}\text { Propensión a la } \\
\text { innovación }\end{array}$ & & 0,032 & 0,045 & $0^{a}$ & - & - & \\
\hline Sensibilidad a la marca & & $-0,218^{\star \star *}$ & $-0,128$ & $0^{a}$ & - & - & \\
\hline
\end{tabular}

Bondad del ajuste

Test Razón de Verosimilitud: ***

${ }^{*} p<0,1 ;{ }^{* *} p<0,05 ;{ }^{* * *} p<0,01$

a Tipo de marca tomado como referencia con parámetros nulos. 
Con relación al afecto de los beneficios buscados en la compra de marcas de distribuidor, el posicionamiento de la marca realmente modera la relación entre el consumo de marcas propias y la sensibilidad al precio. En el caso de Carrefour, el parámetro de sensibilidad al precio disminuye a medida que el posicionamiento en calidad aumenta, es decir, es más elevado para marcas genéricas, seguidas por las marcas estándar y finalmente por las marcas premium. También, en el caso de Eroski, los compradores de marcas estándar son más sensibles al precio que los compradores de marcas premium. Estos resultados confirman $\mathrm{H} 1$. El supuesto papel moderador del posicionamiento de la marca de distribuidor en la relación entre propensión a la promoción y el consumo de marcas de distribuidor (H2) no pudo ser confirmado porque los efectos de estas variables no son significativos. En el caso de la sensibilidad a la calidad de servicios, los resultados revelan que su efecto en el consumo de marcas de distribuidor es negativo para marcas genéricas y estándar para Carrefour y para marcas estándar en el caso de Eroski. Tal efecto negativo desaparece para marcas premium, o bien se torna positivo en el caso de Carrefour. Tales resultados confirman $\mathrm{H} 3$ al menos para la diferencia entre marcas premium y el resto de las marcas de distribuidor consideradas. Con relación al efecto de la diversión en la compra, los resultados muestran pocos efectos significativos. El consumo de marcas premium parece estar positivamente relacionado con la búsqueda de diversión en el caso de Eroski. No obstante, no se encuentran diferencias significativas a través de los diferentes tipos de marcas de distribuidores. Consecuentemente, no se puede confirmar H4. Con respecto a la propensión a la innovación, las evidencias son contrarias a lo esperado. Mientras se ha propuesto que la propensión a la innovación debería estar más relacionada con el consumo de marcas tipo premium, los resultados para Carrefour sugieren lo opuesto, de manera que H5 no puede ser confirmada. Los consumidores de marcas premium parecen estar menos motivados por la innovación. Sin embargo, este resultado debe ser tomado con alguna cautela dado el bajo nivel de confianza (90\%). Finalmente, considerando la sensibilidad a la marca, se encuentra una relación negativa significativa para marcas genéricas y estándar en Carrefour y marcas estándar en Eroski. Estos efectos no son significativos para las marcas premium. Tal 
resultado está en línea con $\mathrm{H} 6$. Sin embargo, las diferencias entre los posicionamientos de marcas de distribuidor no son significativas.

Los resultados muestran algunas diferencias entre los minoristas analizados. Además, los resultados para Eroski son menos robustos que para Carrefour. Estos resultados tienen dos posibles explicaciones. Primero, desde un punto de vista estadístico, el tamaño de la muestra para los consumidores de Eroski es más pequeño que para Carrefour. Segundo, desde un punto de vista de marketing, la madurez de la cartera de marcas propias de estos distribuidores es distinta. Carrefour fue el primer distribuidor en España en lanzar sus marcas propias en 1982, mientras que Eroski ha finalizado la migración de sus marcas blancas hacia sus marcas Eroski en 1994. La percepción de cambio requiere de tiempo (Carrefour 2012, Eroski 2012).

En resumen, se puede decir que el posicionamiento de las marcas de distribuidor realmente modera la relación entre la compra de marcas de distribuidor y el perfil motivacional de los compradores de dichas marcas. La compra de marcas genéricas parece ser conducida por una mayor sensibilidad al precio y una menor sensibilidad a la calidad del servicio. En el otro extremo del continuo calidad-precio, los compradores de marcas premium podrían caracterizados como sensibles a la calidad del servicio, pero no sensibles a precio. También, parecen buscar diversión en la compra, ser menos sensible a la marca $\mathrm{y}$, sorprendentemente, menos innovadores, pero esta última característica debe ser asumida con cautela y requiere una mayor investigación.

\subsection{Conclusiones}

Una reciente tendencia en el mercado de distribución minorista es la gestión de múltiples marcas de distribuidor posicionadas diferentemente en el continuo precio-calidad. En este nuevo escenario, incluso aunque la caracterización del comprador de marcas de distribuidores haya sido un tema 
pionero de investigación en el área, es necesario revisarlo. Tal y como señalan Ailawadi et al (2010), se puede conjeturar que las marcas propias van a ganar aún más fuerza, por tanto, conocer a los consumidores más propensos a su compra es importante para tener ventajas en categorías en las que las marcas de distribuidor tienen mayor poder. Esta investigación se ha centrado en entender el impacto del posicionamiento de las marcas de distribuidor en la caracterización motivacional de los compradores de marcas de distribuidor.

Los resultados empíricos con muestras de consumidores de dos cadenas de distribución minoristas contribuye a la literatura existente indicando claras diferencias entre el perfil de comprador de las marcas de distribuidor genéricas, estándar y premium. Dicho de otra forma, el posicionamiento de las marcas de distribuidor realmente modera la caracterización motivacional de los compradores de dichas marcas. Cuando el posicionamiento de una marca prioriza la calidad en lugar del precio (marcas premium), atrae a consumidores de marcas de distribuidor más preocupados por la calidad del servicio y menos preocupados con el precio. Contrariamente, cuando el posicionamiento de la marca prioriza el precio (marcas genéricas), atrae a consumidores que con más sensibles al precio, pero no a la calidad del servicio. Los resultados también sugieren algunas diferencias con relación a la diversión en la compra, a la propensión a la innovación y a la sensibilidad a la marca.

Este trabajo presenta una serie de contribuciones respecto a la literatura previa. En primer lugar, se aporta a la literatura existente acerca de la caracterización del comprador de marcas de distribuidor al evidenciar empíricamente que sus rasgos motivacionales se ven afectados por el posicionamiento de la marca de distribuidor $\mathrm{y}$, por lo tanto, las marcas de distribuidor no pueden más ser analizadas como un agregado. El fenómeno de marcas de distribuidor actualmente es muy heterogéneo y la respuesta del consumidor depende de las peculiaridades que caracterizan cada marca de distribuidor específica. Segundo, los resultados contribuyen al creciente interés en investigar carteras de marcas de distribuidor y su variado posicionamiento competitivo. Muchas investigaciones recientes han apuntado la necesidad de 
entender las implicaciones de tal fenómeno (Geyskens, Gielens y Gijsbrechts, 2010; Palmeira y Thomas 2011, Martos-Partal y González-Benito, 2011).

Los resultados obtenidos conducen a una serie de interpretaciones e implicaciones para los distintos agentes implicados en el sector de la distribución. . En primer lugar, las marcas de distribuidor claramente no son todas iguales y cada tipo de marca atrae a un segmento de consumidor distinto (Corstjens y Lal, 2000). En otras palabras, los distribuidores pueden gestionar una cartera de marcas propias en que las marcas no compitan entre sí. En segundo lugar, el posicionamiento de las marcas de distribuidor en el continuo calidad-precio elegido por los distribuidores ha sido bien realizado y asimilado por los consumidores. Los esfuerzos en los últimos años de muchos distribuidores en mejorar la percepción de sus marcas propias a través del desarrollo de marcas de alta calidad-alto precio parecen haber valido la pena. Los distribuidores deben mantenerlo, dado que son las marcas posicionadas en calidad las que ofrecen mayores posibilidades de diferenciación y que en mayor medida contribuyen a generar lealtad (Ailawadi, Pauwels y Steenkamp 2008; Corstjens y Lal, 2000). Por otro lado, las marcas genéricas pueden y deben seguir usándose en la guerra de precio con los establecimientos de descuentos, dado que atraen al segmento de consumidores orientado a precio (Corstjens y Lal, 2000; Kumar y Steenkamp, 2007). Tercero, los demás beneficios buscados analizados en este estudio, tales como propensión a la promoción, diversión en la compra y sensibilidad a marca, muestran poca o ninguna diferenciación entre los tipos de marcas de distribuidores. Para los distribuidores, eso constituye una oportunidad de posicionamiento que debe ser explorada a fin de diferenciarse tanto de las marcas de fabricantes como de marcas de otros distribuidores, y aún queda mucho por hacer en este campo. Aunque también es algo que requiere grandes inversiones en marketing para separar claramente los tipos de marcas en relación a los rasgos motivacionales.

La creciente popularidad de las marcas de distribuidor y su vasta oferta trae implicaciones también para los fabricantes: en general, las dichas marcas representan una amenaza para los fabricantes. Sin embargo, un número 
considerable de fabricantes lo enjergan como una oportunidad, y después de evaluar ventajas y desventajas, decidieron producir para los distribuidores. Los principales beneficios de hacerlo son: 1) de carácter económico, como obtener economía de escala y aumentar su rentabilidad; 2) estratégico y de mercado, al aumentar su market share y prevenir la producción de dichas marcas por sus competidore y 3) relacional, al reinforzar su cooperación con grandes minoristas (Oubiña, Rubio y Yague, 2006).

Este estudio no está exento de limitaciones que requieren investigaciones futuras. En primer lugar, España es uno de los mercados más desarrollados en términos de las marcas de distribuidor, con un $49 \%$ de cuota de mercado, de manera que los resultados en otros países podrían diferir de los nuestros. Segundo, las medidas usadas en este trabajo pueden ser mejoradas. Por ejemplo, las medidas de beneficios buscados han sido cuantificadas de manera general y no para cada marca de distribuidor. Además, otros beneficios buscados como restricción presupuestaria (Ailawadi, Neslin y Gedenk, 2001), percepción de comprador inteligente (Garretson, Fisher y Burton, 2002; Manzur et al., 2011; Schindler, 1988), búsqueda de variedad o búsqueda de uniformidad (Ailawadi, Neslin y Gedenk, 2001; Yoon et al, 2011) no han sido explorados en este estudio. Finalmente, esta investigación se centra en la clasificación de las marcas de distribuidor basada en su énfasis en precio versus calidad, pero actualmente los distribuidores tienen grandes carteras de marcas propias y ofrecen otras posibilidades de clasificación como la basada en categorías o la segmentación basada en beneficios (Kumar y Steenkamp 2007). Investigaciones futuras deben explorar estos efectos diferenciales en la caracterización motivacional de los compradores de marcas propias. 


\subsection{Referencias}

ACNielsen (2011) "The rise of the value-conscious shopper". Disponible en http://au.nielsen.com/site/documents/PrivateLabelGlobalReportMar2011.pdf (Acesso el 30 Maio 2011).

Ailawadi, Kusum L., Eric T. Bradlow, Michaela Draganska, Vincent Nijs, Robert P. Rooderkerk, K. Sudhir, Kenneth C. Wilbur y Jie Zhang (2010), "Empirical models of manufacturer-retailer interaction: A review and agenda for future research", Marketing Letters, 21 (3): 273-285

Ailawadi Kusum L. y Kevin L. Keller (2004), "Understanding retail branding: conceptual insights and research priorities", Journal of Retailing, 80: 331-342

Ailawadi, Kusum L., Koen Pauwels, y Jan-Benedict E.M. Steenkamp (2008), "Private label use and store loyalty", Journal of Marketing, 72 (6): 19-30.

Ailawadi, Kusum L., Scott A. Neslin y Karen Gedenk, (2001), "Pursuing the value-conscious consumer: store brands versus national brand promotions", Journal of Marketing, 65: 71-89

Alimarket (2008), Informe Anual de la Distribución. Disponible en http://alimarket.es (Acesso el 30 Maio 2009).

Apelbaum, Eidan, Eitan Gerstner y Prasad A. Naik (2003), "The effects of expert quality evaluations versus brand name on price premiums", Journal of Product and Brand Management, 12 (3): 154-165

Baltas, George (1997), "Determinants of store brand choice: a behavioral analysis," Journal of Product and Brand Management, 6 (5): 315-324

Baltas, George y Paraskevas C. Argouslidis (2007) "Consumer characteristics and demand for store brands", International Journal of Retail \& Distribution Management, 35 (5): 328-341 
Bellizi, Joseph A., Harry F. Kruckeberg, John R. Hamilton, y Warren S. Martin (1981), "Consumer perceptions of national, private and generic brands", Journal of Retailing, 57 (Winter): 56-70

Burt, Steve (2000), "The strategic role of retail brands in British grocery retailing", European Journal of Marketing, 34 (8): 875-890

Burton, Scot, Donald R. Lichtenstein, Richard G. Netemeyer y Judith A. Garretson (1998): "A scale for measuring attitude toward private label products and an examination of its psychological and behavioral correlates", Journal of the Academy of Marketing Science, 26 (4): 293-306.

Carrefour (2012). Disponible en www.carrefour.es/grupo-carrefour/las-marcascarrefour/ (Acesso en Abril, 2012).

Corstjens, Marcel y Rajiv Lal (2000), "Building store loyalty through store brands", Journal of Marketing Research, 37 (3): 281-291

Cox, Anthony D., Dena Cox y Ronald D. Anderson (2005), "Reassessing the pleasures of store shopping", Journal of Business Research, 58 (3): 250-259

Cunningham, Isabella C. M., Andrew P. Hardy y Giovanna Imperia (1982), "Generic brands versus national brands and store brands: a comparison of consumers' preferences and perceptions", Journal of Advertising Research, 22 (7-8): 25-32

Davies, Gary y Eliane Brito. (2004), "Price and quality competition between brands and own brands: a value systems perspective", European Journal of Marketing, 38 (1/2): 30-55.

De Wulf, Kristof, Gaby Odekerken-Schröder, Frank Goedertier and Gino Van Ossel (2005), "Consumer perception of store brands versus national brands", Journal of Consumer Marketing, 24 (4): 223-32 
Dick, Alan, Arun Jain y Paul Richardson (1995), "Correlates of store brand proneness: Some empirical observations", Journal of Product \& Brand Management, 4 (4): 15-22.

Dunne, David y Chakravarthi Narasimhan (1999), "The new appeal of private label", Harvard Business Review, 77: 41-52

Eroski (2012). Disponible en http://www.eroski.es/es/para-nuestrosclientes/marcas-propias (Acesso en Abril, 2012).

Fornerino, Marianela y François d'Hauteville, (2010), "How good does it taste? Is it the product or the brand? A contribution to brand equity evaluation", Journal of Product and Brand Management, 19 (1): 34-43.

Garretson, Judith A., Dan Fisher y Scot Burton (2002), "Antecedents of private label attitude and national brand promotion attitude: similarities and differences", Journal of Retailing, 78 (2): 91-99

Geyskens, Inge, Katrijn Gielens y Els Gijsbrechts (2010), "Proliferating privatelabel portfolios: how introducing economy and premium private labels influences brand choice", Journal of Marketing Research, 47 (5): 791-807

Gómez, Mónica y Natalia Rubio (2010), "Re-thinking the relationship between store brand attitude and store brand loyalty: a simultaneous approach", International Review of Retail, Distribution and Consumer Research, 20 (5): 515- 534.

Haley, Russel I. (1968), "Benefit segmentation: a decision-oriented research tool", Journal of Marketing 32 (3): 30-35

Hansen, Karsten, Vishal Singh y Pradeep Chintagunta (2006), "Understanding store-brand purchase behaviour across categories", Marketing Science, 25 (1): $75-90$ 
Harris, Brian F. and Roger A. Strang (1985), "Marketing strategies in the age of generics", Journal of Marketing, 49: 70-81

IRI. (2007). "Private label 2007: U.S. \& Europe retail branding strategies capture market potential". Chicago: Information Resources, Inc.

Jacoby, Jacob, Robert W. Chestnut y William A. Fisher (1978), "A behavioral process approach to information acquisition in non-durable purchasing", Journal of Marketing Research, 15: 532-544

Kumar, Nirmalya y Jan-Benedict E. M. Steenkamp (2007) Private label strategy: how to meet the store brand challenge. Boston: Harvard Business School Press

Maarten, L. Buis, (2008). "FMLOGIT: Stata module fitting a fractional multinomial logit model by quasi maximum likelihood," Statistical Software ComponentsS456976, Boston College Department of Economics

Manzur, Maciej, Sergio Olavarrieta, Pedro Hidalgo, Pablo Farías, y Rodrigo Uribe (2011), "Store brand and national brand promotion attitudes antecedents", Journal of Business Research, 64 (3): 286-291

Martínez, Eva y Teresa Montaner (2008), "Characterisation of Spanish store brand consumers", International Journal of Retail \& Distribution Management, 36 (6): $477-493$

Martos-Partal, Mercedes y Oscar Gonzalez-Benito (2011); "Store brand and store loyalty: The moderating role of store brand positioning", Marketing Letters, 22 (3): 297-313

Méndez, José Luis, Javier Oubiña y Natalia Rubio (2008), "Expert quality evaluation and price of store vs. manufacturer brands: an analysis of the Spanish mass market", Journal of Retailing and Consumer Services, 15 (3): 144-155 
Obiña, Javier, Natalia Rubio y Maria Jesus Yague (2006), "Strategic anagement of store brands: an analysis from the manufacturer's perspective", International Journal of Retail \& Distribution Management, 34 (10): 742-760

Palmeira, Mauricio M. y Dominic Thomas, (2011) "Two-tier store brands: the benefic impact of a value brand on perceptions of premium brand", Journal of Retailing, 87 (4): 540-548

Park, Ji E., Jun Yu y Joyce Xin Zhou (2010), "Consumer innovativeness and shopping styles“, Journal of Consumer Marketing, 27 (5): 437-446

PLMA (2009). Disponible en http://www.plmainternational.com/es/private_label_es2.htm (Acesso 30 September 2009).

Prendergast, Gerard P. y Norman E. Marr, (1997) "Generic products: who buys them and how do they perform relative to each other?", European Journal of Marketing, 31 (2): 94-109

Quelch, John. A. y David Harding (1996), "Brands versus private labels: fighting to win," Harvard Business Review. 74: 99-110.

Raju, Jagmohan S; Raj Sethuraman y Sanjay Dhar (1995). "National brandstore brand price differential and store brand market share", Pricing Strategy \& Practice: An International Journal, 3 (2): 17-24

Richardson, Paul, Alan S. Dick, y Arun K. Jain (1994), "Extrinsic and intrinsic cue effects on perceptions of store brand quality", Journal of Marketing, 58 (4): 28-36

Richardson, Paul S., Arun K. Jain, y Alan Dick (1996), "Household store brand proneness: A framework," Journal of Retailing, 72 (2): 159-185

Richardson, Paul. S. (1997), "Are store brands perceived to be just another brand?" Journal of Product and Brand Management, 6: 388-404 
Schindler, Robert M. (1989), "The excitement of getting a bargain: some hypotheses concerning the origins and effects of smart-shopper feelings," Advances in Consumer Research, 16 (1): 447-453.

Schreier, Martin, Stefan Oberhauser y Reinhard Prügl (2007), "Lead users and the adoption and diffusion of new products: Insights from two extreme sports communities", Marketing Letters, 18 (1): 15-30

Sethuraman, Raj (2006) "Private-label marketing strategies in packaged goods: management beliefs and research insights", Marketing Science Institute Working Paper, 27-44.

Sethuraman, Raj y Catherine Cole (1999), "Factors influencing the price premiums that consumers pay for national brands over store brands," Journal of Product and Brand Management, 8 (4): 340-351.

Shannon, Randall y Rujirutana Mandhachitara (2008). "Causal path modeling of grocery shopping in hypermarkets", Journal of Product \& Brand Management. 17 (5): 327-34.

Sinapuelas Ian Clark y William T. Robinson (2009), "Entry for supermarket feature me-too brands: An empirical explanation of incidence and timing", Marketing Letters, 20 (2): 183-196.

Sinha, Indrajit y Rajeev Batra (1999). "The effect of consumer price consciousness on private label purchase", International Journal of Research in Marketing, 16 (3): 237-251.

Soberman, David A. y Philip M. Parker (2006), "The economics of qualityequivalent store brands", International Journal of Research in Marketing, 23: 125-139.

Steenkamp, Jan-Benedict E,M, Harald J. van Heerde e Inge Geykens (2010), "What makes consumers willing to pay a price premium for national brands over private labels?", Journal of Marketing Research, 47 (6): 1011-1024. 
Sudhir K. y Debabrata Talukdar (2004), "Does store brand patronage improve store patronage?", Review of Industrial Organization, 24 (2): 143-160.

Szymanowski, Maciej y Els Gijsbrechts, (2012), "Consumption-based crossbrand learning: Are private labels really private?", Journal of Marketing Research 49 (2). 231-246.

Völckner, Franziska y Julian Hofmann (2007), "The price-perceived quality relationship: A meta-analytic review and assessment of its determinants", Marketing Letters, 18 (3):181-196.

Xie, Yu Henry (2008) "Consumer innovativeness and consumer acceptance of brand extensions", Journal of Product and Brand Management, 14 (4): 235-243.

Yelkur, Rama (2000), "Consumer perception of generic products: a Mexican study", Journal of Product and Brand Management, 9 (7): 446-456.

Yoon, Song Oh, Kwanho Suk, Seon Min Lee y Eun Young Park. "To seek variety or uniformity: The role of culture in consumers' choice in a group setting", Marketing Letters, 22 (1): 49-64.

Williams, Tarrel G., Mark Slama y John Rogers (1985), "Behavioral characteristics of the recreational shoppers and implications for retail management", Journal of the Academy of Marketing Science, 13 (3): 307-16. 


\section{REFLEXIONES FINALES}




\section{REFLEXIONES FINALES}

Es innegable la evolución de las marcas de distribuidor en los últimos años. Ellas están actualmente entre los ítems más populares y de mayor crecimiento disponibles en el mercado. ¿Y por qué? Porque ofrecen más posibilidad de elección y ayudan a los consumidores a ahorrar (Forbes, 2011). El momento económico actual de contracción indica que el crecimiento de dichas marcas debe continuar. La recesión normalmente fuerza a los consumidores a probar nuevos hábitos de compra. Buenos resultados con marcas de distribuidor durante períodos de dificultad crean familiaridad $y$, consecuentemente, lealtad a dichas marcas y a los establecimientos que las comercializa (PLMA, 2012). Pero su precio bajo no es el único atractivo. Baltas y Argouslidis (2007) muestran que la preferencia por las marcas de distribuidor derivan de un complejo proceso en el que la calidad tiene el papel más significantivo, de manera que no se debería asumir que dichas marcas son sólo una alternativa de bajo precio para quienes no pueden pagar por una marca de fabricante. A lo largo de estos años, ese crecimiento de las marcas de distribuidor ha venido acompañado por una mejora en la percepciñon de dichas marcas (PLMA, 2012).

En la actualidad, muchos distribuidores cuenta con estrategias sofisticadas de marcas de distribuidor. Que va desde opciones que compiten en precio, las marcas genéricas, o en valor, estándar, hasta marcas que compiten por ser los mejores productos del mercado, marcas premium. Pero los distribuidores también manejan otros criterios de segmentación, como los beneficios buscados o la segmentación por categorías de producto. Por ejemplo, Carrefour ofrece líneas de productos especiales ecológicos - Eco Planet y EcoBio - y una línea de productos propios para niños, la Carrefour Kids. Los distribuidores manejan, por lo tanto, una cartera de marcas de distribuidores con el objetivo de llegar a distintos segmentos de consumidores (Geyskens, Gielens y Gijsbrechts, 2010; Kumar y Steenkamp 2007a). 
El enfoque adoptado en esta tesis de analizar las marcas de distribuidor en un contexto actual y desagregando las distintas marcas de distribuidor, en concreto el análisis de marcas genéricas, estándar y premium, conduce a una serie de interpretaciones e implicaciones para los distintos agentes implicados en el sector de la distribución que se detallan a continuación.

Desde un punto de vista académico, en primer lugar, este trabajo de investigación contibuye a la literatura previa, al ir más allá de los clásicos critérios de segmentación demográficos y socioeconómicos y caracterizar al comprador de marcas propias en cuanto a los beneficios buscados en la compra de este tipo de productos. Los resultados empíricos del capitulo 3 muestran que el consumidor de marcas de distribuidor puede caracterizarse motivacionalmente como un consumidor más sensible a precios, y menos sensible a la calidad del servicio y a las marcas reconocidas. Además, sugieren que diversión en la compra es un beneficio buscado por los consumidores de estas marcas, pero esta relación en específico merece cautela por su menor nivel de significancia (90\%).

Adicionalmente, dada la múltiple oferta de marcas de distribuidor, se considera que el perfil del consumidor de marcas propias no puede plantearse de forma general, sino que depende del tipo de marca del distribuidor, cuyo posicionamiento estará alineado con el posicionamiento del distribuidor. En este caso concreto, el énfasis está en el posicionamiento respecto a la dimensión precio. Los resultados del capítulo 3 muestran que el posicionamiento en precio del distribuidor modera a la compra de marcas de distribuidor. Dicho de otra forma, en las cadenas menos orientadas al precio, la compra de marcas de distribuidor parece estar menos motivada por la búsqueda de precios ventajosos, y más por la calidad, reconocimiento y reputación de las mismas.

El capitulo 4 aporta evidencias empíricas sobre el valor objetivo, valor de marca y valor percibido de las marcas de distribuidor frente a las marcas de fabricante. Los resultados evidencian que, de manera general, los consumidores no aprecian diferencias objetivas entre la marca de distribuidor y 
las marcas de fabricante. Por lo tanto, la diferencia en la valoración percebida de marcas nacionales y marcas de distribuidor reside casi totalmente en el valor de la marca: el valor de todas las marcas de distribuidor analizadas es significativamente inferior al de todas las marcas de fabricante, incluso la marca premium. Tal resultado confirma la importancia de tener estrategias encaminadasa mejorar el valor de marca, puesto que éste determina en gran medida la valoración percibida por los consumidores, mucho más que una valoración objetiva de sus características. En este sentido, las marcas de distribuidor están en clara desventaja con relación a las marcas de fabricante en lo que se refiere a su reputación, reconocimiento y credibilidad de sus marcas

Asimismo, también se compara algunos posicionamientos habituales en la cartera de marcas de distribuidor, concretamente la estrategia de tres escalones: marca genérica, estándar y premium, analizando cómo afectan al valor objetivo, valor de marca y valor percibido. Entre las marcas de distribuidor, las marcas genéricas son percibidas según su posicionamiento pretendido como la de menor valor. Sin embargo, en la mente de los consumidores, no hay diferencia entre el valor de marca de la marca estándar y la premium, evidenciando el débil posicionamiento de la marca premium como una alternativa de calidad. Dicho de otra forma, las marcas premium todavía no son capaces de competir con las marcas de fabricante de más altos niveles de calidad.

Adicionalmente, dicho capitulo pone de manifiesto que valorar los productos de manera objetiva es bastante difícil para los consumidores y que, además, la valoración objetiva tiene poca importancia en la valoración global. Por esto motivo, los minoristas tendrán que seguir trabajando para conseguir el aprendizaje de los consumidores con respecto a los elementos objetivos de los productos, a través de distintas herramientas como, por ejemplo, la prueba de marcas de distribuidor en sus establecimientos (Beldona y Scott,2007) o la entrega de muestras de productos para mejorar la valoración de sus marcas. 
Finalmente, en el capitulo 5 se confirma el efecto moderador del posicionamiento de marca también en las motivaciones subyacentes a la compra de marcas de distribuidor. Así, se traza un perfil actual del comprador de marcas de distribuidor analizando los beneficios buscados en la compra de marcas genérica, estándar o premium. Los resultados de dicho capitulo muestran que la compra de marcas genéricas es motivada por una mayor sensibilidad al precio, pero por una menor sensibilidad en la calidad del servicio. En el caso de las marcas tipo premium, éstas son compradas por consumidores sensibles a la calidad, pero no sensibles a precio. Además, dichos consumidores parecen buscar diversión en la compra y, sorprendentemente, son menos innovadores que los compradores de marcas genéricas. Por último, y como habría de esperar, los consumidores de marcas estándar están en el medio del camino entre los de marcas genéricas y premium: son menos sensibles a precio que los consumidores de marcas genéricas, pero tampoco son tan sensibles a la calidad del servicio como los consumidores de marcas premium. Los consumidores de marcas genérica y estándar parecen ser menos sensibles a la marca.

La tesis contribuye a la reciente y emergente línea de investigación centrada en el efecto moderador del posicionamiento de la marca de distribuidor (e.j., Geyskens, Gielens y Gijsbrechts 2010; Martos-Partal y González-Benito, 2011, Palmeira...;Kumar y Steenkamp 2007a). El presente trabajo muestra evidencias sobre el papel moderador del posicionamiento en constructos tan relevantes en marketing como son el valor de marca y caracterización motivacional de los compradores de marcas de distribuidor

Los trabajos presentados en esta tesis doctoral ponen de manifiestoque un fenómeno tan heterogéneo como es el de las marcas de distribuidor no pueden ser analizadas de forma agregada. Este trabajo pone de manifiesto que la la respuesta del consumidor depende y dependerá cada vez más de las peculiaridades que caracterizan cada marca de distribuidor en particular.

Desde la perspectiva empresariallos resultados muestran que, a pesar de la evolución en la estrategia de marcas de distribuidor, aún no han obtenido el 
desarrollo en términos de su reputación, notoriedad y calidad del que disfrutan las marcas de fabricante. El capitulo 4 corrobora dicha percepción al mostar que a las marcas de distribuidores les falta valor de marca, incluso para las opciones premium.

A pesar de los esfuerzos hechos por los distribuidores en los últimos años en mejorar las percepciones de sus marcas propias, parece que la elección de los consumidores por dichas marcas aún es muy basada en su ventaja financiera con relación a las marcas nacionales. No obstante, los resultados del capitulo 3 sugieren que para los distribuidores menos orientados a precio el atractivo de sus marcas de distribuidor ya reside más en su capacidad para satisfacer los clientes más exigentes y menos en su precio, lo que confirma que las marcas de distribuidor pueden ser una herramienta poderosa competencia forjar la imagen del minorista e incluso diferenciarse del resto. Sin embargo, cabe destacar que los resultados obtenidos sugieren que el desarrollo de una cartera de marcas de distribuidor con distintos posicionamientos en el continuo calidad-precio resulta más apropiada a medida que el distribuidor se aleja de una orientación precio. Al ofrecer marcas de mayor calidad, el minorista atrae a los consumidores más exigentes y a través de la diferenciación, fideliza tales consumidores, además de competir directamente con las marcas líderes de fabricante. Por otro lado, ofrecer una marca genérica atrae a los consumidores que buscan economía y permite al establecimiento competir con los formatos más agresivos en precio.

Es preciso resaltar que los distribuidores van por el buen camino. Los distribuidores tienden a comercializar marcas propias que son coherentes con su posicionamiento estratégico $\mathrm{y}$, en este sentido, parece que distribuidores menos orientados al precio están venciendo la tradicional percepción de las marcas de distribuidor como marcas de baja calidad y bajo precio. El atractivo de sus marcas propias está más en su capacidad de ofrecer productos de calidad y satisfacer a los clientes más exigentes.

El capitulo 4, a su vez, resalta que las marcas de distribuidor están en desventaja con relación a las marcas nacionales en lo que se refiere al valor de 
marca. Crear marcas de alta calidad, con buena imagen y asociaciones fuertes en la mente de los consumidores a través de una estrategia de diferenciación aún debe ser el enfoque de los distribuidores, puesto que es la percepción total de la marca depende mucho más de su valor de marca que de su valor objetivo. La revista americana Forbes, por ejemplo, destaca la reciente estrategia de los distribuidores en ese sentido, al hacer contratos de exclusividad con diseñadores famosos, como por ejemplo, los accesorios de cocina de Michael Graves vendidos exclusivamente por Target (Forbes, 2011)

A pesar de que las marcas de distribuidor se hanalejado de la percepción de baja calidad, lograr un posicionamiento premium puede ser todo un reto para los minoristas. Los resultados del capitulo 4 muestran que, en la mente de los consumidores, no hay diferenciación en el valor de marca entre las marcas estándar y premium. Los resultados del capitulo 5, a su vez, no muestran diferencias significativas en los beneficios buscados por consumidores de marcas premium para Eroski. .

Si por un lado, hace falta inversiones de los distribuidores en el marketing de sus marcas propias, para los fabricantes es importante mantener sus inversiones en marcas para al menos mantener las distancias usando estrategias que ayuden a mantener su reputación construyendo valor al consumidor. Las estrategias de inversión en innovación parecen estar dando buenos resultados para competir con las marcas de distribuidor y mantener su diferencial de precio, que los consumidores consideran justo por percibir la diferenciación alcanzada por los fabricantes, (Kumar y Steenkamp, 2007b; Quelch y Harding, 1996; Martos-Partal, 2012; Steiner, 2004; Steenkamp, van Heerde y Geykens, 2010; Gielens, en prensa, Rubio y Yague, 2007), así como el uso combinado de innovación y publicidad (Steenkamp, van Heerde y Geykens, 2010).

Respecto a los beneficios buscados por los consumidores de marcas propias, estos dependen del tipo de marca que se considere. Puesto que cada tipo de marca atrae a un segmento distinto de consumidores, el distribuidor puede ofrecer una cartera de marcas con distintos posicionamientos que no 
compitan entre sí. Las marcas premium, posicionadas en consumidores más preocupados con la calidad y menos con el precio, deben ser usadas como herramienta de diferenciación, como base para la lealtad del consumidor (Gómez y Rubio, 2010) y como fuente de rentabilidad para el distribuidor (Corstjens y Lal, 2000). Por otro lado, las marcas genéricas deben continuar siendo utilizadas en las guerras de precios, una vez que enfatizan la sensibilidad al precio (Corstjens y Lal, 2000).

En este sentido, parece que los esfuerzos en los últimos años de muchos distribuidores en mejorar la percepción de sus marcas propias a través del desarrollo de marcas de alta calidad-alto precio ha valido la pena, puesto que los resultados de esta investigación muestran que los compradores de este tipo de marcas de hecho perciben diferencias entre los distintos posicionamientos de las marcas de distribuidor. El desafio de los minoristas ahora es mejorar su percepción de marca entre aquellos consumidores que no utilizan marcas de distribuidor de manera que dichas marcas empienzen a hacer parte del grupo de consideración en la elección de marca. El contexto actual de recesión económica es una oportunidad de oro para los minoristas, puesto que tal situación impone nuevos hábitos de compra a los consumidores.

Si por un lado, la tendencia de crecimiento de las marcas de distribuidores es una gran oportunidad para los minoristas, también lo puede ser para los fabricantes que producen para los minoristas. Oubiña, Rubio y Yague (2006) muestran que los desde la perspectiva de los fabricantes, sus principales motivaciones y objetivos al fornecer productos para marcas de distribuidor son 1) de carácter económico, como obtener economía de escala y aumentar su rentabilidad; 2) estratégico y de mercado, al aumentar su market share y prevenir la producción de dichas marcas por sus competidore y 3) relacional, al reinforzar su cooperación con grandes minoristas.

Por último, el capitulo 5 pone de manifiesto que hay posicionamentos no explorados con relación a las marcas de distribuidor, puesto que en la mente del consumidor hay poca o ninguna diferenciación entre las marcas de distribuidor estudiadas no que se refiere a beneficios buscados como 
propensión a la promoción, diversión en la compra y sensibilidad a marca. Ocupar estos poscionamientos exigirá de los distribuidores grandes inversiones en el marketing de sus marcas.

Esta tesis doctoral presenta una serie de limitaciones que podrían ser subsanados en futuras trabajos de investigación. A continuación se señalan las más relevantes.

En primer lugar, cabe resaltar que los tres estudios de esta tesis doctoral fueron realizados en España, uno de los países más desarollados en lo que se refiere a las marcas de distribuidor, con una cuota de mercado actual alrededor de los $49 \%$. Por lo tanto, resultados en otros países podrían diferir de los nuestros. La réplica del estudio en otros mercados internacionales contribuiría una mayor generalización de los resultados alcanzados respecto a marcas de distribuidores.

Segundo, se puede mejorar las medidas utilizadas. Las medidas de beneficios buscados y de compra de marcas de distribuidor se han cuantificado en general, y no para cada categoría de productos concreta. También se puede mejorar la medida utilizada para el posicionamiento en precio del distribuidor que ha sido cuantificado de manera simple y unidimensional.

Con relación a los beneficios buscados, hay otras motivaciones subyacentes a la compra que pueden influir en la elección de marca que no han sido explorados en este trabajo como presupuestarias o búsqueda de variedad o uniformidad (Ailawadi, Neslin y Gedenk, 2001; Yoon et al, 2011), conciencia de calidad (Sethuraman, 2006; Ailawadi, Pauwels y Steenkamp, 2008; Bao, Bao y Sheng, 2010; Hoch y Banerji, 1993), por ejemplo.

Además, este trabajo clasifica las marcas de distribuidores en cuanto a su posicionamiento en calidad y precio, pero los distribuidores ya ofrecen otras posibilidades de clasificación, como basada en categorías o en beneficios (Kumar y Steenkamp 2007). 
En cuanto al experimiento, se ha utilizado una muestra por conveniencia con estudiantes universitarios, que a pesar de estudios anteriores haber probado útil dicha amostra, pueden no retractar la realidad de consumo. Otra limitación se debe al uso de una única categoría de producto, tabletas de chocolate con leche, y un único minorista, Carrefour. A lo mejor para productos de carácter más funcional que hedónico como el chocolate, la valoración objetiva del producto sea más importante que sus aspectos intangibles.

Por último, cabe resaltar que hay otros factores que pueden influir en la valoración de la marca. Por ejemplo, la familiaridad con la marca (Richardson, Jain y Dick , 1996, De Wulf et al., 2005), la actitud hacia las marcas de distribuidor (Zielke y Dobbelstein, 2007; Puccinelli et al, 2009), la lealtad hacia el establecimiento (Kumar y Steenkamp 2007b, Ailawadi, Neslin y Gedenk, 2001 y Ailawadi y Keller 2004), o la imagen del establecimiento (Semeijn, van Riel y Ambrosini , 2004). Una línea de investigación futura podría analizar el efecto de estas variables sobre la valoración de marcas de distribuidor con distintos posicionamientos. 


\subsection{Referencias}

Ailawadi, Kusum L. y Kevin L. Keller (2004), "Understanding retail branding: conceptual insights and research priorities," Journal of Retailing, 80 (4): 331 342.

Ailawadi, Kusum L., Koen Pauwels, y Jan-Benedict E.M. Steenkamp (2008), "Private-label use and store loyalty," Journal of Marketing, 72 (6): 19-30.

Ailawadi, Kusum L., Scott A. Neslin, y Karen Gedenk (2001), "Pursuing the value-conscious consumer: store brands versus national brand promotions," Journal of Marketing, 65 (1): 71-89.

Baltas, George y Paraskevas C. Argouslidis (2007) "Consumer characteristics and demand for store brands", International Journal of Retail \& Distribution Management, 35 (5): 328-341

Bao, Yongchuan, Yeqing Bao y Shibin Sheng (2011), "Motivating purchase of private brands: effects of store image, product signatureness, and quality variation", Journal of Business Research, 64 (2): 220-226

Beldona, S. y Wysong, S. (2007), "Putting the "brand" back into store brands: an exploratory examination of store brands and brand personality", Journal of Product and Brand Management, 16 (4): 226-235.

Corstjens, Marcel y Rajiv Lal (2000), "Building store loyalty through store brands", Journal of Marketing Research, 37 (3): 281-291

De Wulf, Kristof, Gaby Odekerken-Schröder, Frank Goedertier y Gino Van Ossel (2005), "Consumer perceptions of store brands versus national brands," The Journal of Consumer Marketing, 22 (4): 223-232. 
Forbes, 2011. "10 secrets about store brands". Disponible en http://www.forbes.com/sites/lauraheller/2011/06/29/10-secrets-about-storebrands/ . (Acesso 20 Abril 2011)

Geyskens, Inge, Katrijn Gielens y Els Gijsbrechts (2010): "Proliferating privatelabel portfolios: how introducing economy and premium private labels influences brand choice", Journal of Marketing Research, 47 (5): 791-807.

Gielens, Katrijn (en prensa), "New products, the antidote to private label growth?"'. Journal of Marketing Research, en prensa

Gómez, Mónica y Natalia Rubio (2010), "Re-thinking the relationship between store brand attitude and store brand loyalty: a simultaneous approach", The International Review of Retail, Distribution and Consumer Research, 20 (5): 515- 534

Hoch, Stephen y Shumeet Banerji (1993), "Why do private label succed?", Sloan Management Review; 34 (4): 57-67

Kumar, Nirmalya y Jan-Benedict E. M. Steenkamp (2007a) Private label strategy: how to meet the store brand challenge. Boston: Harvard Business School Press

Kumar, Nirmalya y Jan-Benedict E. M. Steenkamp (2007b), "Brand Versus Brand," International Commerce Review : ECR Journal, 7 (Spring), 47.

Martos-Partal, Mercedes (2012), "Innovation and the market share of private labels", Journal of Marketing Management, 28 (5-6): 695-715

Munuera, José Luis Alemán y Ana Isabel Rodríguez Escudero (2002), "Estrategia de marketing: teoría y casos", Ediciones Piramide.

Obiña, Javier, Natalia Rubio y Maria Jesus Yague (2006), "Strategic anagement of store brands: an analysis from the manufacturer's perspective", International Journal of Retail \& Distribution Management, 34 (10): 742-760 
PLMA

(2012).

Disponible

en

http://www.plmainternational.com/es/private_label_es2.htm (Acesso el 15 Junio 2012).

Puccinelli, Nancy M, Ronald C. Goodstein, Dhruv Grewal, Robert Price, Priya Raghubir y David Stewartf (2009), "Customer experience management in retailing: understanding the buying process," Journal of Retailing, 85 (1): 15-30

Quelch, J. A. y Harding, D. (1996), "Brands versus private labels: fighting to win”, Harvard Business Review, 74 (1): 99-109

Richardson, Paul S., Arun K. Jain y Alan Dick (1996), "Household store brand proneness: a framework," Journal of Retailing, 72 (2): 159-185

Rubio, Natalia y Maria Jesus Yague (2007), "The determinants of store brand market share: A temporal and cross-sectional analysis", International Journal of Market Research, 51 (4): 501-519

Semeijn, Janjaap, Allard C. R. van Riel y Ana Beatriz Ambrosini (2004), "Consumer evaluations of store brands: effects of store image and product attributes," Journal of Retailing and Consumer Services, 11 (4): 247-58.

Sethuraman, Raj (2006), "Private-label marketing strategies in packaged goods: management beliefs and research insights," Marketing Science Institute Working Paper: 27-44.

Steenkamp, J.-B., van Heerde, H.J., y Geykens, I. (2010). "What makes consumers willing to pay a price premium for national brands over private labels?" Journal of Marketing Research, 47(6): 1011-1024.

Steiner, R. L. (2004), "The nature and benefits of national brand/private label competition", Review of Industrial Organization, 24 (2): 105-127. 
Yoon, Song Oh, Kwanho Suk, Seon Min Lee y Eun Young Park. "To seek variety or uniformity: The role of culture in consumers' choice in a group setting", Marketing Letters, 22 (1): 49-64

Zielke, Stephan y Thomas Dobbelstein (2007), "Customers' willingness to purchase new store brands," The Journal of Product and Brand Management, 16 (2): 112-121. 


\section{APENDICE 1 - Custionario del test ciego}

A continuación, usted tiene toda la información sobre el producto que acaba de probar. Considerando esa información y la prueba que acaba de realizar, señale sus percepciones sobre el producto. Los valores van de " 1 - mala" hasta " 5 excelente". Recuerde que no hay respuestas correctas ni incorrectas, solamente nos interesa conocer su opinión.

\begin{tabular}{|l|c|c|c|c|c|}
\multicolumn{4}{c}{ Mala } & \multicolumn{3}{c|}{ Excelente } \\
\hline Calidad & 1 & 2 & 3 & 4 & 5 \\
\hline $\begin{array}{l}\text { Valor nutritivo / } \\
\text { ingredientes }\end{array}$ & 1 & 2 & 3 & 4 & 5 \\
\hline Apariencia & 1 & 2 & 3 & 4 & 5 \\
\hline Sabor & 1 & 2 & 3 & 4 & 5 \\
\hline Textura & 1 & 2 & 3 & 4 & 5 \\
\hline $\begin{array}{l}\text { Evaluación } \\
\text { General }\end{array}$ & 1 & 2 & 3 & 4 & 5 \\
\hline
\end{tabular}

\section{MARCA A}

\section{Ingredientes:}

Azúcar, leche en polvo (21\%), manteca de cacao, pasta de cacao, lactosa, mantequilla, emulgente (lecitina), aroma (vainilla).

Puede contener trazas de frutos secos.

Cacao: 30\% mínimo.

\section{MARCA B}

Ingredientes: Azúcar, manteca de cacao, leche en polvo $(14,6 \%)$, pasta de cacao, emulgente (lecitina de soja), aroma (vainilla). Puede contener trazas de cacahuetes, frutos de cáscara y gluten.

Cacao: $27 \%$ mínimo.

\section{MARCA C}

Ingredientes: Azúcar, manteca de cacao, leche entera en polvo $(23,4 \%)$, cacao de Ecuador, lactosa y proteínas de la leche, materia grasa láctea, emulgente (lecitina de soja), aroma de vainilla. Puede contener trazas de frutos de cáscara y gluten. Cacao: 33\% mínimo. 


\begin{tabular}{|l|c|c|c|c|c|}
\multicolumn{4}{c}{ Mala } & \multicolumn{3}{c|}{ Excelente } \\
\hline Calidad & 1 & 2 & 3 & 4 & 5 \\
\hline $\begin{array}{l}\text { Valor nutritivo / } \\
\text { ingredientes }\end{array}$ & 1 & 2 & 3 & 4 & 5 \\
\hline Apariencia & 1 & 2 & 3 & 4 & 5 \\
\hline Sabor & 1 & 2 & 3 & 4 & 5 \\
\hline Textura & 1 & 2 & 3 & 4 & 5 \\
\hline $\begin{array}{l}\text { Evaluación } \\
\text { General }\end{array}$ & 1 & 2 & 3 & 4 & 5 \\
\hline
\end{tabular}

\section{MARCA D}

Ingredientes: Azúcar, manteca de cacao, leche entera en polvo, pasta de cacao, lactosa, leche desnatada en polvo, emulgente (lecitina de soja), extracto de malta de cebada, aroma. Puede contener trazas de avellanas y almendras.

Cacao: $31 \%$ mínimo.

\begin{tabular}{|l|c|c|c|c|c|}
\multicolumn{4}{c}{ Mala } & \multicolumn{3}{c|}{ Excelente } \\
\hline Calidad & 1 & 2 & 3 & 4 & 5 \\
\hline $\begin{array}{l}\text { Valor nutritivo / } \\
\text { ingredientes }\end{array}$ & 1 & 2 & 3 & 4 & 5 \\
\hline Apariencia & 1 & 2 & 3 & 4 & 5 \\
\hline Sabor & 1 & 2 & 3 & 4 & 5 \\
\hline Textura & 1 & 2 & 3 & 4 & 5 \\
\hline $\begin{array}{l}\text { Evaluación } \\
\text { General }\end{array}$ & 1 & 2 & 3 & 4 & 5 \\
\hline
\end{tabular}

\section{MARCA E}

\section{Ingredientes:}

Azúcar, manteca de cacao, leche, pasta de cacao, suero de leche en polvo, emulgente (lecitina de soja), aroma, trazas de frutos secos.

Cacao: $30 \%$ mínimo. 


\section{APENDICE 2 - Cuestinario del test con marca}

A continuación, usted tiene toda la información sobre el producto que acaba de probar. Considerando esa información y la prueba que acaba de realizar, señale sus percepciones sobre el producto. Los valores van de "1 - mala" hasta "5 excelente". Recuerde que no hay respuestas correctas ni incorrectas, solamente nos interesa conocer su opinión.

\begin{tabular}{|l|c|c|c|c|c|}
\multicolumn{4}{c}{ Mala } & \multicolumn{3}{c|}{ Excelente } \\
\hline Calidad & 1 & 2 & 3 & 4 & 5 \\
\hline $\begin{array}{l}\text { Valor nutritivo / } \\
\text { ingredientes }\end{array}$ & 1 & 2 & 3 & 4 & 5 \\
\hline Apariencia & 1 & 2 & 3 & 4 & 5 \\
\hline Sabor & 1 & 2 & 3 & 4 & 5 \\
\hline Textura & 1 & 2 & 3 & 4 & 5 \\
\hline $\begin{array}{l}\text { Evaluación } \\
\text { General }\end{array}$ & 1 & 2 & 3 & 4 & 5 \\
\hline
\end{tabular}

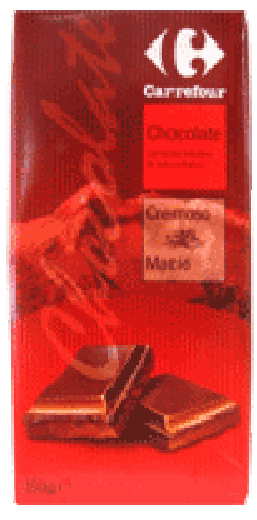

\section{CHOCOLATE CARREFOUR}

\section{Ingredientes:}

Azúcar, leche en polvo (21\%), manteca de cacao, pasta de cacao, lactosa, mantequilla, emulgente (lecitina), aroma (vainilla).

Puede contener trazas de frutos secos.

Cacao: $30 \%$ mínimo.

\begin{tabular}{|l|c|c|c|c|c|}
\multicolumn{4}{c}{ Mala } & \multicolumn{3}{c|}{ Excelente } \\
\hline Calidad & 1 & 2 & 3 & 4 & 5 \\
\hline $\begin{array}{l}\text { Valor nutritivo / } \\
\text { ingredientes }\end{array}$ & 1 & 2 & 3 & 4 & 5 \\
\hline Apariencia & 1 & 2 & 3 & 4 & 5 \\
\hline Sabor & 1 & 2 & 3 & 4 & 5 \\
\hline Textura & 1 & 2 & 3 & 4 & 5 \\
\hline $\begin{array}{l}\text { Evaluación } \\
\text { General }\end{array}$ & 1 & 2 & 3 & 4 & 5 \\
\hline
\end{tabular}

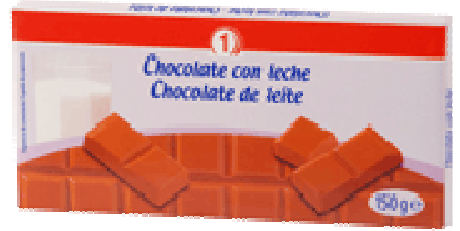

CHOCOLATE No1

Ingredientes: Azúcar, manteca de cacao, leche en polvo $(14,6 \%)$, pasta de cacao, emulgente (lecitina de soja), aroma (vainilla). Puede contener trazas de cacahuetes, frutos de cáscara y gluten.

Cacao: $27 \%$ mínimo. 


\begin{tabular}{|l|c|c|c|c|c|}
\multicolumn{4}{c}{ Mala } & \multicolumn{3}{c|}{ Excelente } \\
\hline Calidad & 1 & 2 & 3 & 4 & 5 \\
\hline $\begin{array}{l}\text { Valor nutritivo / } \\
\text { ingredientes }\end{array}$ & 1 & 2 & 3 & 4 & 5 \\
\hline Apariencia & 1 & 2 & 3 & 4 & 5 \\
\hline Sabor & 1 & 2 & 3 & 4 & 5 \\
\hline Textura & 1 & 2 & 3 & 4 & 5 \\
\hline $\begin{array}{l}\text { Evaluación } \\
\text { General }\end{array}$ & 1 & 2 & 3 & 4 & 5 \\
\hline
\end{tabular}

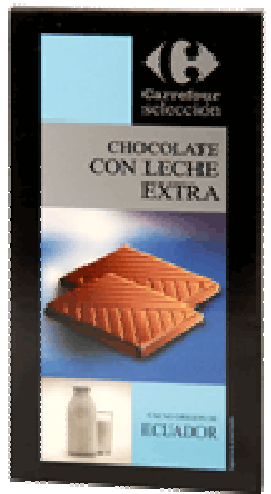

\section{CHOCOLATE CARREFOUR SELECCIÓN}

Ingredientes: Azúcar, manteca de cacao, leche entera en polvo $(23,4 \%)$, cacao de Ecuador, lactosa y proteínas de la leche, materia grasa láctea, emulgente (lecitina de soja), aroma de vainilla. Puede contener trazas de frutos de cáscara y gluten.

Cacao: 33\% mínimo.

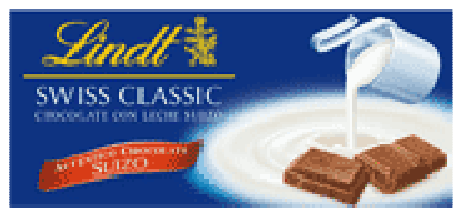

\section{CHOCOLATE LINDT}

Ingredientes: Azúcar, manteca de cacao, leche entera en polvo, pasta de cacao, lactosa, leche desnatada en polvo, emulgente (lecitina de soja), extracto de malta de cebada, aroma. Puede contener trazas de avellanas y almendras. Cacao: $31 \%$ mínimo.

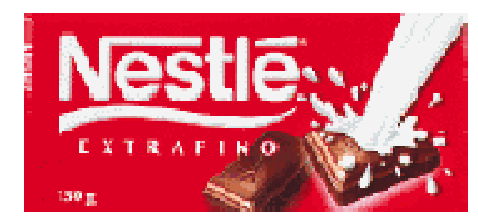

\section{CHOCOLATE NESTLÉ}

\section{Ingredientes:}

Azúcar, manteca de cacao, leche, pasta de cacao, suero de leche en polvo, emulgente (lecitina de soja), aroma, trazas de frutos secos.

Cacao 30\% mínimo. 


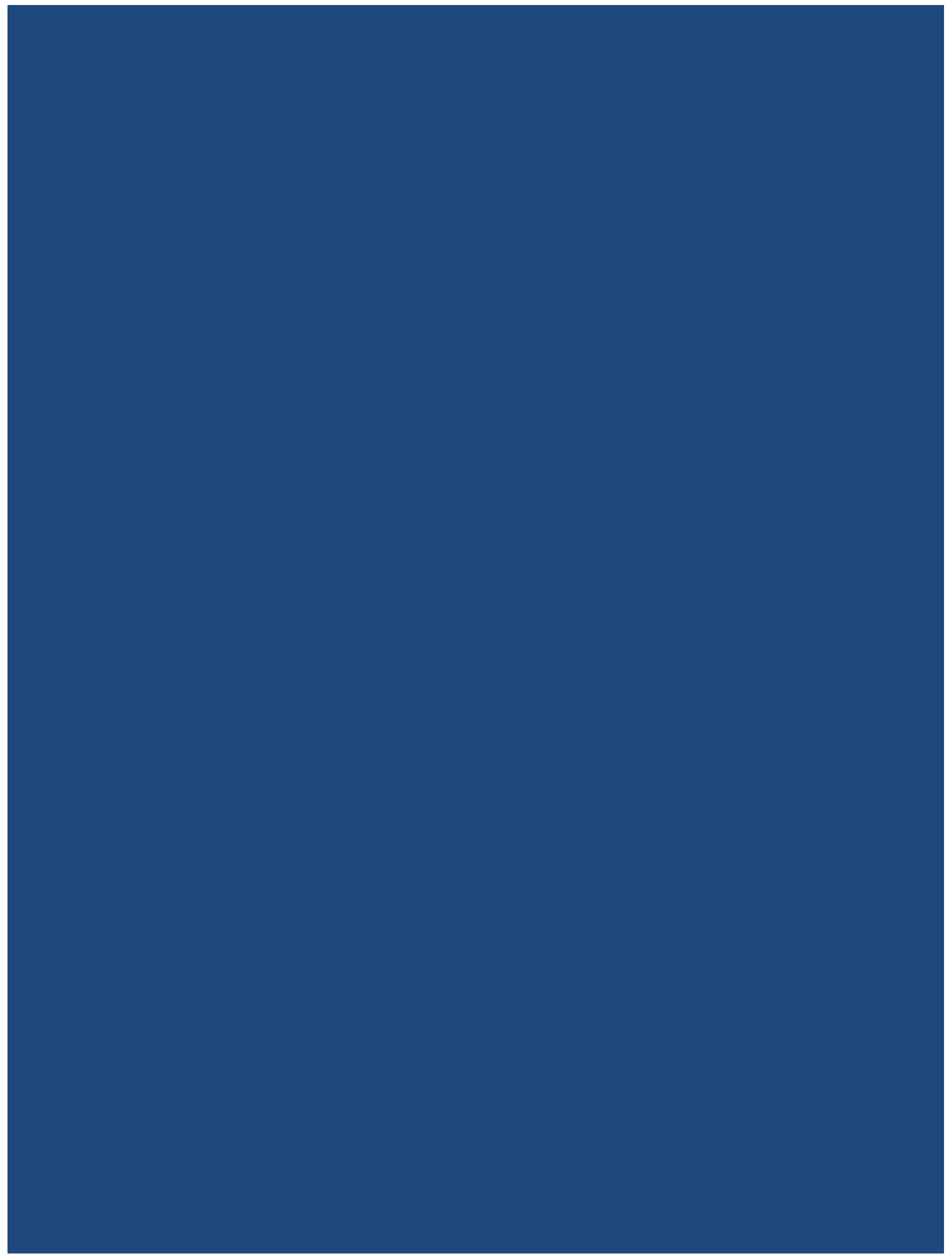

